\title{
Anglo-Saxon bling — a warrior king's Golden Helmet
}

\author{
Frank Cooper ${ }^{1}$
}

Received: 9 March 2020 / Accepted: 25 May 2021 / Published online: 11 June 2021

(C) The Author(s) 2021

\begin{abstract}
In 2009, a metal detectorist discovered a hoard of Anglo-Saxon gold and silver in a field in Staffordshire. Hence, it quickly became known as 'The Staffordshire Hoard'. It was, and remains, the biggest collection of Anglo-Saxon gold (4 kg) and silver $(1.7 \mathrm{~kg})$ ever discovered and comprised of more than 4000 fragments that equated to over 600 discrete objects and larger pieces. The Staffordshire Hoard is co-owned by Birmingham and Stoke-on-Trent City Councils and is cared for on behalf of the nation by Birmingham Museums Trust and The Potteries Museum \& Art Gallery. Over the intervening years, most of the larger and recognisably important pieces have now been identified and catalogued. We now also know an exceptional amount about their probable methods of manufacture, artistic styles, date, and function. This paper focuses on what is now known to be one of the most fragmented yet magnificent of its objects, a Helmet that has been declared as being 'fit for a king', but which was found scattered into well over 1000 disparate fragments. Fragments that are now considered to make up around one-third of the Hoard's total of finds and compose this single high-status Golden Helmet. Too damaged and incomplete to be re-joined or displayed in a form that delivers to the casual observer a true sense of the majesty of the original. Thus, the museums responsible for the collection commissioned an experimental reconstruction project to create two of the helmets for display in their shared Hoard collections.
\end{abstract}

Keywords Staffordshire Hoard · Anglo-Saxon · Gold · Silver · Helmet · Reconstruction · Goldsmithing · Artisanal · Digital · Technology

\section{The reconstruction of an Anglo-Saxon, Golden, Kings Helmet}

In 2009, a metal detectorist discovered a hoard of AngloSaxon gold and silver in a field in Staffordshire. Hence, it quickly became known as 'The Staffordshire Hoard' [ $\left.{ }^{1}\right]$. The find was declared 'Treasure' under a UK law 'The Portable Antiquities Scheme' $\left[{ }^{2}\right]$ which is intended to encourage the reporting and recording of archaeological objects found by members of the public. This allowed for the hoard to be purchased from the finders to come under public ownership and to be subject to extensive research and conservation. It was, and remains, the biggest collection of Anglo-Saxon gold (4 $\mathrm{kg}$ ) and silver $(1.7 \mathrm{~kg})$ ever discovered and comprised of more

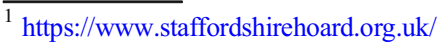

2 https://finds.org.uk/

Frank Cooper

frank.cooper@bcu.ac.uk

1 School of Jewellery, Birmingham City University, Birmingham, UK
}

than 4000 fragments that equated to over 600 discrete objects and larger pieces. Most of the objects in the hoard are considered to be of martial origin - they are elements of the equipment of a male, warrior elite. In particular, fittings from swords, considered to be the apex weapon of the AngloSaxon warrior world, make up most of the hoard. A small selection of hoard artefacts reflects a degree of access to Christianity, items such as crosses, and some are unusual objects whose function and use are uncertain. Interestingly there are no steel blades and most of the items appear to have either been deliberately destroyed or to have been severely damaged when ripped away from their original mounts. The Christian items are mainly large, ceremonial display objects: perhaps reliquaries (containers for holy relics), bibles, royal saddles, and so on. All of these could easily have been carried with an army, so they fit with the war gear as well. The hoard possibly represents the possessions of Anglo-Saxon kings and princes and their warrior retinues.

The Staffordshire Hoard is co-owned by Birmingham and Stoke-on-Trent City Councils and is cared for on behalf of the nation by Birmingham Museums Trust and The Potteries Museum \& Art Gallery. Over the intervening years, most of 
the larger and recognisably important pieces have now been identified and catalogued ${ }^{[3]}$. We now also know an exceptional amount about their probable methods of manufacture, artistic styles, date, and function. This paper primarily focuses on what is now known to be one of the most fragmented yet magnificent of its objects, a Helmet that has been declared as being 'fit for a king', but which was found scattered into well over 1000 disparate fragments. Fragments which are now considered to make up around one-third of the Hoard's total of finds and compose this single high-status Golden Helmet and thought to date back to the sixth or seventh century. Too damaged and incomplete to be re-joined or displayed in a form that delivers to the casual observer a true sense of the majesty of the original. Thus, the museums responsible for the collection commissioned an experimental reconstruction project to create two of the helmets for display in their shared Hoard collections.

\section{Gold and the Staffordshire Hoard}

There are numerous references in this paper about the gold, and silver, found in the Staffordshire Hoard and there is a plethora of research data and information available that is worthy of a separate research paper of its own and so I will treat references to the gold content of the Hoard with a light touch from here on but if you wish to do your own reading about the gold and silver in the Hoard, here are some of the references that will get you started along the path $\left[{ }^{4,5,6,7,8,9,10}\right]$.

\section{Reproducing the two Helmets}

This paper describes in some considerable detail the various traditional artisanal crafts and modern digital technologies and techniques currently used in the jewellery and silversmithing industries to create two reproduction helmets. These reproductions were commissioned because the surviving helmet parts are too damaged and incomplete to be re-joined or displayed

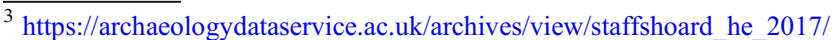
downloads.cfm

${ }^{4}$ https://archaeologydataservice.ac.uk/archiveDS/archiveDownload?t=arch2457-1/dissemination/pdf/SHResearchReports/SHRR16_Blakelock.pdf

5 https://archaeologydataservice.ac.uk/archiveDS/archiveDownload?t=arch2457-1/dissemination/pdf/SHResearchReports/SHRR6_Blakelock.pdf

${ }^{6} \mathrm{https}$ ://archaeologydataservice. ac.uk/archiveDS/archiveDownload? $\mathrm{t}=$ arch2457-1/dissemination/pdf/SHResearchReports/SHRR7_Blakelock.pdf

${ }^{7}$ https://archaeologydataservice. ac.uk/archiveDS/archiveDownload? $\mathrm{t}=$ arch2457-1/dissemination/pdf/SHResearchReports/SHRR9_Blakelock.pdf

${ }^{8} \mathrm{https}$ ://archaeologydataservice. ac.uk/archiveDS/archiveDownload?t=arch2457-1/dissemination/pdf/SHResearchReports/SHRR10_Blakelock.pdf

9 https://archaeologydataservice. ac.uk/archiveDS/archiveDownload?t=arch2457-1/dissemination/pdf/SHResearchReports/SHRR12_Blakelock.pdf

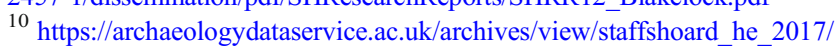
downloads.cfm?group $=1090$
}

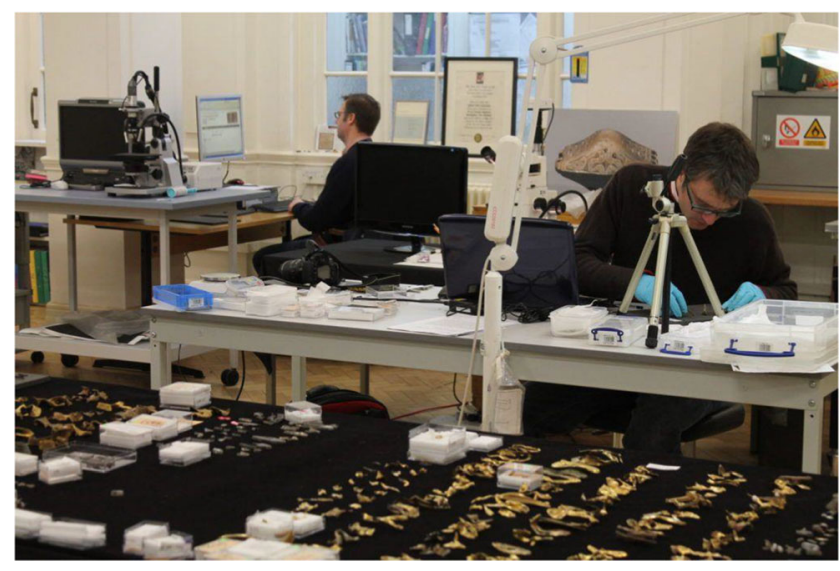

Image 1. The experts at work on the 'jigsaw' in the Birmingham Museum and Art Gallery conservation lab (Image (C) Birmingham Museums Trust)

in a form that delivers to the casual observer a true sense of the majesty of the original. Thus, the museums responsible for the collection commissioned an experimental reconstruction project to create two of the helmets for display in their shared Hoard collections. This reconstruction project was to be based on the findings of the main Helmet research project, but it also provided a valuable opportunity to explore the questions of form and manufacture which could not be resolved by studying the original fragments alone. The reconstruction of this ancient 'jigsaw' (missing many pieces and without a picture

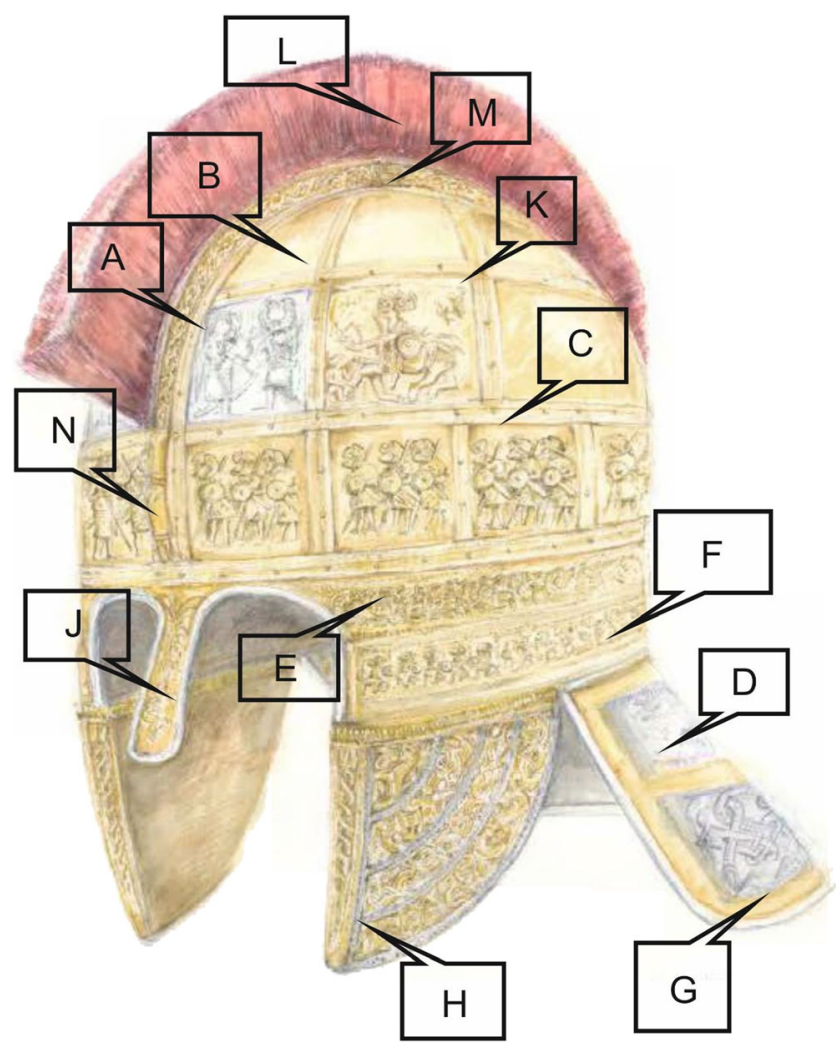

Image 2. Initial conceptual Helmet drawing (Image (C) Birmingham Museums Trust) with the various major components indicated 


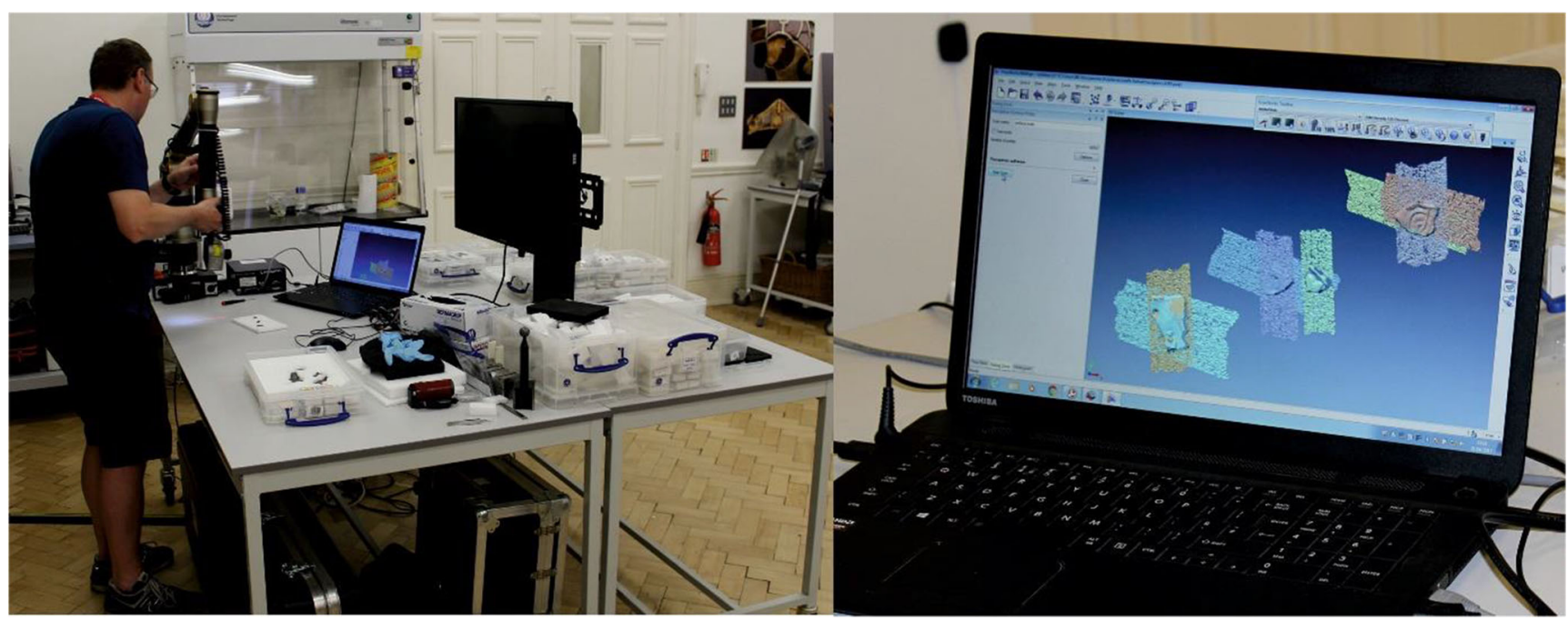

Image 3. Laser scanning helmet fragments in the museum's conservation lab

on the lid to follow) into a coherent scheme of decorative panels and bands, showing either animal art or warrior imagery, and fixed in place by the reeded strips and rivets, was achieved by the hard work of a select group of conservators, archaeologists, Hoard researchers, Anglo-Saxon iconography experts, art historians, and of course the various digital and traditional skill sets available here at the Birmingham School of Jewellery (Image 1) $\left[^{11}\right]$.

The Centre for Digital Design and Manufacturing (DDM) at the School of Jewellery (SoJ) was first approached by Birmingham Museum in 2016 to quote for fabricating and assembling the various components of the two helmets and the drawing, Image 2, was to be our starting reference point from which we extrapolated and calculated a requirement, per helmet, for the following components that would need to be fabricated using a variety of the jewellery and silversmithing techniques and technologies available to us here at the SoJ.

16 embossed rectangular panels (A)

12 plain panels of varying profiles (B)

$6 \mathrm{~m}$ of reeded strip (C)

9 cast items including cheek guards $(\mathrm{H})$ crest channel (M) horse head finial $(\mathrm{N})$

6 additional cast items for the neck guard (D)

1 squared $U$ 'channel' approximately .75 of a metre long

2 embossed strips approximately .75 of a metre long (E and F)

1 shaped retaining panel for the neck guard components (G)

1 shaped tubular $\mathrm{U}$-shaped edging strip for the neck guard

1 shaped tubular U-shaped edging strip for the nasal and eyebrows (J)

150 (approximately) rivets (reeves or roves) (K)

1 horsehair plume (L) dyed red

\footnotetext{
${ }^{11} \mathrm{https} / / / \mathrm{www} . b c u . a c . u k / j e w e l l e r y$
}

All components to be brightly lustre polished

Gold plating where required

Silver plating where required

For the purposes of this paper, we shall divide our reporting on the technological production of the various components of the helmet into various discrete sub-sections describing the multiple and differing fabricating processes used to create the reproduction components for the two replicas, starting with a section about the digitisation processes used followed by the various artisanal and digital techniques and technologies and a final section that covers the actual assembly process and presents the results.

The techniques and technologies used included the following which are referenced to the call outs in Image 2 where appropriate:

1. Laser scanning and analogue measuring instruments

2. Low wear, low usage stamping tooling developed using CAD and CNC milling (A, E, F)

3. Wire drawing using a swage block (C)

4. $\mathrm{CAD}, 3 \mathrm{D}$ printing and lost wax investment casting $(\mathrm{H}$, $\mathrm{M}, \mathrm{N}, \mathrm{D})$

5. Anticlastic raising and forming $(\mathrm{J})$

6. Water jet cutting $(\mathrm{G})$

7. Rivet making of various lengths and diameters $(\mathrm{K})$

8. Horsehair plume (L)

9. Polishing

10. Electroplating

\section{The digitisation processes}

The iterative development and constant refining of the data that would eventually go to inform the selected manufacturing 


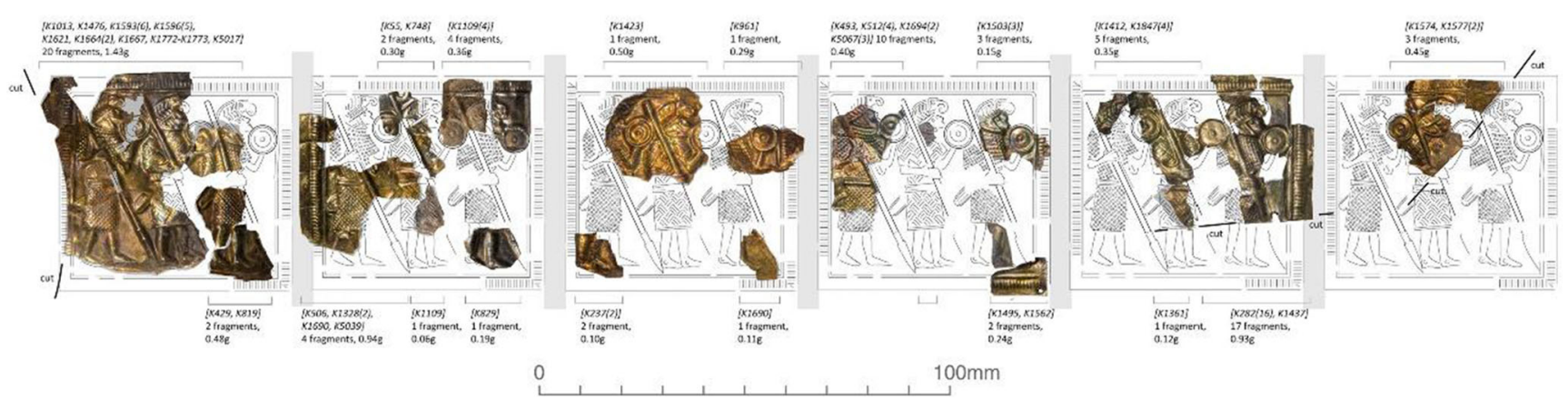

Image 4. Left-facing warriors' fragments series (Image @ C Birmingham Museums Trust)
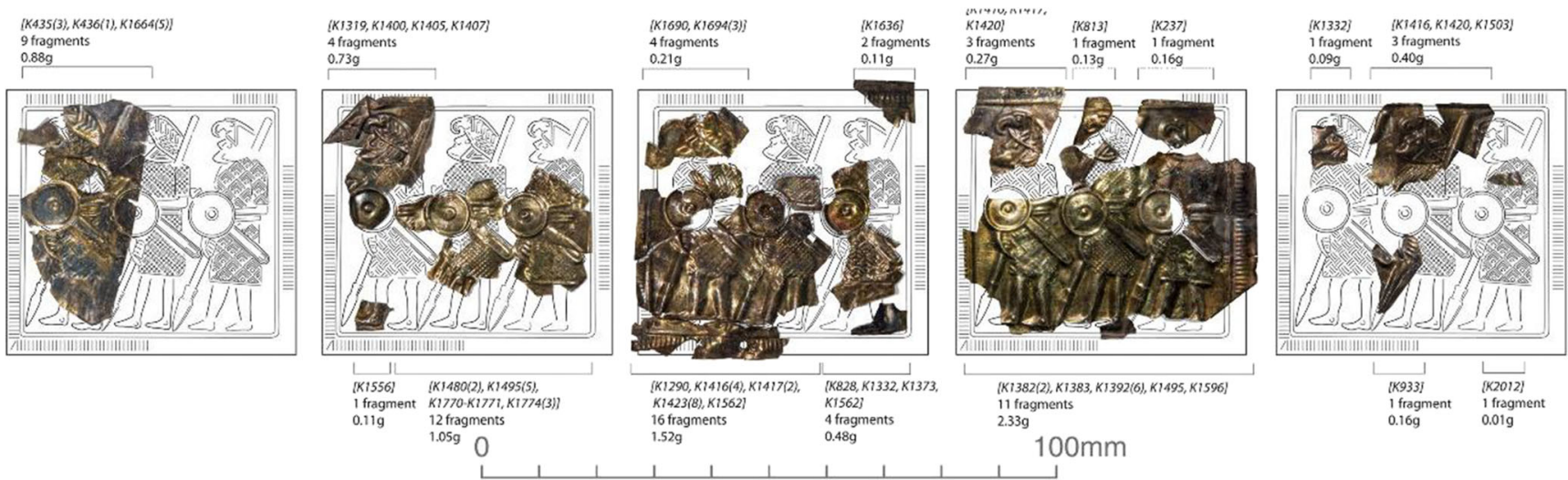

Image 5. Right-facing warriors' fragments series (Image (c) Birmingham Museums Trust)

process for each reproduction component part started with a close and intensive study of the original Hoard artefacts held by the museums and in detailed consultations with the museum's conservators. This necessitated several visits by the DDM team to the BMAG conservation lab with our laser scanner where the conservators had laid out the various components to be studied, scanned, measured, photographed, observed closely, and discussed extensively. The conservators were also integral in explaining to the DDM team the various interpretations of what the various sets of fragments
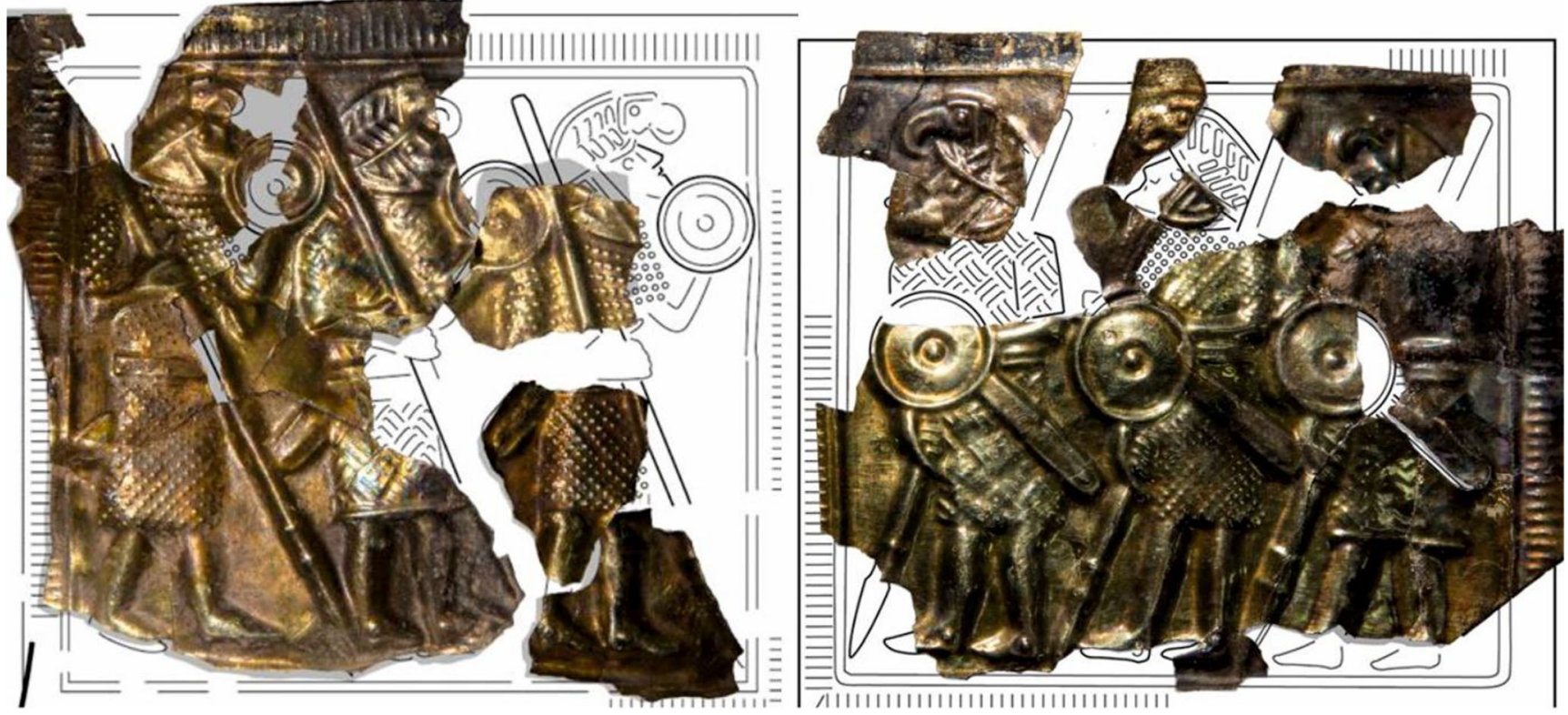

Image 6. Enlarged partial views of left- and right-facing warriors (Image @ B Birmingham Museums Trust) 

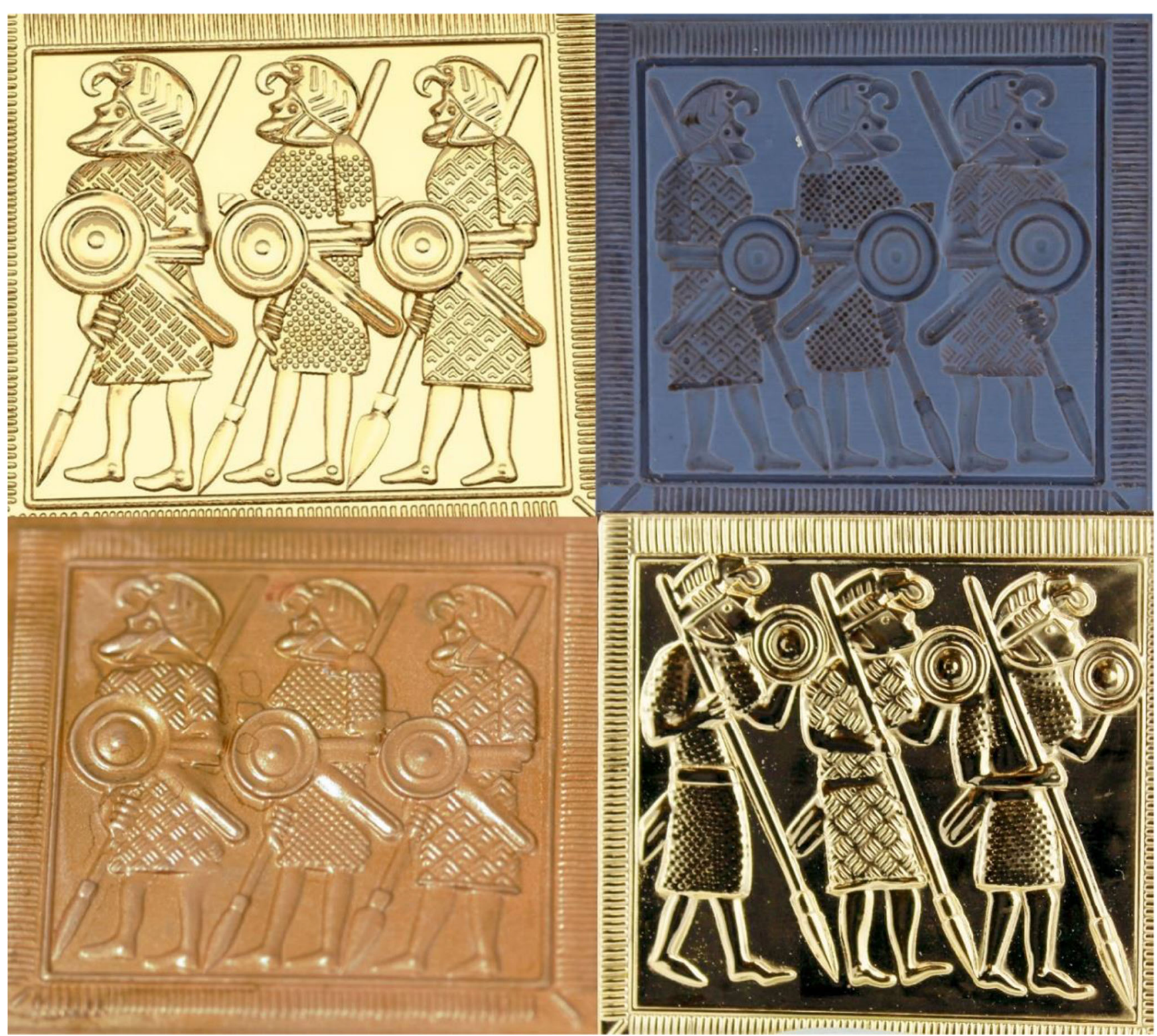

Image 7. The various stages of manufacturing a reproduction patterned panel stamping of the standing warriors
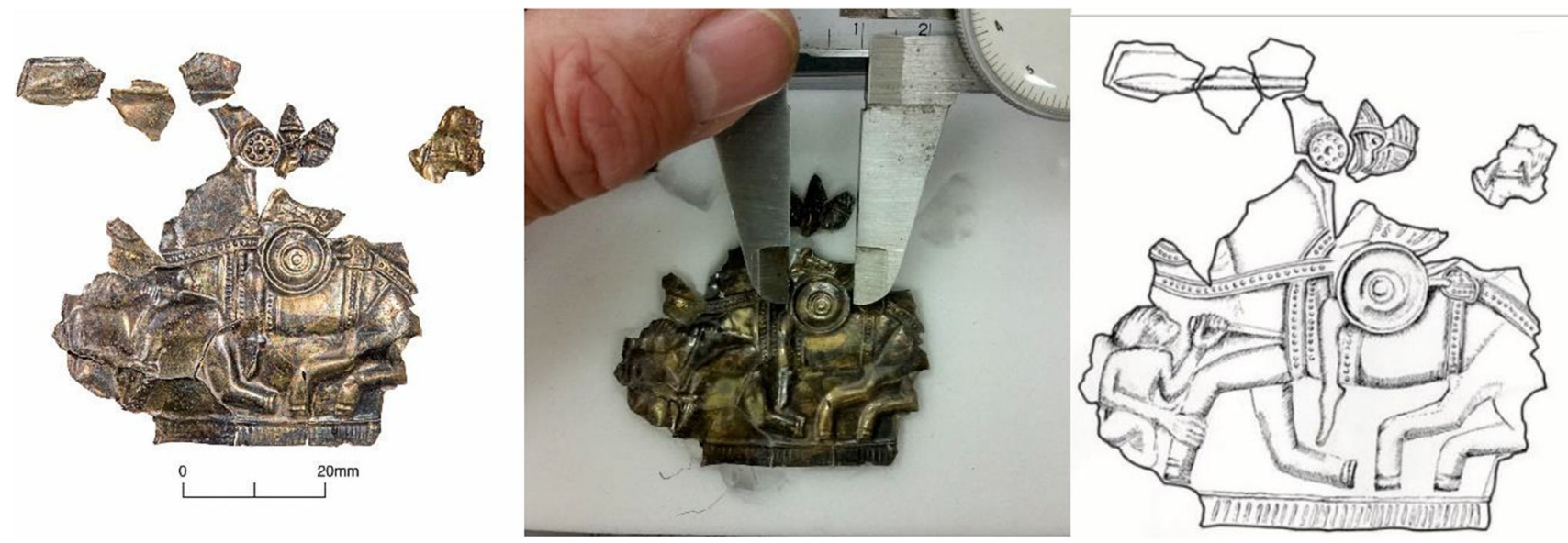

Image 8. The horseman fragments 


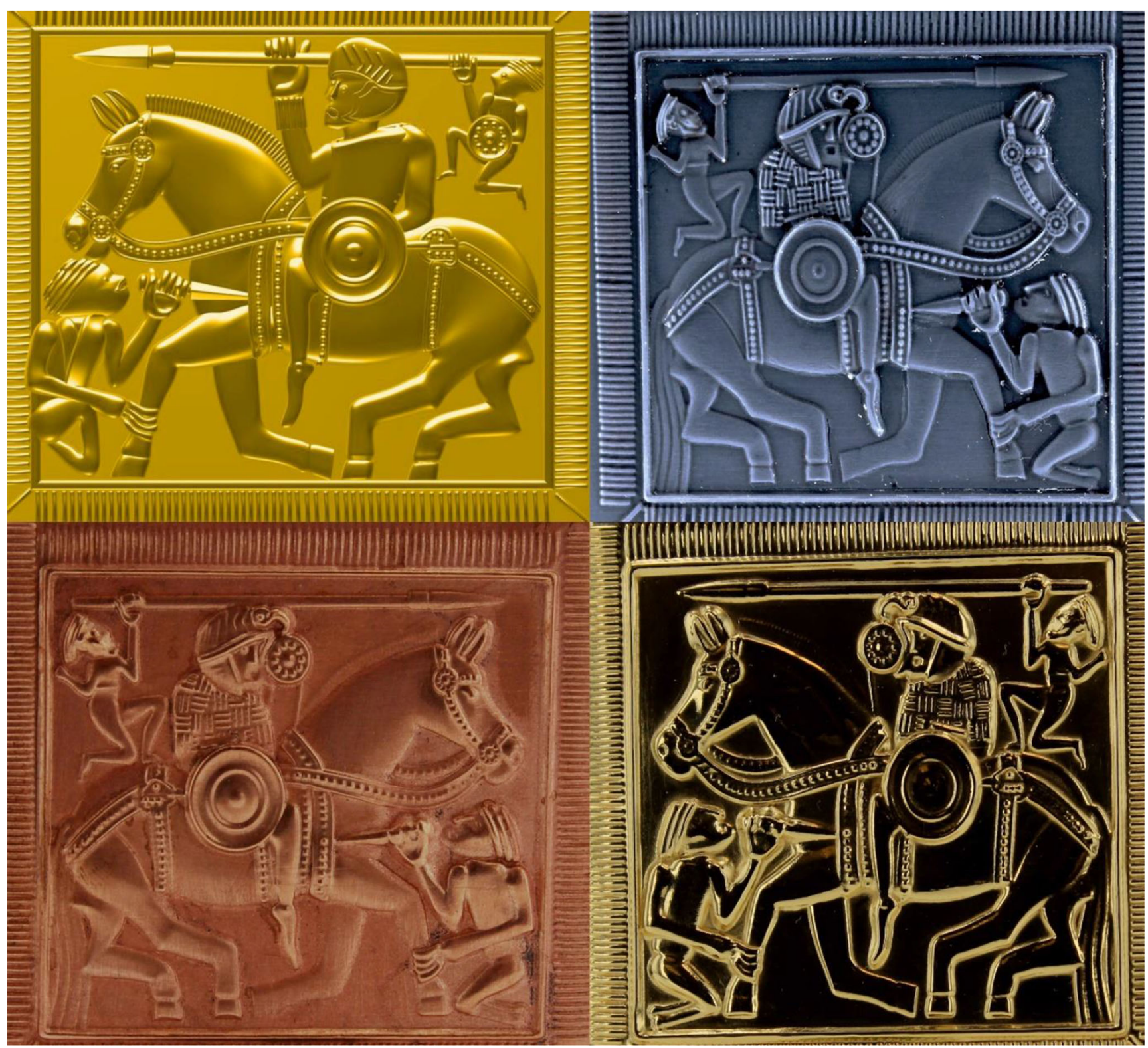

Image 9. The various stages of manufacturing a reproduction patterned panel stamping of the horseman

represented and how they considered missing parts should be represented or interpreted in the digital files to be created. They also added where possible their understanding of how the original components of the Helmet may have been manufactured.

Laser scanning is a non-contact, non-destructive technology that digitally captures the shape of physical objects using a line of laser light. Laser scanners create 'point clouds' of data from the surface of an object. Laser scanning is a way to capture a physical object's exact size and shape into a computer as a digital three-dimensional representation of the object being scanned (Image 3).

Laser scanners measure fine details and capture free-form shapes to quickly generate highly accurate point clouds and are ideally suited to the measurement and inspection of contoured surfaces and complex geometries. The laser projects a line of laser light onto the surface whilst two sensor cameras continuously record the changing distance and shape of the laser line in three dimensions (XYZ) as it sweeps along the object. The shape of the object appears as millions of points called a 'point cloud' on the computer screen as the laser moves around capturing the entire surface shape of the object. The process is very fast, gathering up to 750,000 points per second and very precise (to \pm 0.0005 inch). After the point cloud data files are created, they are registered and merged into one three-dimensional representation of the object and post processed with various software packages suitable for the intended final application.

Let us now address each of the key digitisation tasks starting with the two sets of standing warrior panels. In 
Images 4 and 5, you can see the various fragments allocated by the experts to a series of left- and right-facing warriors. The fragments have been placed on a drawing, supplied to us by the museum's conservation team, of what was agreed the final panel design should look like, these drawings are based primarily on the observable fragments with any missing parts being based where possible on existing similar panels to be found on other helmets from this period. The DDM team then scanned the fragments and superimposed or traced that scan data onto a single panel image eventually giving us the full data set required for creating the necessary tool paths for cutting the stamping tools. Also, notice there were sufficient fragments identified to be able to indicate six left-facing warriors but only five right-facing warriors and so the decision was made to have six of each panel on the two reproduction helmets. As discussed earlier, you can also observe in the two sets of enlarged images that the actual designs of the warriors are completely different with differing shields and costumes along with weapon placements and types. This meant that the CAD process of 'Mirroring' (i.e. reversing an image) was not an option here

The two enlarged partial images of the left- and right-facing warriors (Image 6) give a clearer idea of the details involved. It is also possible to here observe the ridged edging around each panel which also acts as a sort of keying point when the panels are overlaid on their edges with reeded strip which is then riveted in place to hold the panels firmly in place on the helmet.
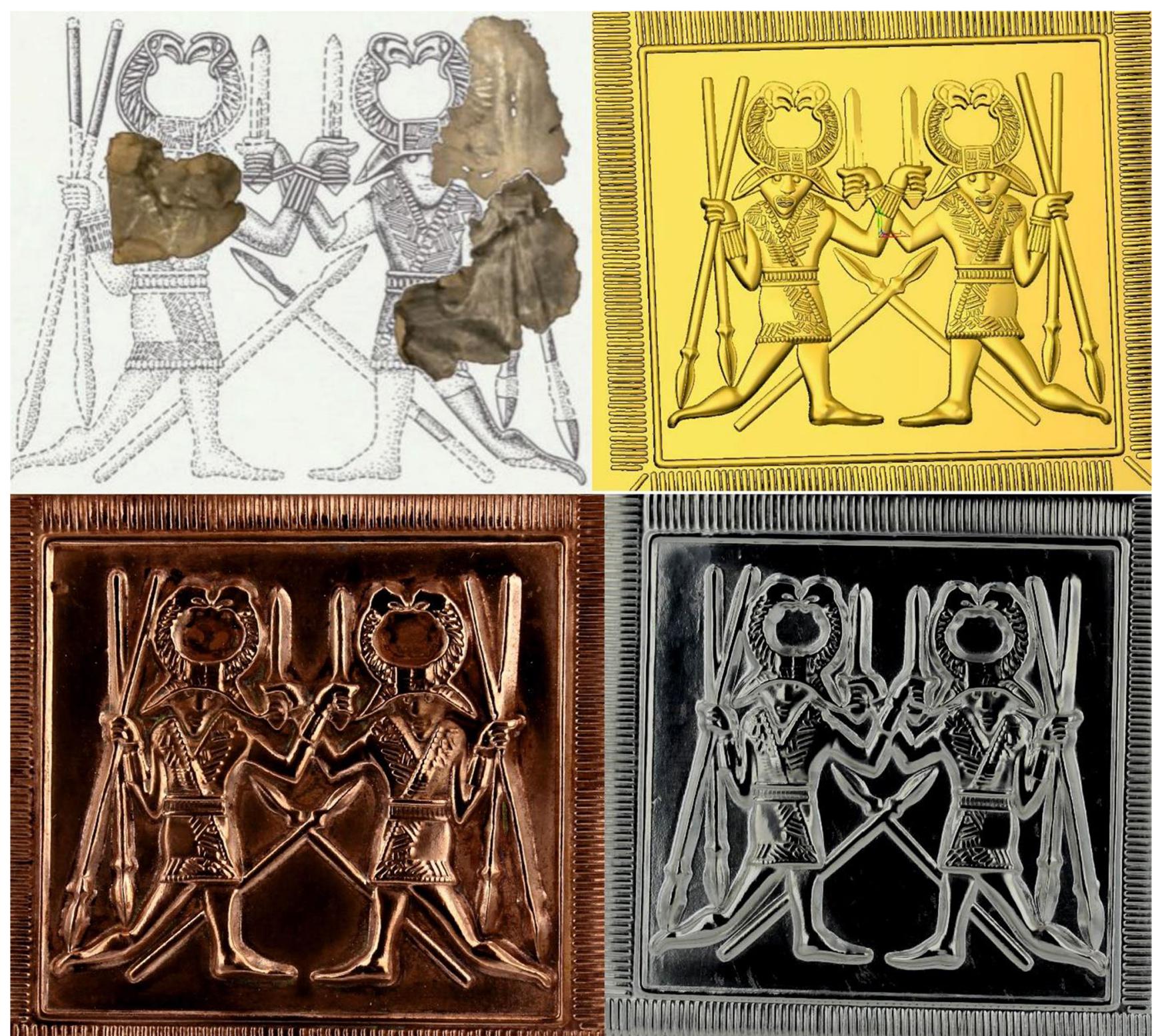

Image 10. The silver priests' panels (Image @ B Birmingham Museums Trust) 

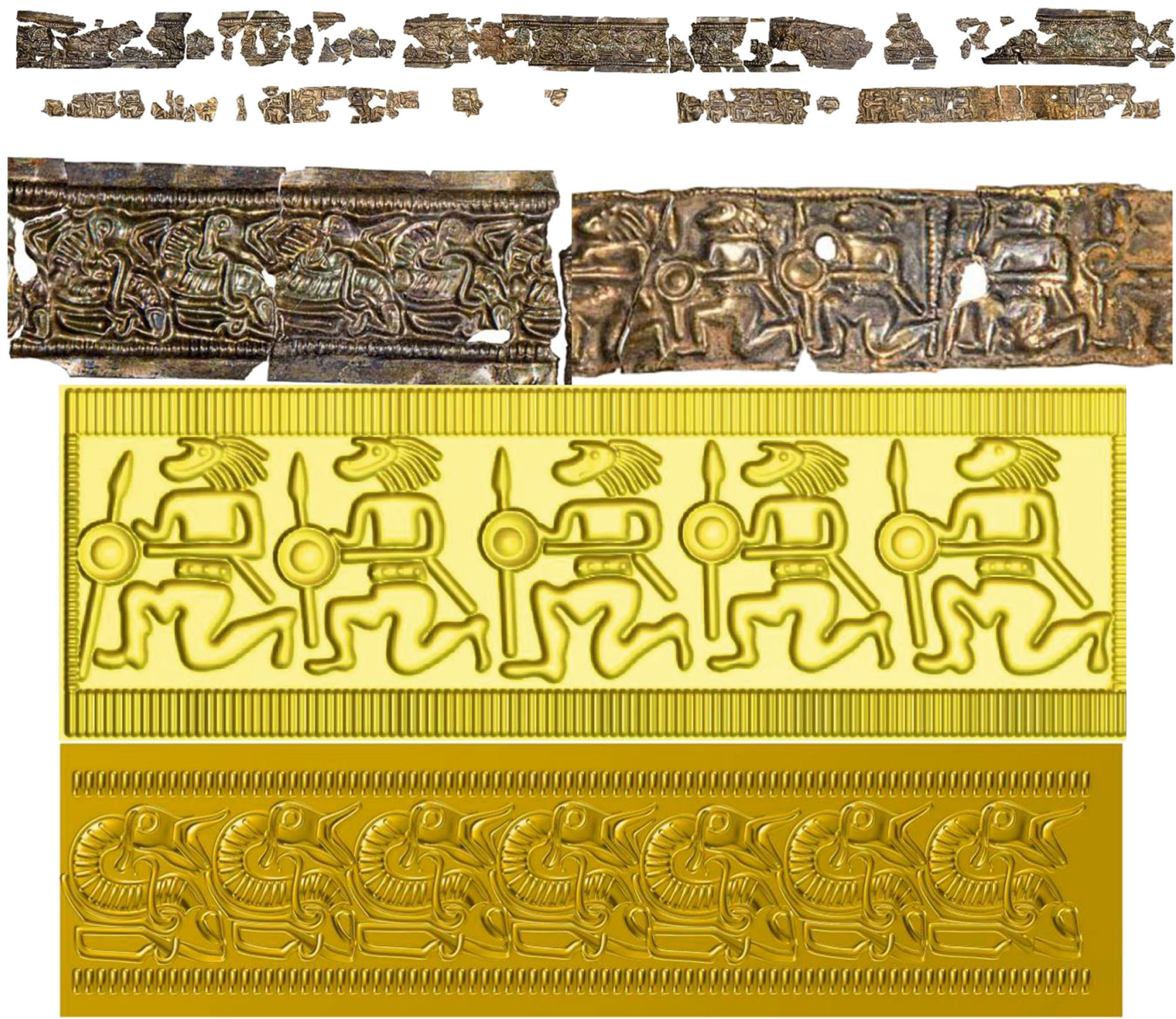

Image 11. The Multiple kneeling warriors and quadrupeds strip fragments (Image $\odot$ Birmingham Museums Trust) and resultant rendered CAD files used to create the stamping tooling

The digitisation process then gave us the results below, a CAD file renders for approval, a die and force for each pattern, raw stampings, polished and gold-plated stampings. This process was then also followed for each of the subsequent examples shown below (Images 7, 8, 9, 10, and 11).

Note the use of an analogue vernier used to measure precise diameter of the shield for later cross referencing.

Note that changes, particularly the patterning on the tunic, were made to the final polished and gold-plated versions of this panel once the render had been reviewed by the conservators and some changes were indicated to the CAD interpretation. 18.

The die and force for the priest are also featured in Image

The dies and forces for these strips are further illustrated in Images 23, 24, and 25.

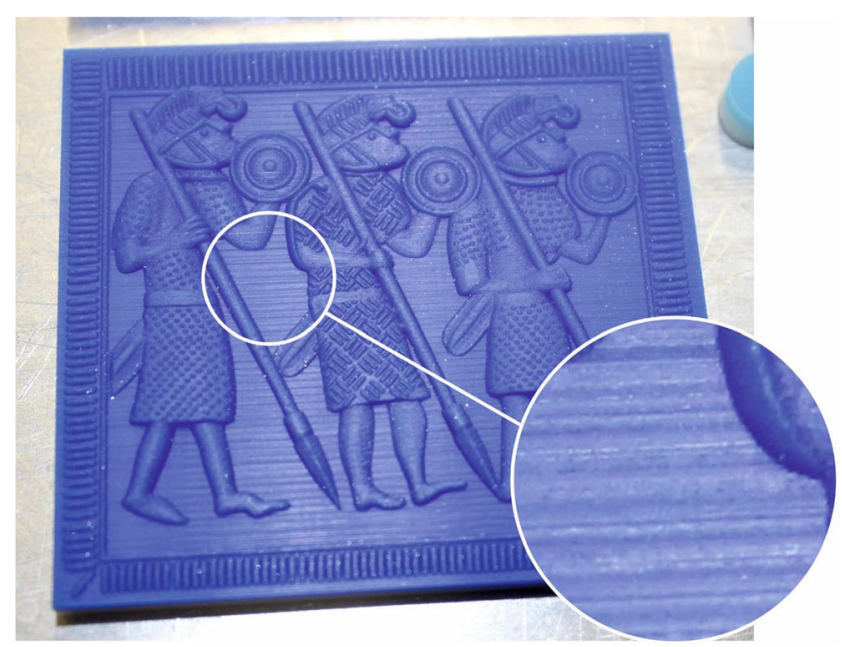

Image 12. A 3D printed resin panel of three warriors and the problematical build lines 


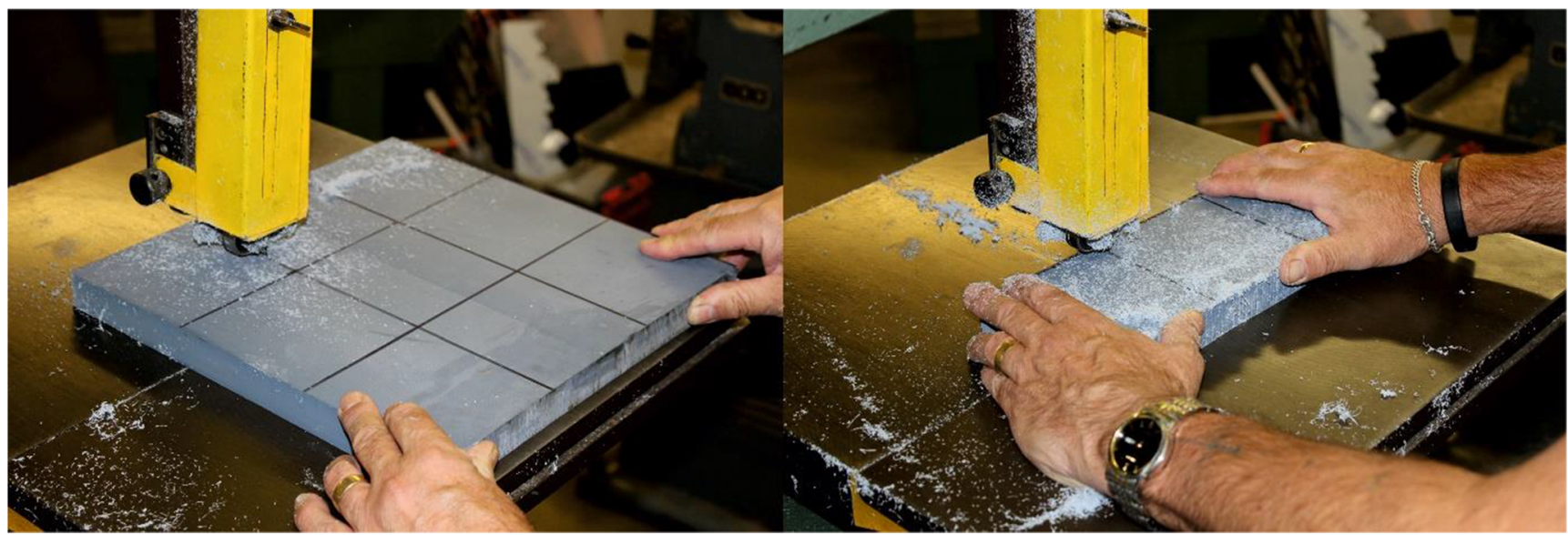

Image 13. Bandsawing

\section{The artisanal and digital manufacturing processes used}

\section{The embossed panels}

The embossed panels are approximately $60 \mathrm{~mm} \times 55 \mathrm{~mm}$ rectangles and an average of 0.004 inch thick; the originals are primarily silver gilt or with a gold enriched surface $\left[{ }^{12}\right]$. The reproductions are stamped from 0.004 inch copper shim that has then been polished and electrolytically gold plated once embossed. The archaeological Hoard research literature describes these components as being 'die impressed sheet fragments' $\left[{ }^{13}\right]$.

There are five distinct iconographic images embossed on to the various panels the largest number of which are described as 'standing warriors' where these warriors face either to their left or to their right with distinct differences in their dress, armaments, and pose so a simple CAD driven mirroring or reversing of the image was not going to be possible.

The next grouping are the mounted warriors where there was only clearly identifiable physical evidence of the mounted warrior facing in one direction; however, the experts asked us to produce left- and right-facing versions of what they considered the original Helmet probably looked like and which was based on comparisons with other Anglo-Saxon, Scandinavian, and Roman examples, some of which are cited later in this paper. So, in this case, we were able to use our digital technologies to create a mirrored or reversed digital data set for the mounted warrior.

The final grouping consists of just two panels on each helmet and was, to us non-experts, intriguingly described as 'The Priests' who are two of the most warlike warrior priests you are ever likely to come across in that between them on

\footnotetext{
$12 \mathrm{http} / / /$ archaeologydataservice.ac.uk/archiveDS/archiveDownload?t=arch2457-1/dissemination/pdf/SHResearchReports/SHRR6_Blakelock.pdf

${ }_{13} \mathrm{http}: / /$ archaeologydataservice.ac.uk/archiveDS/archiveDownload?t=arch2457-1/dissemination/pdf/SHResearchReports/SHRR17_Shearman_etal.pdf
}

each panel, they have six spears and two swords and are wearing fearsome-looking horned helmets!

Our original plan was to create the appropriate CAD STL file and in a castable photopolymeric resin, print the panels on our ProJet 3500 CPX 3D Printer and then cast directly into bronze; early experiments with this process proved disappointing in both achieving the desired thickness and an acceptable level of surface detail that would withstand the polishing process without the loss of important features. In Image 12, you can clearly see the horizontal 'build lines' that would eventually prove to be very difficult and time consuming to remove during polishing without compromising the warrior's more important surface details.

Luckily on the SoJ DDM team working on this project was a colleague who is an apprenticed tool maker and die sinker with many years of experience in die and force making for the jewellery industry who is now the senior CAD/CAM tutor here at the SoJ. He proposed we adopt an innovative and cost-effective method for making the necessary sets of dies and forces in a resilient material that could be $\mathrm{CNC}$ milled yet not require the time consuming and costly post-processes, like furnace hardening, that are normally associated with more traditional dies and forces made from expensive tool steels.

This process started with his knowledge of a material called SikaBlock ${ }^{\circledR}\left[{ }^{14}\right]$ which is a very dense model-board material resource which has a density of $1000 \mathrm{~kg} / \mathrm{cm}^{3}$, good milling behaviour, a very low coefficient of thermal expansion coupled with good compressive and edge stability. It is most typically used for foundry pattern making, gauges, and other applications in mould and tool making. In use, we found it to have excellent dimensional stability when CNC milled, despite its comparatively low density, which was good for handling, yet coupled with a high-tensile surface which makes it an excellent choice for being easily mechanically workable which happily for us translated into being very machineable

\footnotetext{
${ }^{14}$ https://advanced-resins.sika.com/content/sikaaxson/gbr/en/solutions products/product-groups/block-materials/model-and-tooling-boards.html
} 


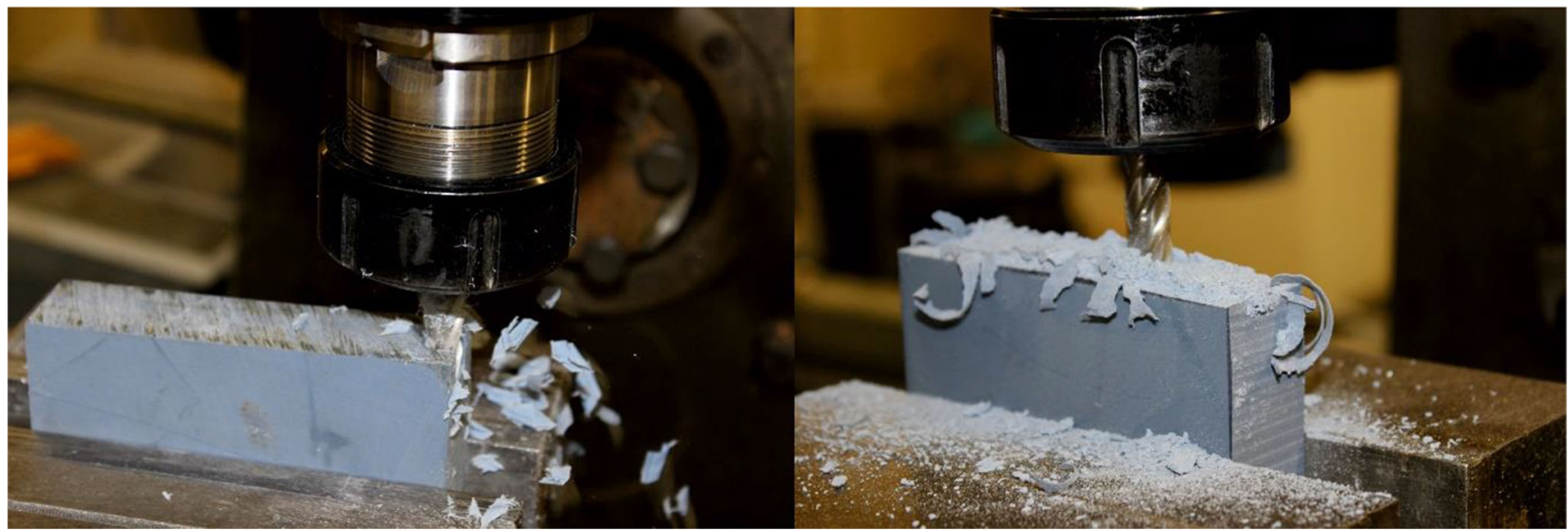

Image 14. Milling the edges square

on our 'lower end' CNC milling machine which is more typically used to $\mathrm{CNC}$ softer materials like woods and wax for our student body.

\section{Stamping tooling development}

The first stage of creating the stamping tools involved cutting down on a bandsaw the as supplied fibre boards from approximately 1.5 meters square, and 2 centimetres thick, into useable and suitably sized blocks. Image 13, and the subsequent images in this section (Images 14, 15, and 16), will amply demonstrate how well the SikaBlock ${ }^{\circledR}$ fibre board accepts the rigours of the various cutting, milling and press stamping operations it was subsequently put through.

The edges then needed to be squared and made true on a Lagun FU-TV 125 miller

We then milled in the edge slots to enable safe and secure 'dogging' (locking in place) of the tools into the $\mathrm{CNC}$ miller and the large hand press that was to be used to stamp the various replica Helmet panels

\section{Die and force cutting}

Taking the data captured and created from the process of laser scanning and digitally re-assembling the multiple fragments in the museum's Hoard collection and filling in the blanks are covered in some detail earlier in this paper. By the end of the digitisation and file creation process, we were able to create the necessary tool paths to allow cutting to begin using ArtCAM software (now discontinued as part of the Autodesk stable of software's). We used a $2 \mathrm{~mm}$ and $1 \mathrm{~mm}$ diameter roughing ball drill and a $0.50 \mathrm{~mm}$ conical finishing tool. The die and force cutting was done on our Charlyrobot 4U CNC milling machine which uses Grail Pilot control software (Image 17).

Six millimetre diameter holes were drilled into diametrically opposite corners of each die and force and $6 \mathrm{~mm}$ dimeter steel dowels tightly hammered into the force to act as location guides during the stamping operations (Image 18).

The offset used to cut these dies and forces is a 2D offset only that subtracts the meatal thickness of the copper shim from the vertical sides of the force (or male) die. ArtCAM is perfectly capable of offsetting the 3D form and purists would

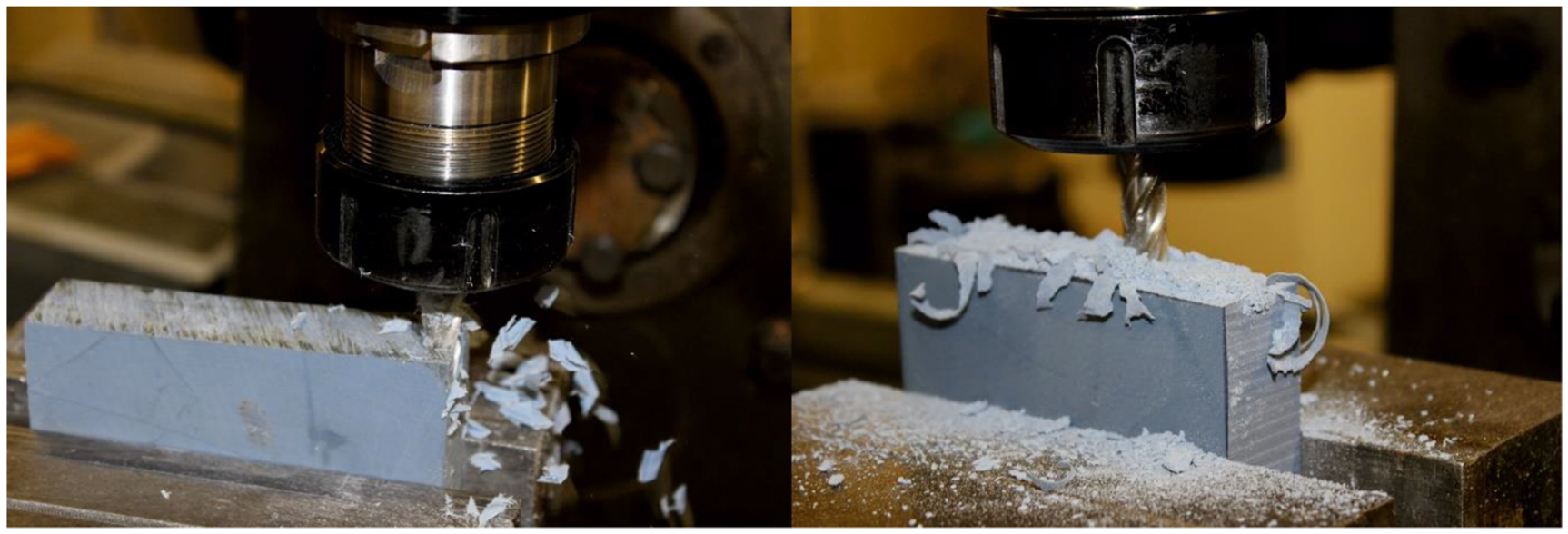

Image 15. Slotting the boards 


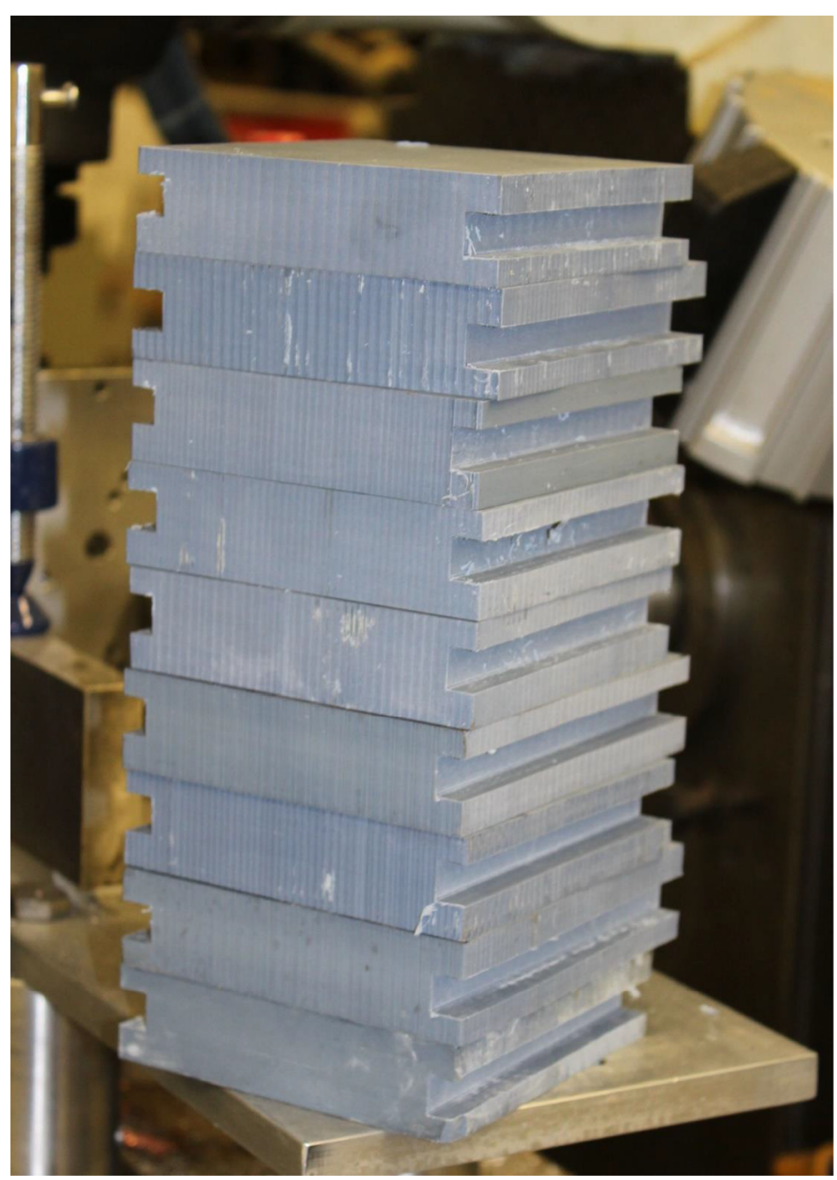

Image 16. The fully prepped tooling boards ready for $\mathrm{CNC}$ die and force milling

say that this is the correct thing to do, to create a gap between the male and female dies that is occupied by the material being stamped. When stamping simple shapes this would probably work quite well.

However, in reality, what we tend to find when stamping complex shapes like these panels that tend to 'pull' the metal in multiple directions in a short space, and in a very malleable metal, is that detail on the upper faces tends to look as though it has not been struck hard enough. This is because the dies are held apart by the thickness of the stamping material more on the top surfaces than at the sides. Think in terms of a stack of inverted plastic drinking cups where the top edges will never touch. To allow for this we removed material from the male die on the vertical sides only. In ArtCAM, a boundary vector is created around the figure on the stamping; this is then offset inwards by approximately $80 \%$ of the metal thickness, so $0.08 \mathrm{~mm}$ in this particular case (Images 19 and 20).

Next step, the same as we would with steel stamping dies, was to test stamp some annealed 0.004 inch copper shim squares to look for splitting at any high spots on the die that would require easing. The stamping was carried out on the SoJ's largest, No3, hand press with extra weight added to the counterbalance swing arm which gave us around 30 tons of downward force and with a false nose and heavy metal plate between the stamping tools and the ram of the press in order to widely distribute the downward force of each blow as evenly as possible over the stamping tools. This exercise revealed a number of 'high spots' on the tools that caused splits in the stampings to be identified that required some 'easing' of the tools (Images 21 and 22).

Image 23 (below left) shows the use of a spit stick graver to ease one of the panel stamping tools, use of such a graver was possible due to the softer nature of the SikaBlock® fibre board when compared to working on steel dies and forces, although a pendant motor and fine steel burr were also used quite extensively during these easing exercises. Both the stamped panels and the stamped strips required a pre-raise of the copper sheet and strip followed by an open hearth anneal* and scouring clean to remove oxide before a second, and occasionally third, and final raising blow on the hand press. The sticky tape visible on the right-hand side of Image 23 below provided for a bit of extra pressure in any places where the stamping is considered not quite sharp enough. With a hand press and semi-soft tooling, we could not just endlessly turn up the tonnage, as we probably could have done with a hydraulic press and hardened steel tooling.

*Annealing — when being worked (hammered, rolled, stamped etc.), metals harden due to changes in their crystalline structure and need to be heat treated in order to soften the metal back to a more malleable state. Typically, in this project, the annealing was carried out on an open hearth using a flame generated by the mixing of gas and air through a handheld torch and applied until the metal acquired a deep cherry red colouration $\left[{ }^{15}\right]$.

\section{Progression or follow-on tooling}

The Helmets project also required the development of stamping tooling able to create two different repeating strip patterns, one that was unofficially known by us as 'the ducks' which are described by the Anglo-Saxon iconography experts to be a representation of a 'zoomorphic quadruped' the second strip was a much more easily identifiable 'kneeling, or running, warrior'. Luckily, both had an identifiable repeat line that gave us a repeat blow length we felt could be accommodated using a similar stamping tooling method as that used for the panels to produce the progression force and die in SikaBlock $®$ whilst also manually feeding the strip through. In the case of the warriors, it was a dotted vertical line after every fifth warrior and for the ducks, it was a less visible 'witness mark' after every sixth duck (Image 24).

In the case of the ducks, we constructed the tool with a seventh duck in only the die which was used to locate the

\footnotetext{
${ }^{15}$ https://en.wikipedia.org/wiki/Annealing_(metallurgy)
} 

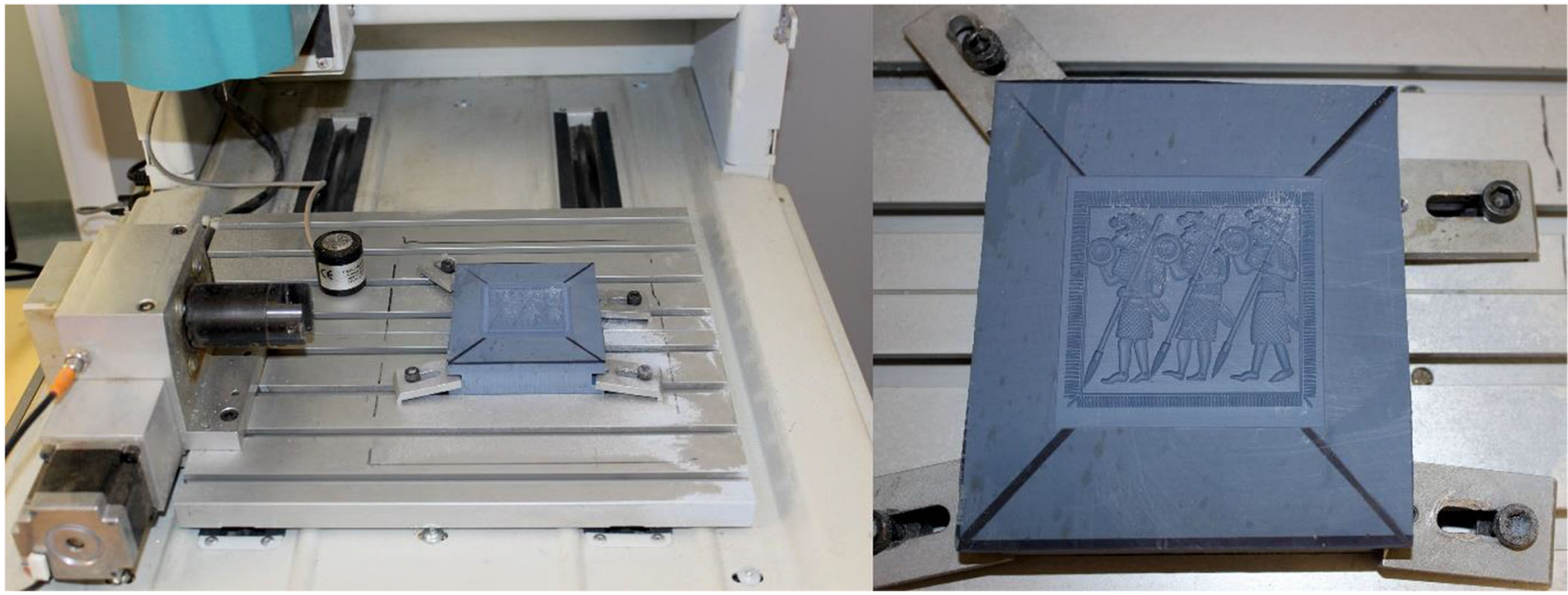

Image 17. $\mathrm{CNC}$ milling the dies and forces on the Charlyrobot

strip into the tool after advancing it forward by six. The seventh duck deliberately did not get re-stamped as this could have led to additional splitting issues, also note that the ducks, or quadrupeds, and warriors are deliberately not identical as per the original strips.

The warriors were easier to index as they were in two groups of five with a dotted dividing line, so they were advanced in their groups of five with ten warriors cut into the die and only five into the force. The stamping of both of these strips was again done on the large No3 hand press and the strips were being torch annealed as required, the strips were also being advanced and located by hand. Early strip stamping trials resulted in a decision to double up the thickness of the bases and tops of these tools compared to when being used for stamping the panels as they were found to flex a little as they were being stamped, this doubling up also helped to distribute the press 'blow' more evenly along its length rather than being concentrated through the centre of the tool directly below the headstock. The progression tooling was also doweled to improve the accuracy of each blow of the tool; it was also necessary to develop a strip guide and feed system in order to present the annealed copper strips evenly and aligned straight into the progression tools. The 0.004 -inch-thick copper strips had been sheared to a width of $25 \mathrm{~mm}$ on a small handcranked shear we have here in the SoJ and finally open hearth annealed (this annealing process is described earlier in this chapter) in one of our silversmithing workshops using a gas and air handheld torch, after annealing they were pickled and cleaned with pumice* before rinsing and drying. Again, some splits were observed in the stampings, despite annealing and a

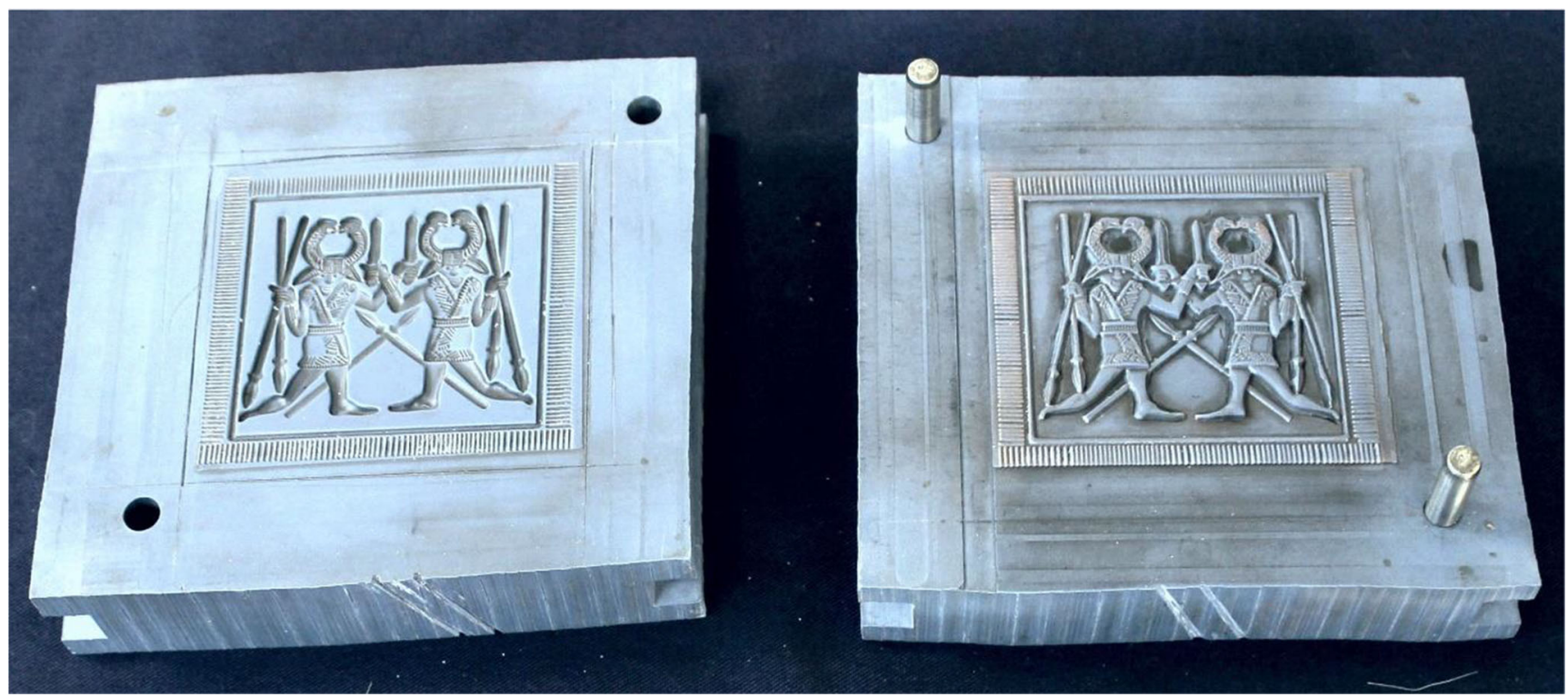

Image 18. Doweled die and force 

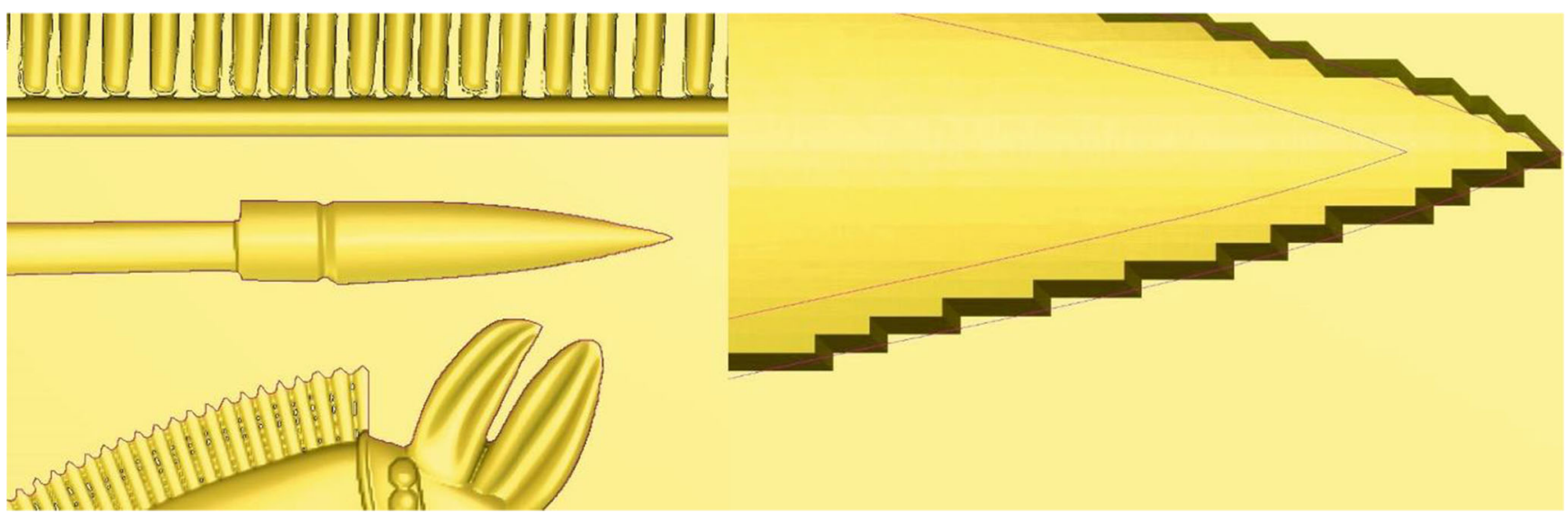

Image 19. How the offset toolpath vector around the spear point works in ArtCAM

pre-raise blow, so the forces or dies were eased as appropriate in much the same way as the panels (Images 25, 26, and 27).

*When using an open flame to anneal dark oxides will form on the surface of the copper these are removed by first immersing in a dilute acid solution (pickling) which loosens the oxide layer which is then removed by rubbing pumice powder over the metal and scouring the surface with a toothbrush under warm running water.

\section{The cast reproduction pieces}

Several of the original Helmet artefacts were identifiable as possibly being the result of a casting manufacturing process whilst a number of the reproductions were also chosen to be cast.* The most important items were the two cheek pieces, which when compared to the rest of the Hoard, were in relatively good condition and quite easily interpreted, and the sections of crest channels which were more damaged but in parts retained enough of their original curvature to be able to be used as decent points of reference. The two 'horses head' terminal ends of the channels also survived in an easily interpretable condition. The six parts of the neck guard were those that mostly fell under the 'academically respectable guestimate' heading as there were so few surviving fragments, and which were certainly also stamped items on the original helmet. Again, we used a mixture of laser scanned data capture and multiple $\mathrm{CAD}$ programs to create the files for our $3 \mathrm{D}$ Printers, a combination of the ArtCAM and Rhino software's were the principle software's used by the DDM team. The actual scanning and interpretation of these and other components into a digital format are covered earlier in this paper.

*In this case, we are referring to the lost wax investment casting process as typically used in the jewellery and silversmithing industries. In very simple terms, a wax pattern is encased in a slurry-like 'investment' material (similar to

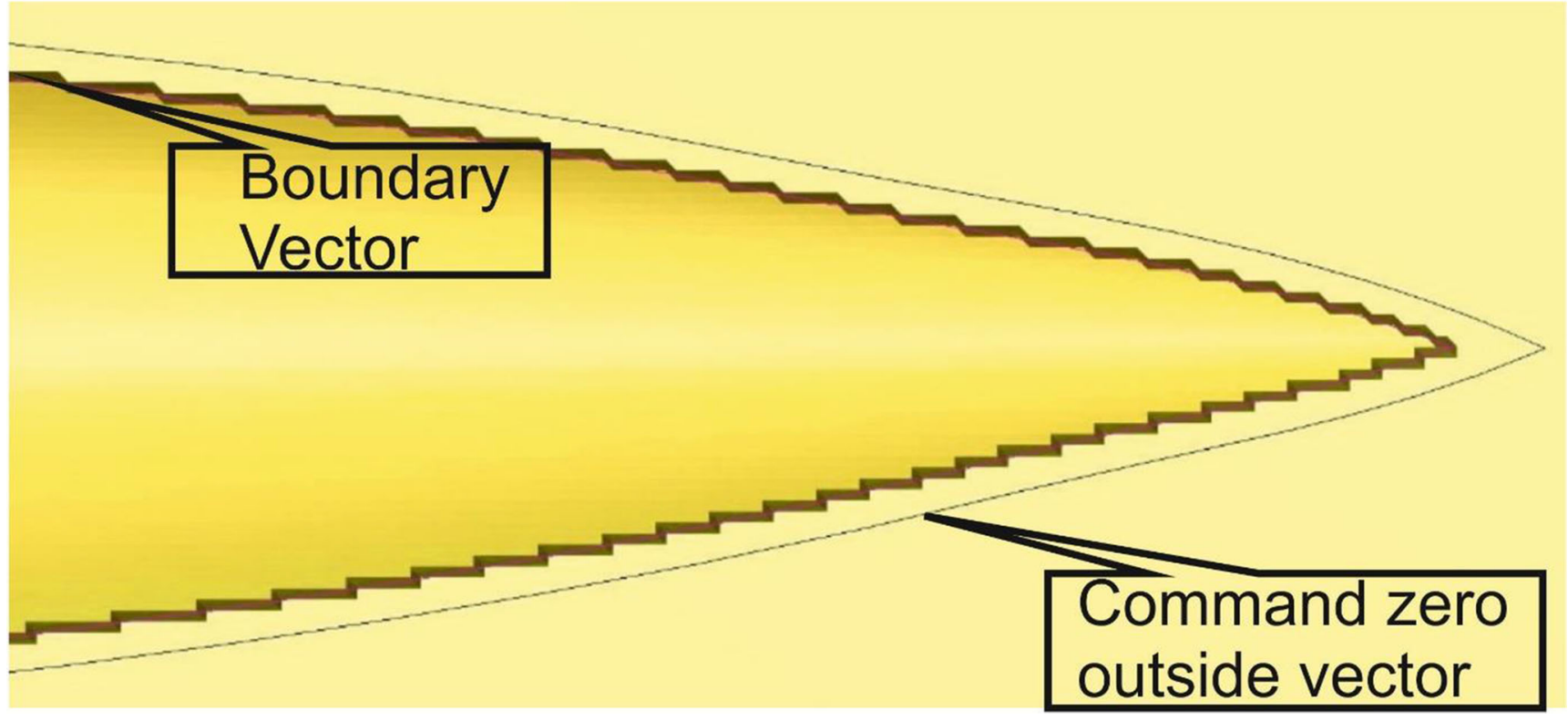

Image 20. The 'command' zero outside vector is then used to cut away the relief outside the vector 


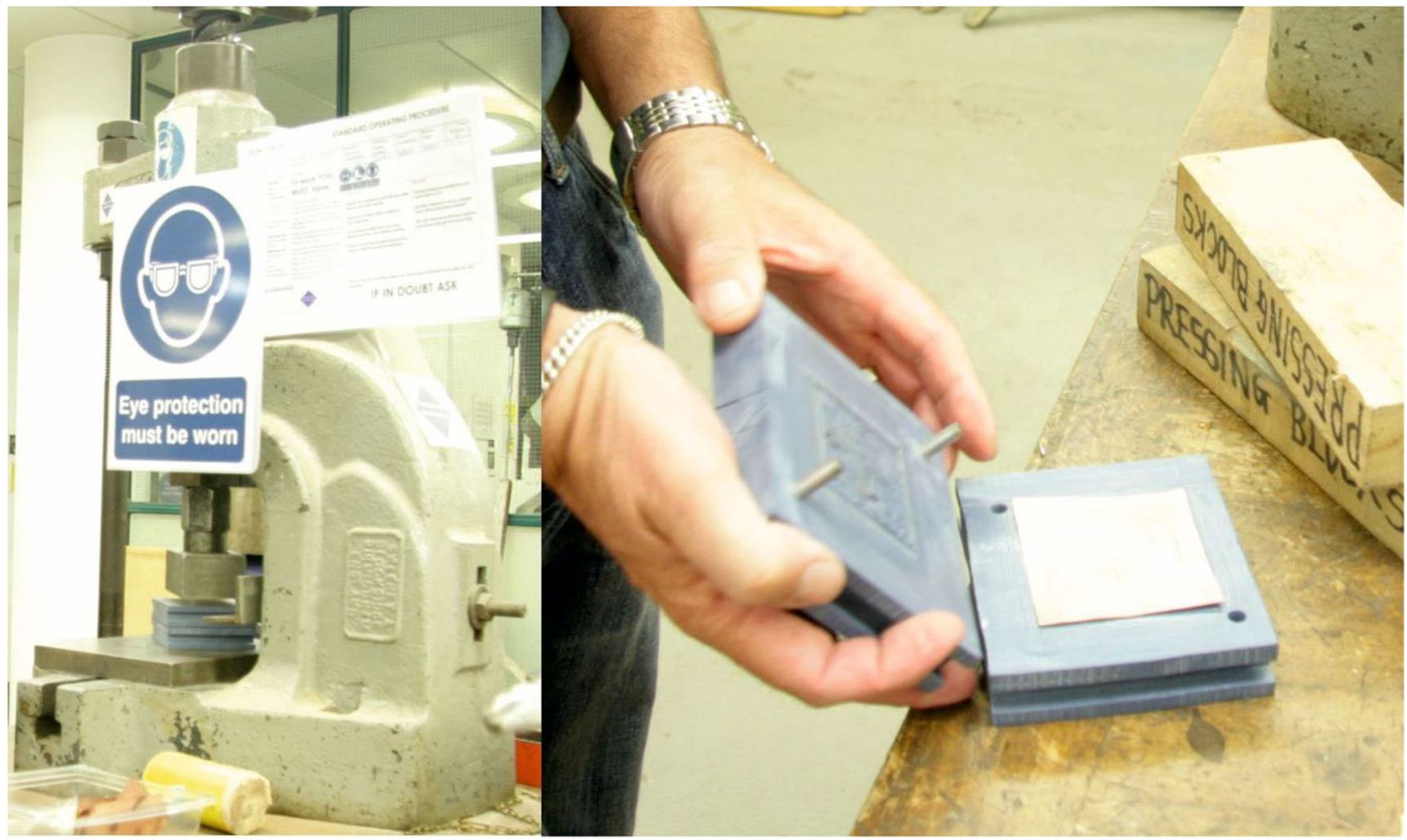

Image 21. Stamping trials

plaster of Paris) which is allowed to harden around the wax pattern. Feed channels are required to allow for the removal of the wax pattern by melting it away and the same feed channel is also used to introduce the molten metal into the resulting void. Once the metal has cooled, the investment material is broken away to release the cast item

\section{The cheek pieces}

The two cheek pieces were the first items in the Hoard to be interpreted as parts of a helmet and two additional, beaded

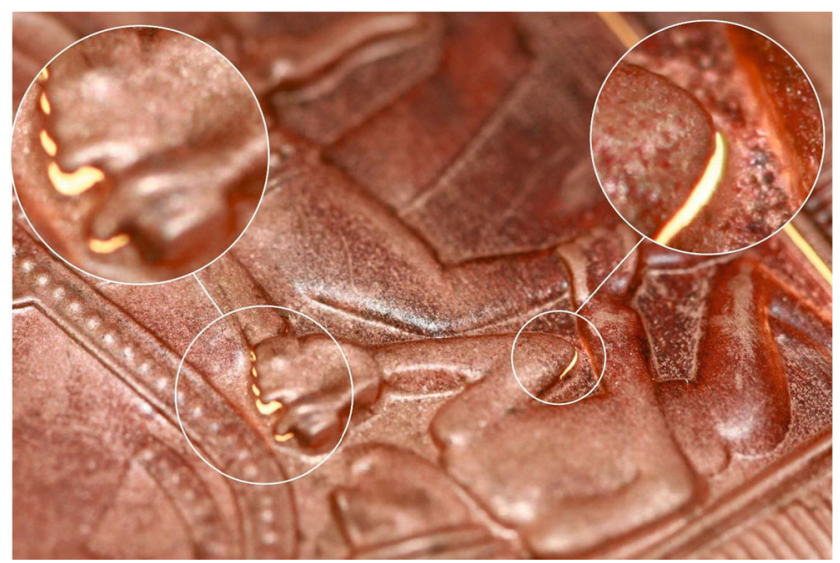

Image 22. Splits identified during the stamping trials by lighting from behind wire style, fittings were quickly identified as clearly belonging to the cheek pieces due to their closely corresponding profiles (Images 28 and 29).

The reproduction cheek pieces were printed on our 3D Systems ProJet 3500 CPX 3D Printer and cast using the lost wax investment process directly into bronze in the SoJ casting shop on a Neutec J-zCE Series 3 casting machine. After sprue removal and fettling they were pre-polished in a magnetic pin barrel before receiving a final light polish on a Swans Down mop mounted on a spindle polisher (Image 30).

At this point, it might be worth considering one of the key questions we most often asked ourselves during this project 'how did they do that?' Their casting patterns must have been hand carved in some way, perhaps into soap stone or perhaps directly into wax and all done without artificial lighting, hard carbonised steel tools and minimal, if any, magnification. Although we have had some vigorous discussions amongst the team around how their iron (steel?) swords must have been tempered and hardened in some way even if only along their cutting edges but again this is a conversation and practical research for another time.

Metal melting, and even alloying, must have been done on some sort of an ancient equivalent of our modern charcoal fired barbeque! All of which presumes these items actually were cast.

"The basic rule of thumb amongst many of the experts in this field is that the Saxons (like most other ancient societies in 

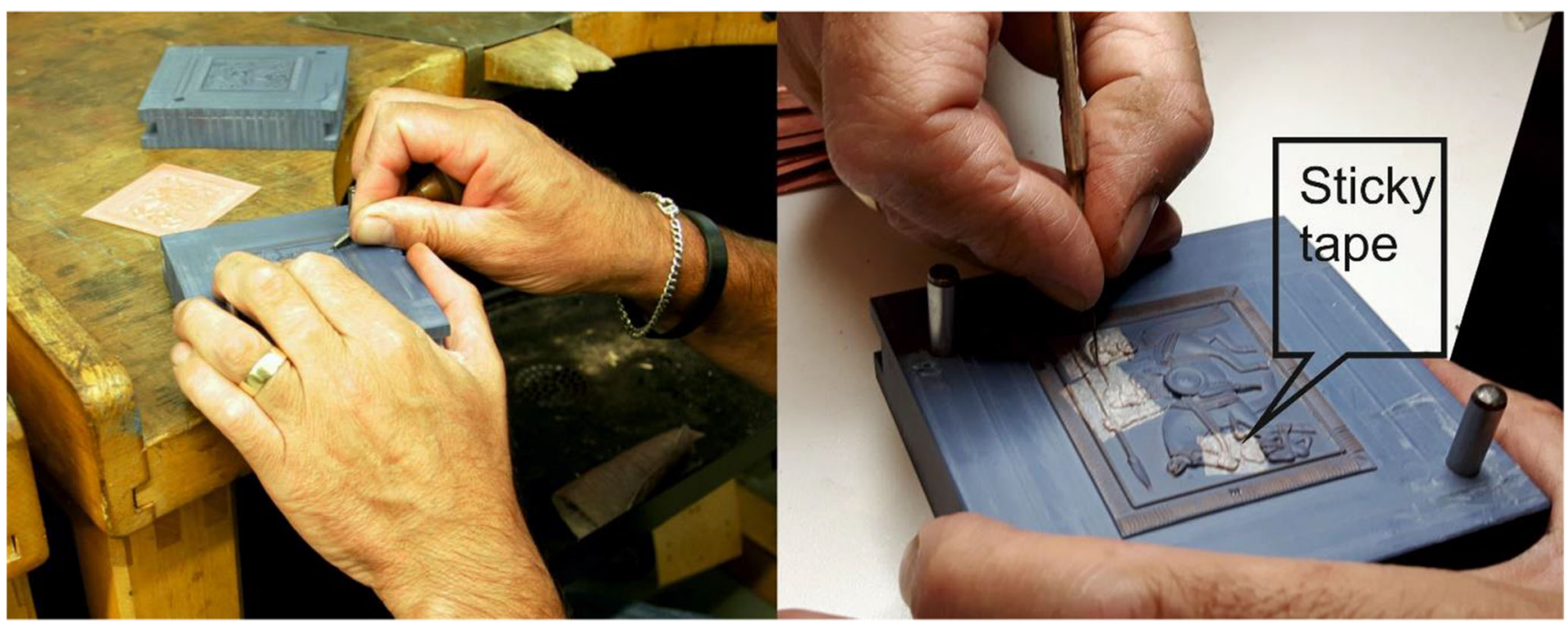

Image 23. Easing the stamping tools at the bench

the Old World) seem to have cast gold very, very rarely other than into ingots which were then wrought in some way. There are various probable reasons, not least that it was impossible to make a mould that would utilize exactly a predetermined quantity of gold. (The wealthy guy who ordered a ring from his goldsmith and gave him a couple of gold coins to use as raw material did not want to get back a ring plus a little bag with filings, cut-off sprue etc etc). One problem is that cataloguers/curators have usually described any solid and robust gold objects as 'cast', whereas you can often see the hammer marks, solder seams etc. The exceptions are many of the Prehistoric and Celtic Iron Age European ornaments where the evidence of casting-on is an almost sure sign that a version of the lost wax process was being used. Egyptian, Greek, Roman etc gold work is hardly ever cast, but then gold casting seems to come into use, perhaps introduced from the East along the Silk Route. There is evidence of some use of casting around the 6-7th century AD in Eastern Europe." - A private conversation with Jewellery historian and Associate Professor at The School of Jewellery Dr Jack Ogden [ $\left.{ }^{16}\right]$

From these assorted views of one of the Hoard cheek piece components (Image 31), it is difficult to make out evidence for indication of either a direct casting or a forging process having been used. Though if it had been forged, it is difficult to envisage how the zoomorphic patterns were raised due to the absence of any obvious tooling marks from a chasing or engraving technique having been used. It is also worth noting that the two detached lobes for hanging the cheek piece on the Helmet have been placed back into their original positions. The enlarged image of one of the lobes (Image 32) may give metallurgical clues at its point of fracture as to how it was manufactured as part of any future research. It is also interesting to note the deliberately placed tooling marks on either side

$\overline{16}$ https://en.wikipedia.org/wiki/Jack_Ogden_(jewellery_historian) of the square hole which clearly had some functional message for the original makers of the Helmet also the wear resulting in 'rounding' of the upper edge, on the left in this image, which was almost certainly as a result of the cheek pieces having been hung from a leather strapping fixture of some kind on the Helmet. My own personal and very uninformed and unscientific take on these questions is that the cheek pieces and some other larger key Hoard items were almost certainly cast at a near net shape and form (Image 33).

\section{Silver gilt on the cheek pieces}

Again, and discussed earlier, there is a long and often convoluted discussion to be had elsewhere about the ancient gilt and gilding techniques used on the original artefacts discovered in the Hoard. For the purposes of the reproduction Helmet the decision was taken to electroplate the bronze cheek piece castings in silver after polishing, mask off the areas that were clearly silver in the originals, re-plate them in gold and finally to remove the resist, which in this case was some pink nail varnish (nail polish). If you take a look back at, Image 28 , the silver wavy lines we are seeking are just about discernable dividing up the four zoomorphic panels that make up the cheek piece and down the edges of the return on the cheek piece (Images 34, 35, and 36).

\section{The crest pieces and terminals}

The next set of items to be identified as potential helmet fittings suitable for casting were the two curved crest pieces and their horses head terminals. The crest pieces were more damaged than the cheek pieces but enough of their original shape and structure remains to allow a more than reasonable interpretation of their probable original structure including the likely curvature of the helmet to which they were attached. The 


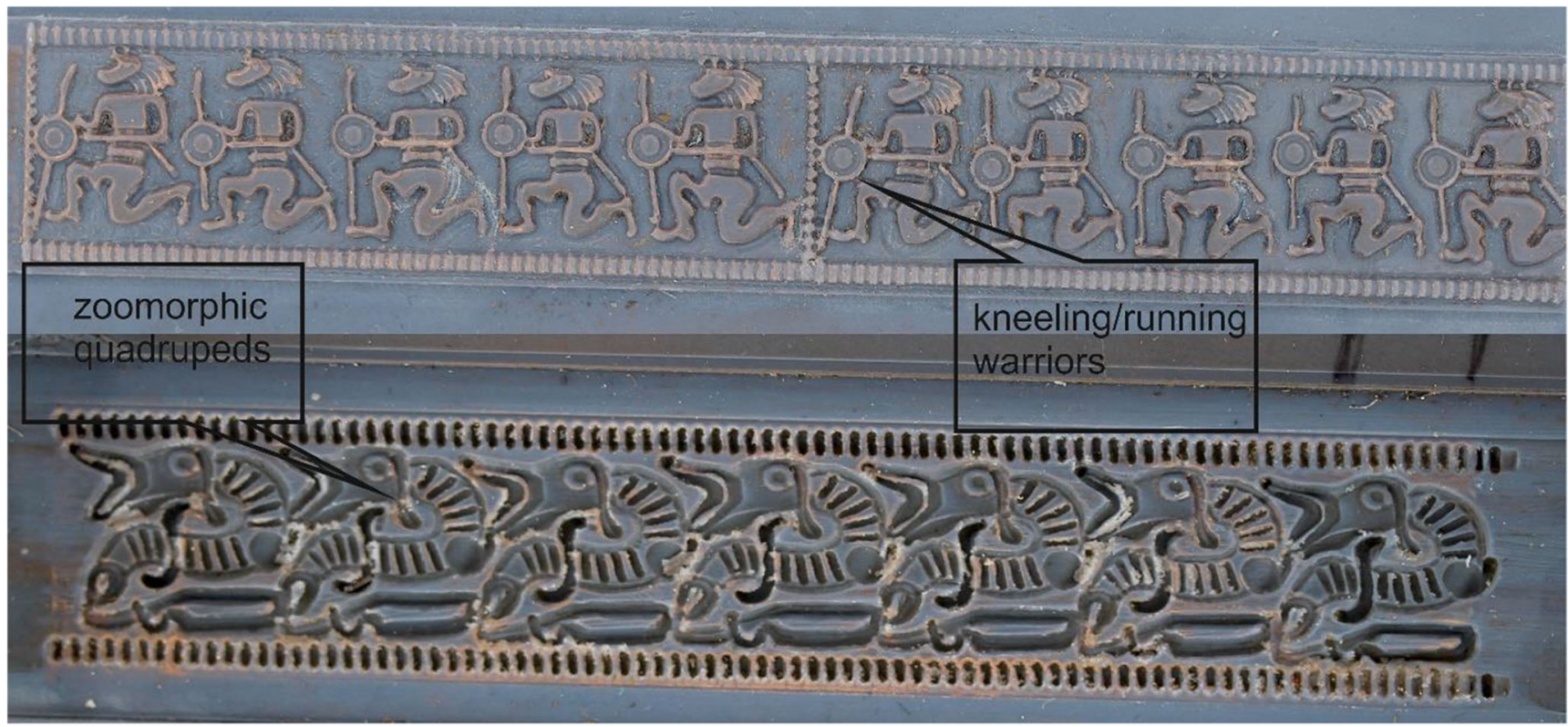

Image 24. Warriors and 'ducks' follow on tooling detail

crest pieces are squared off U-shaped channels inside of which organic materials of mostly a beeswax-based paste have been identified and that most probably indicates their use as a fitting for a hair or feather plume. As with the cheek pieces they were laser scanned, suitable CAD files created, 3D printed and cast in Bronze. The longer length of the pieces pictured far left (Image 37) was felt to be the closest example for the curvature of the leather helmet to which the crests and other panels were to be attached and so this was extrapolated from in creating the copy channels and also for proposing the probable shape of the leather helm.

Note the large central rivet in Image 38 which it is believed was one of three large rivets used to fix the terminal through both the leather and steel parts of the helmet. Riveting was found to be the primary method for fixing the various components of the helmet to both the leather and steel inner parts and the manufacturing and use of suitable rivets was to become an integral part of the reproduction process for the helmets.

The two rivet holes on the far left of Image 40 (near fragment label K1882) correspond closely with the two large holes visible on the flange of the reproduction terminal in Image 39.

\section{The other cast reproduction components}

The other components that were cast as part of the reproduction process were, as described earlier, most probably stamped sheet items but were selected to be laser scanned, digitised into suitable CAD files, 3D Printed and cast. These were the nasal, or nose, guard and the various components that went to make up the neck guard. The neck guard was thought to have silver sections contained within a gilt framework and again fixing holes for rivets can be discerned in the corner fragment of the frame in Image 40. The various components of the neck guard reproduction were also to be fixed with rivets to a shaped leather panel.

The front and rear images of the stamped fragment of the nasal, on the right of Image 41, give an idea of the occasionally limited amount of data available from which to extrapolate the probable final form of a component which is shown on the left of Image 41.

Again, these neck guard fragments are a good example of the occasionally limited data available from which to extrapolate probable final form and fit (Images 42 and 43).

The rear view of the neck guard (Image 44) shows how the shape and six components had to work and move on the curve in a third dimension and were also partially held in place by

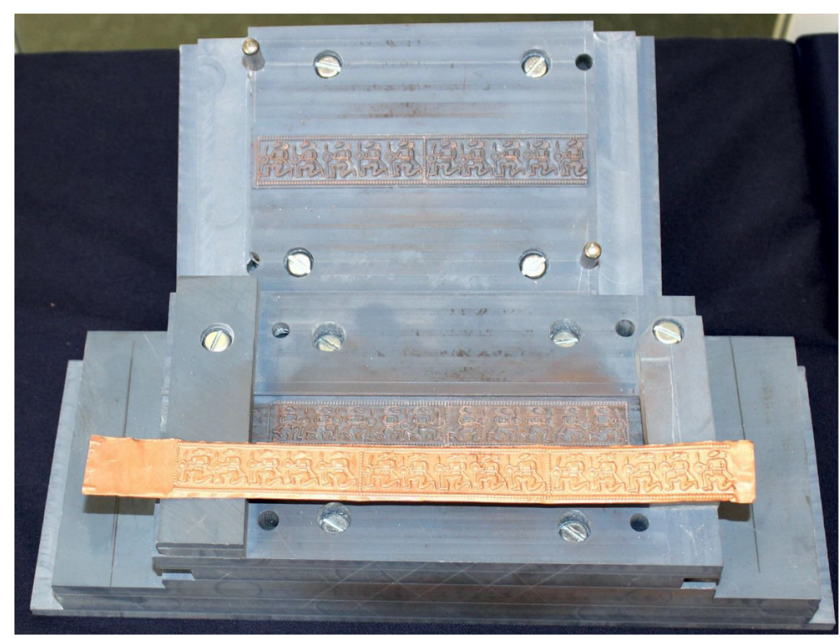

Image 25. The warrior's progression tooling 


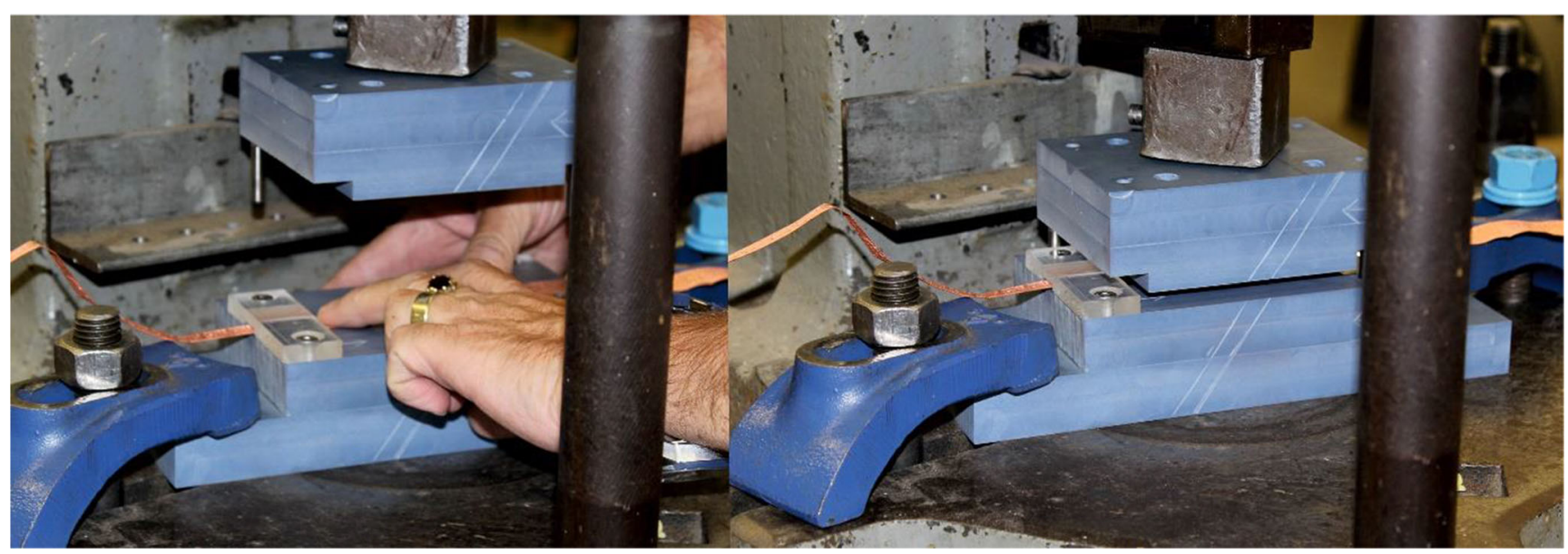

Image 26. Progression stamping of a strip in the large hand press

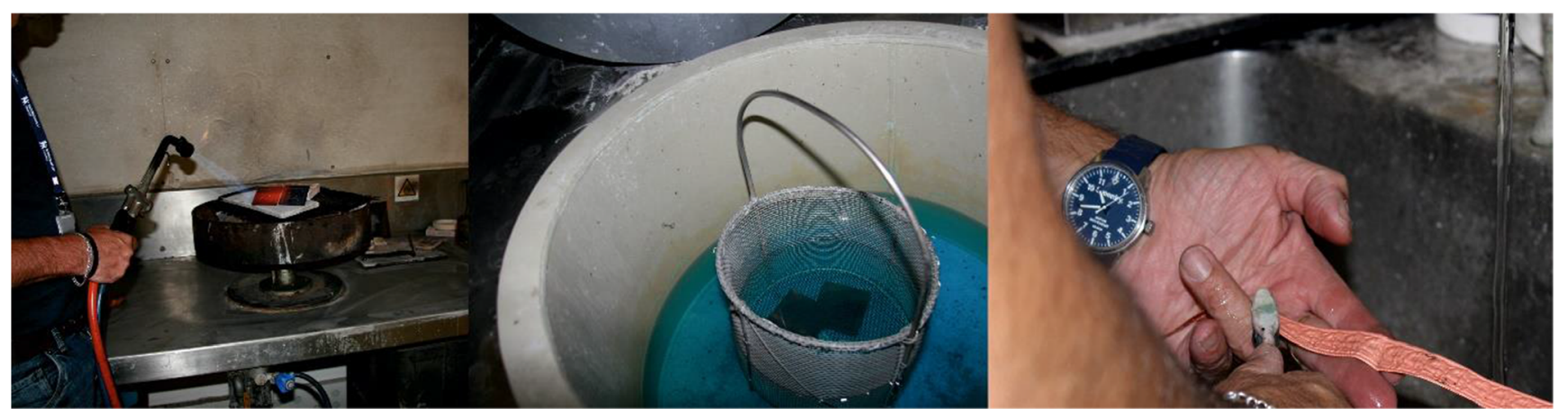

Image 27. Torch annealing, pickling, and pumice scouring copper stamping materials on the silversmithing hearth

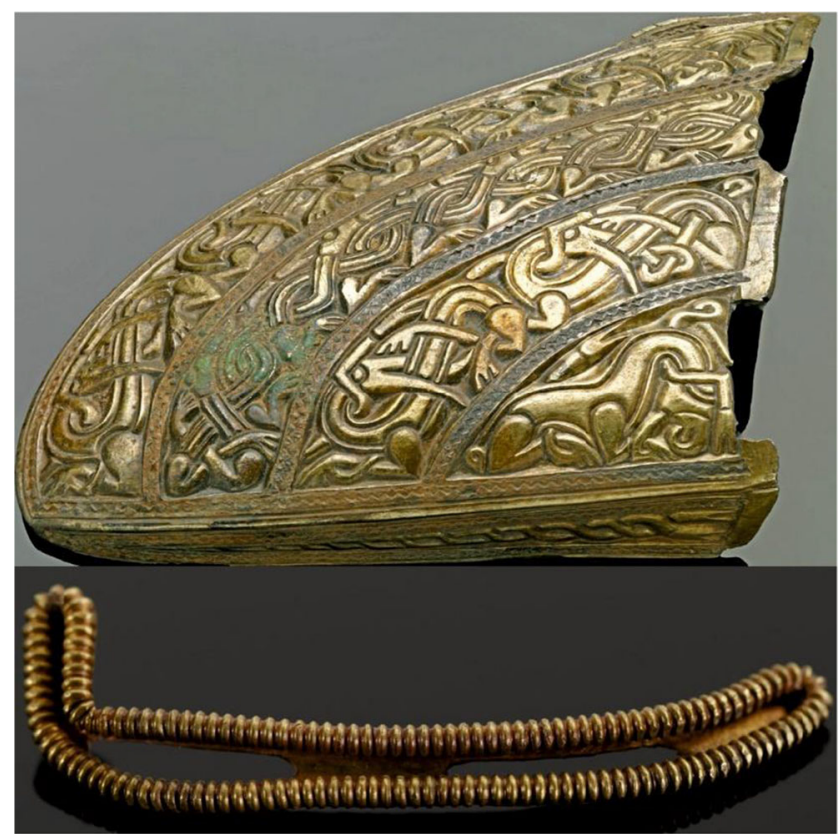

Image 28. Cheek piece and beaded wire fitting after conservation (Image (C) Birmingham Museums Trust)

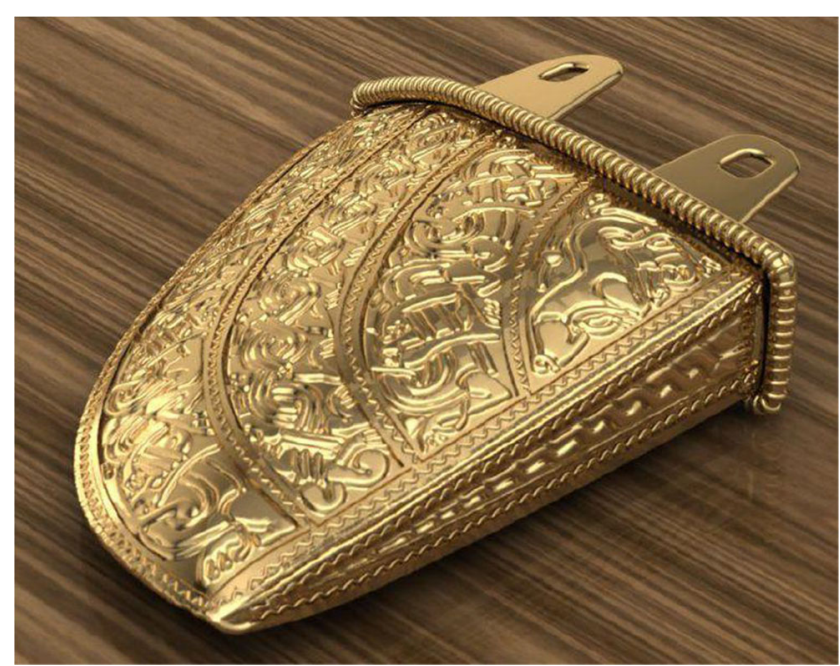

Image 29. Rendered CAD image of a complete cheek piece generated from the file created from the laser scanned data 

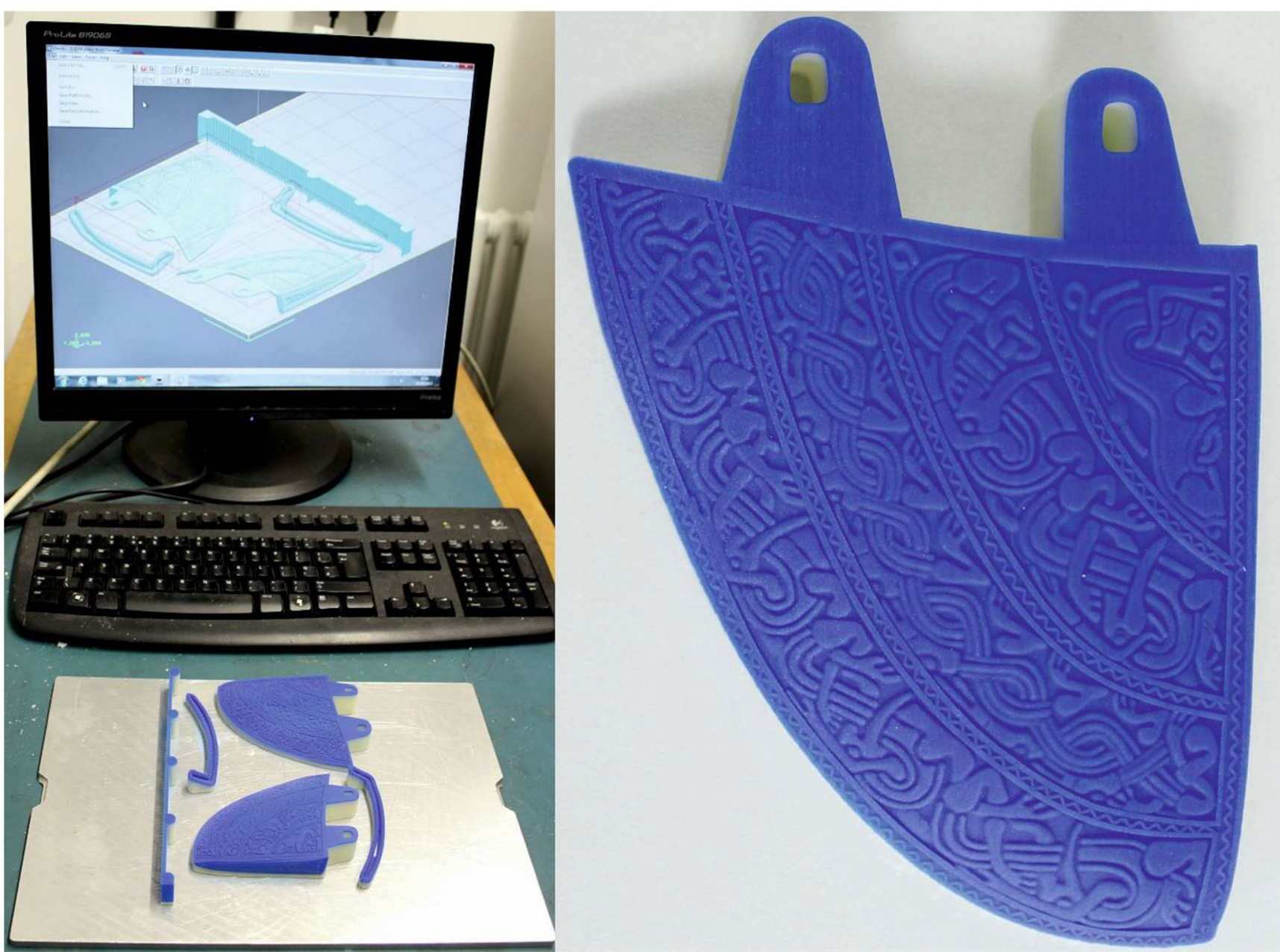

Image 30. 3D Printed wax cheek pieces ready for casting

Image 31. A cheek piece and beaded fitting viewed from all possible angles (Image (C) Birmingham Museums Trust)
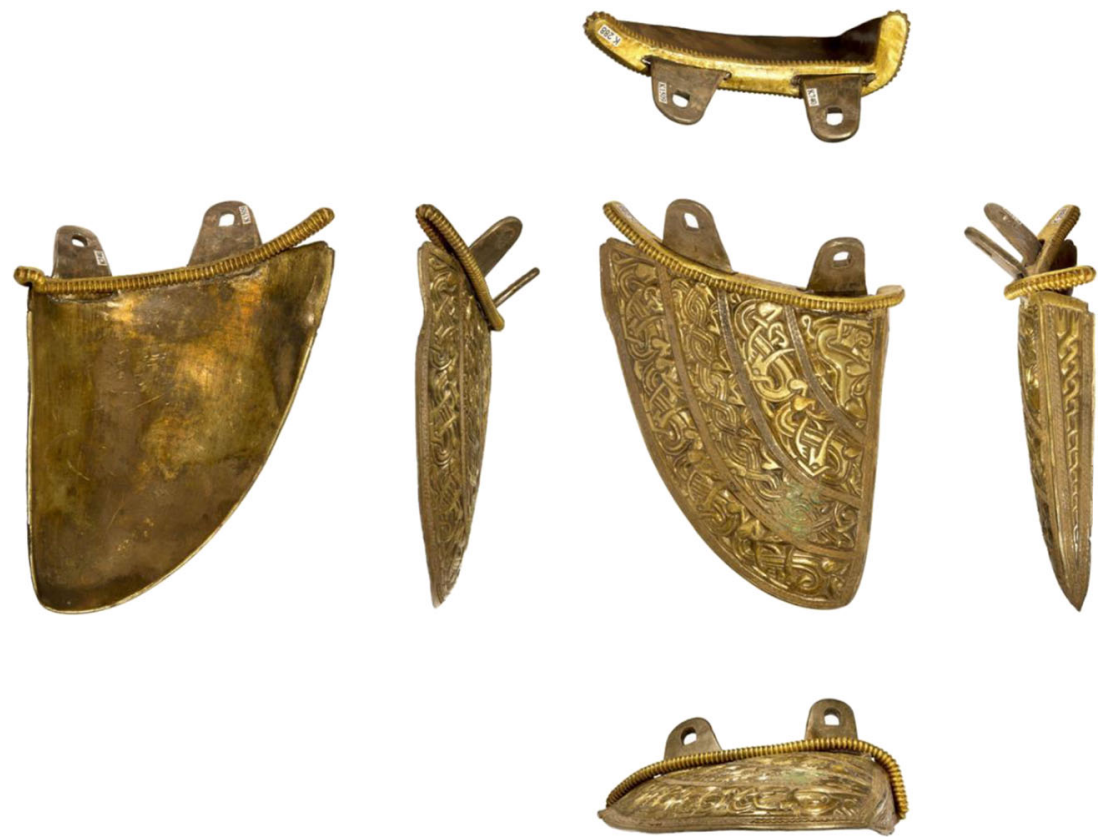


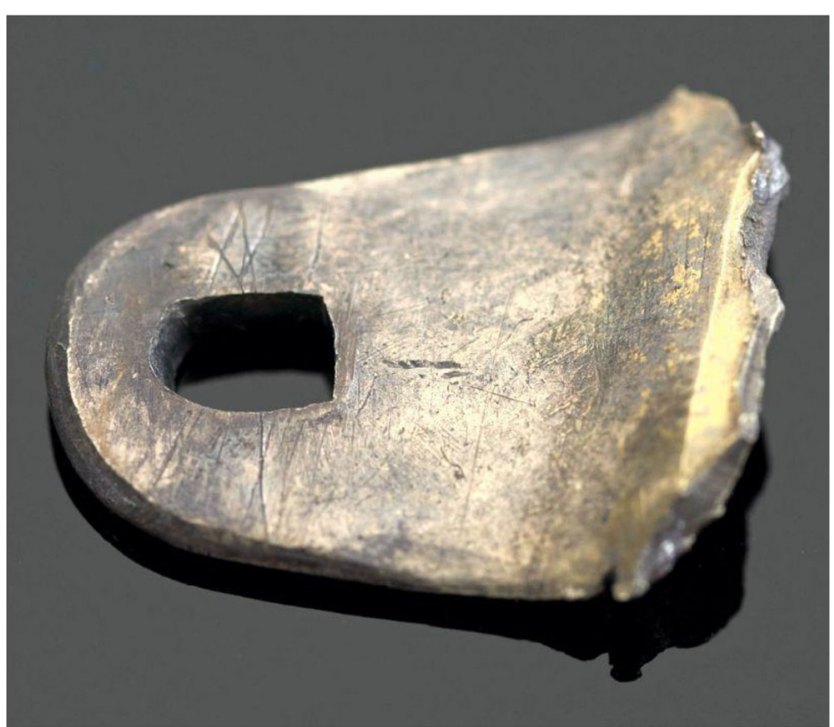

Image 32. A cheek piece lobe fragment with tooling and wear in use marks

the channel formed strips as well as the rivets that were eventually added during final assembly

The frame into which the neck guard components were to be set was cut using waterjet technology and then shaped/ curved to fit the leather template and designed to be held in

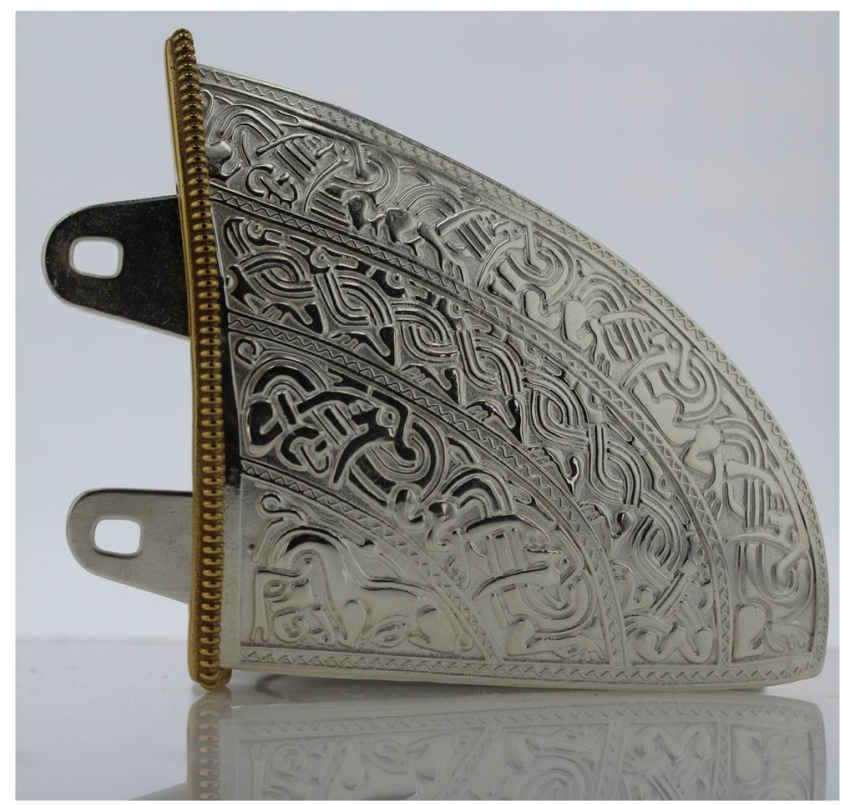

Image 34. Silver-plated reproduction cheek piece with its gold plated top fitting

place with rivets, finally after polishing it was gold plated. Silver rivets were also used to fit the six components to the leather template and the locating holes for these can also be identified in Image 45 (Image 46).

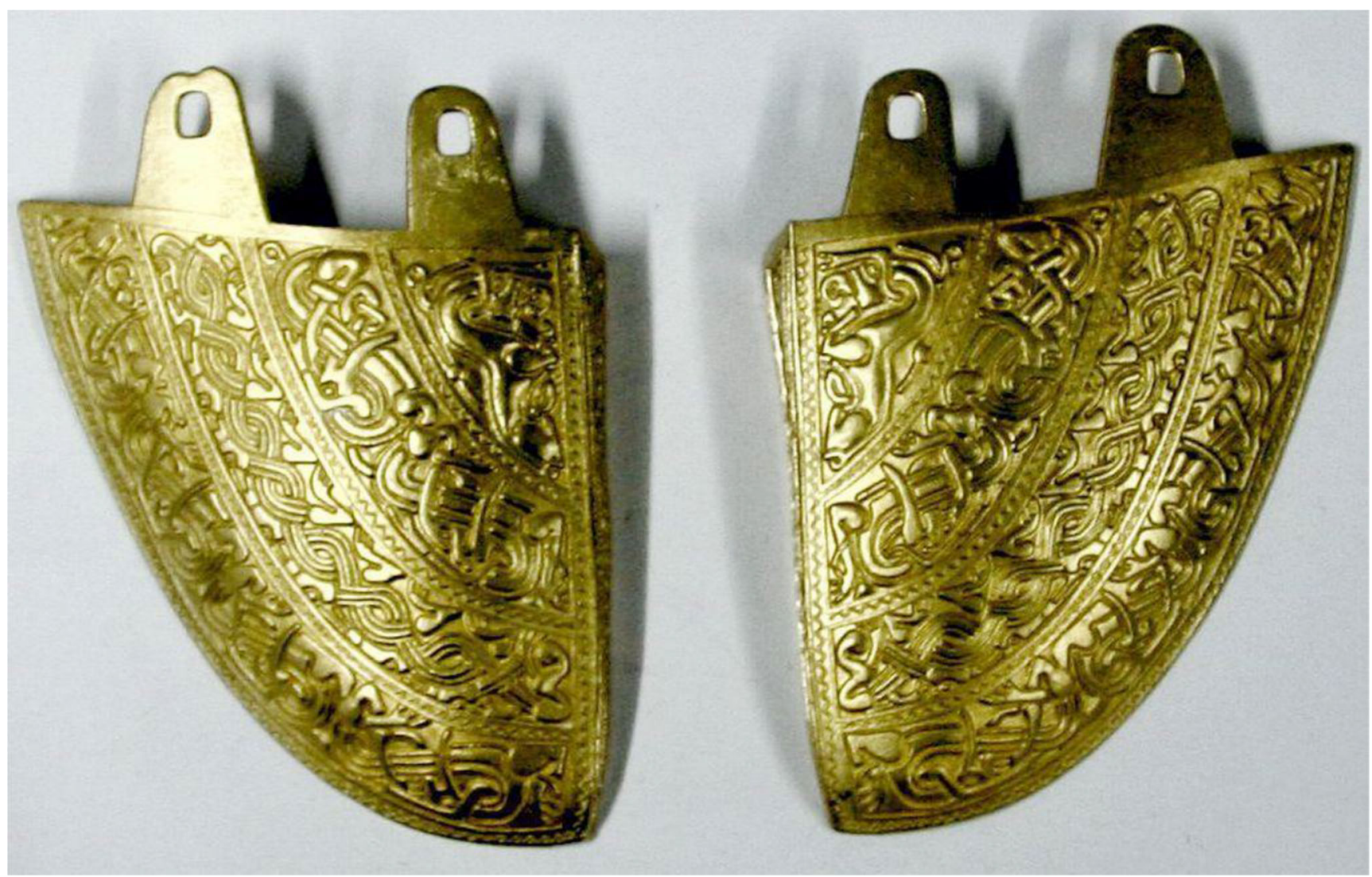

Image 33. Cheek piece left and right reproductions cast in Bronze 


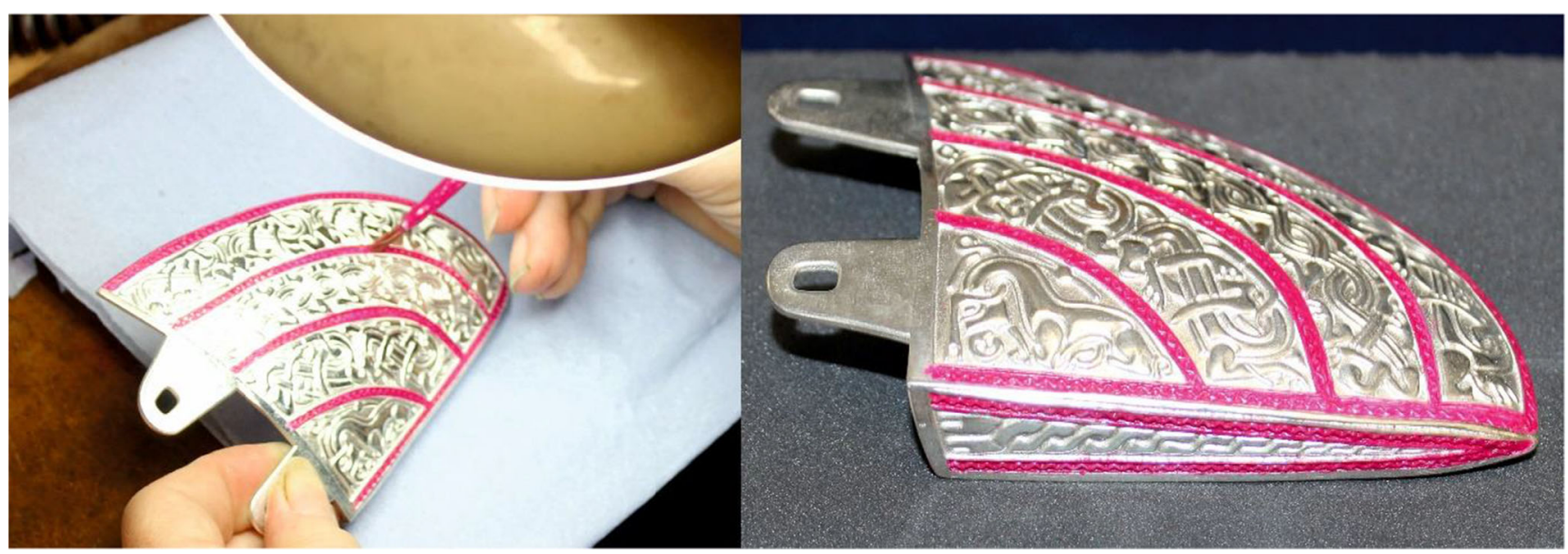

Image 35. Adding the nail polish resist before gold plating

\section{The reeded strip}

A substantial number of both large and small fragments of a reeded strip were identified, again with many of them exhibiting the retaining rivet holes and rivets. The various fragments of reeded strip identified finally totaled up to a length of $156 \mathrm{~cm}$ as depicted in Image 47. It was thought that the reeded strip was being used to both divide up the various sections of the helmet, hide the rivets holding the panels in place, and to act as an additional 'retainer' to hold the stamped and plain panels securely in place, and once again equivalent examples were identified on other helmet finds, particularly from Scandinavia. The reeded strips consist of four longitudinal ridges, or reeds, each separated by a shallow furrow, on either side of a wider and deeper central furrow and are approximately $8 \mathrm{~mm}$ wide. For what appears to be such a relatively 'simple' pattern how to manufacture the reproduction reeded strip was the cause of much debate and considerable head scratching amongst the teams working on the project. The favourite theory amongst the archaeologists and conservators for how the reeded strip may have been manufactured by the Anglo-Saxon goldsmith was the 'scraper tool' as depicted in Image 48, though amongst the makers and jewellery practitioners on the School's team, we tended to lean more towards our actual solution of using a Draw-Swage. As reported in the archaeological literature, 'the absence of any

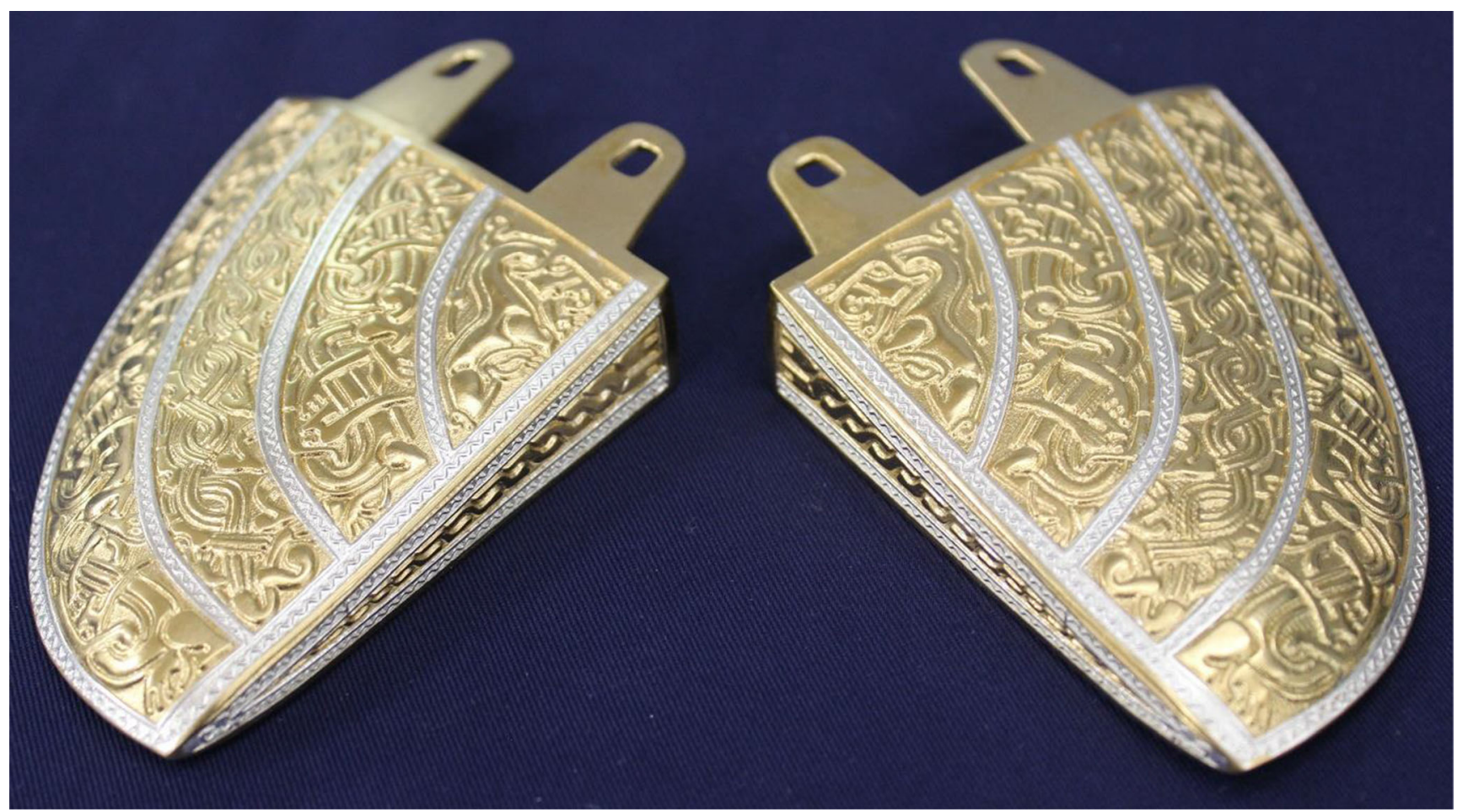

Image 36. Finished gold plated and resist removed reproduction cheek pieces 


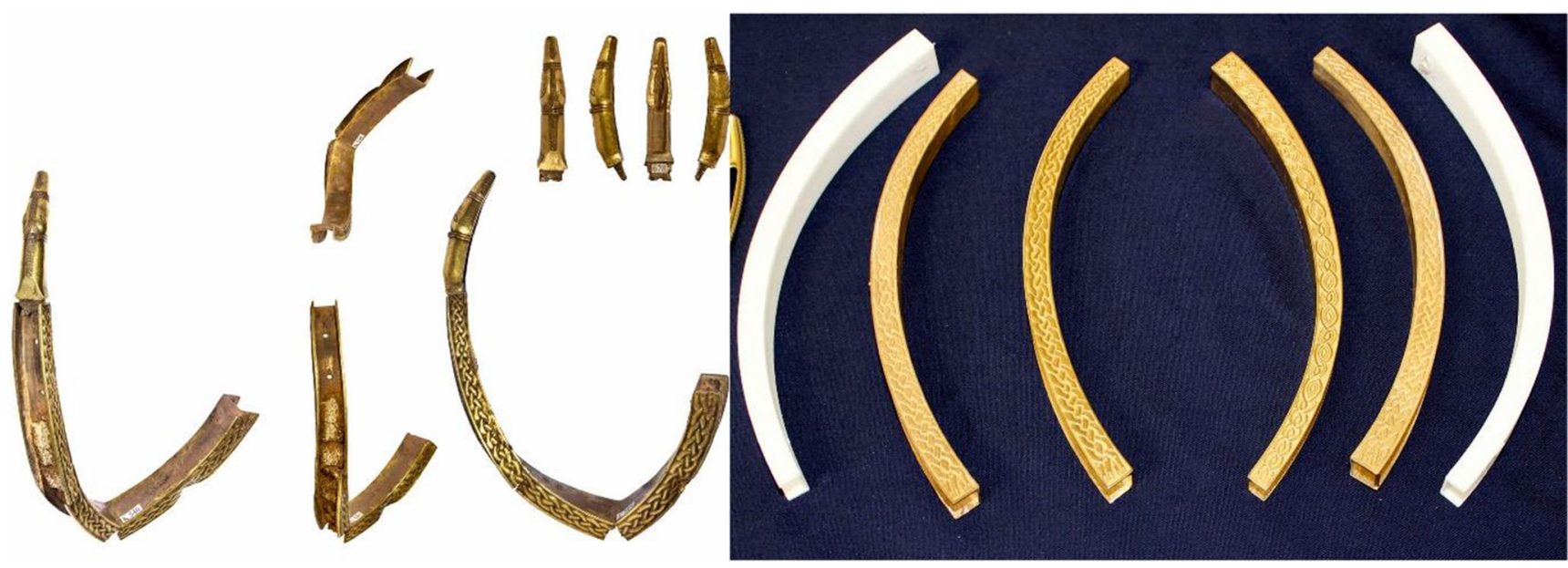

Image 37. The original crest pieces after conservation (Image @ B Birmingham Museums Trust) and right the various 3D Printed and cast reproductions

contemporary tools which can definitely be assigned to the making of these reeded strips means that the use of any particular reeding technique in Anglo-Saxon England must be conjectural. There is clearly a strong relationship between draw-swaging and wire drawing, but we still await firm proof of suitable tools for either technique in the sixth and seventh centuries.' $\left[{ }^{17}\right]$

Our modern solution to the manufacture of the reproduction reeded strip rested on the discovery of a Draw-Swage at the back of a dusty drawer in the SoJ tool stores. We fitted the swage with a set of hardened steel tools one of which was suitably profiled on both sides with the reeded pattern, which was cut using an external, local, supplier of wire eroding technology, the second tool was profiled flat and both tools then had to be hardened and then required suitably rounded lead in and lead out edges hand filed and smoothed into them (Images 49 and 50).

The screw adjustment of the draw swage allowed for multiple reducing passes of the sheared and open-hearth torch annealed copper strips to be drawn through the tool on one the SoJ's two ancient wooden draw-benches and where we quickly discovered that lubrication was the key to minimising the tool 'chatter' that was leaving unwanted marks on the reeded strips (Image 51).

\section{Various shaped channels (anticlastic raising)}

Several the reproduction components of the helmet required us to revisit our silversmithing anticlastic raising classes of many years ago. (When the two dominant axes curve in opposite directions the result is known as an anticlastic form, a saddle-like shape could easily be described as an anticlastic

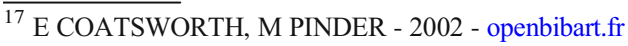
CNRS |; DGDS |; DIST |; INIST. Home; Search; Topics; Export. Fr | En. Help. Search. XML. Title : The art of the Anglo-Saxon goldsmith : fine metalwork in Anglo-Saxon England : its practice andpractitioners. Authors : COATSWORTH, Elizabeth ; PINDER, Michael ; Publication year : 2002
}

form.) These silver and ungilded components made for some strikingly distinctive and contrasting decoration on three separate parts of the Helmet. The largest was the squared-off Ushaped channel that encircled the lower part of the Helmet and into which the kneeling warriors stamped strip was to be fitted and is thought to also have been integral to the design and secure positioning of the cheek pieces. The next two groupings were semi-circular U-shaped channels one of which was threaded around the nasal and brow areas and the other was threaded round the outer edges of the neck guard. Both channels, as well as being decorative, were used to hide rivets and hold the edges of strips, panels, and castings firmly in place wherever they abutted up to the raw edges of the leather helm to which all the components were eventually fixed. An extra fixing was the use of short lengths of the reeded strip bent into $\mathrm{U}$ shapes and firmly riveted through all flat and channel components and through the leather. A few examples of these

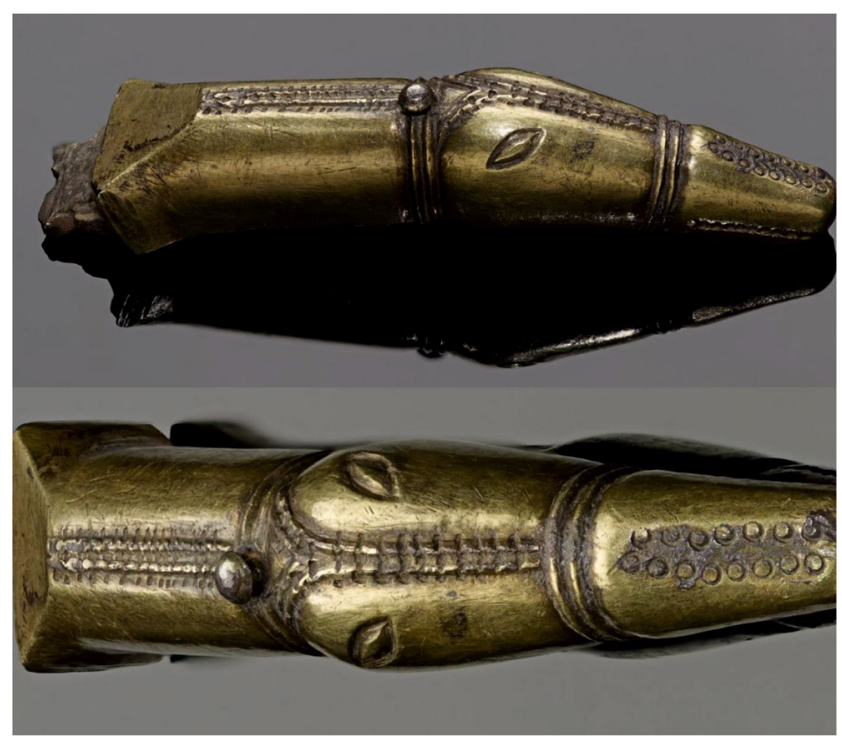

Image 38. Horses head terminal (Image @ B Birmingham Museums Trust) 


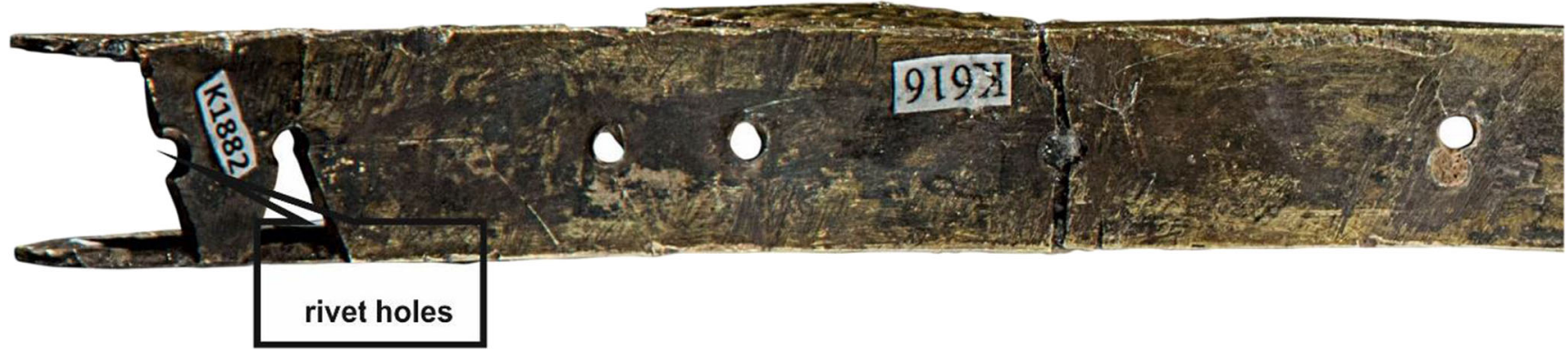

Image 40. Large riveting holes visible in the base of the crest panels (Image $\odot$ Birmingham Museums Trust)

Image 39. The 3D printed and cast horses head terminal reproduction

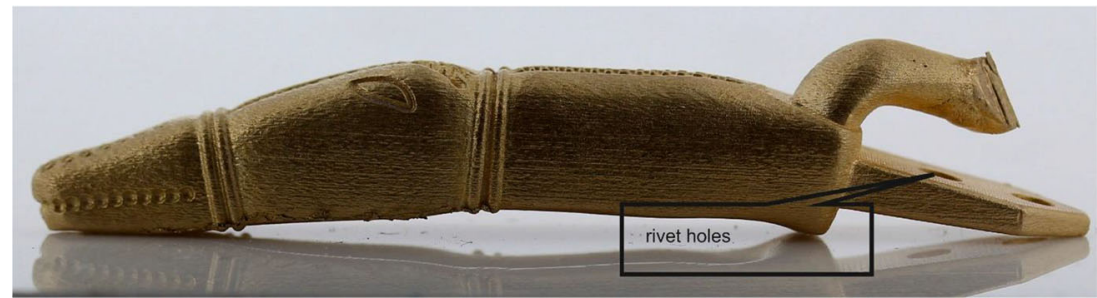

fixings can clearly be seen in Image 46 around the edges of the neck guard.

Creating the squared channel forming jig was done by laser cutting 30-mm-thick Perspex sheet into a profile that precisely matched the encircling profile of the leather helm when stretched over the inner steel, this profile was developed by using the SoJ laser scanning facility and the scanned profile transferred into a suitable file format for the laser cutting technology. The laser cut jig was used to shape the semi-circular helmet profile first then once the inner section was placed into the jig it was a relatively simple job to use a rawhide mallet to hammer over the two edges to create the correctly curved
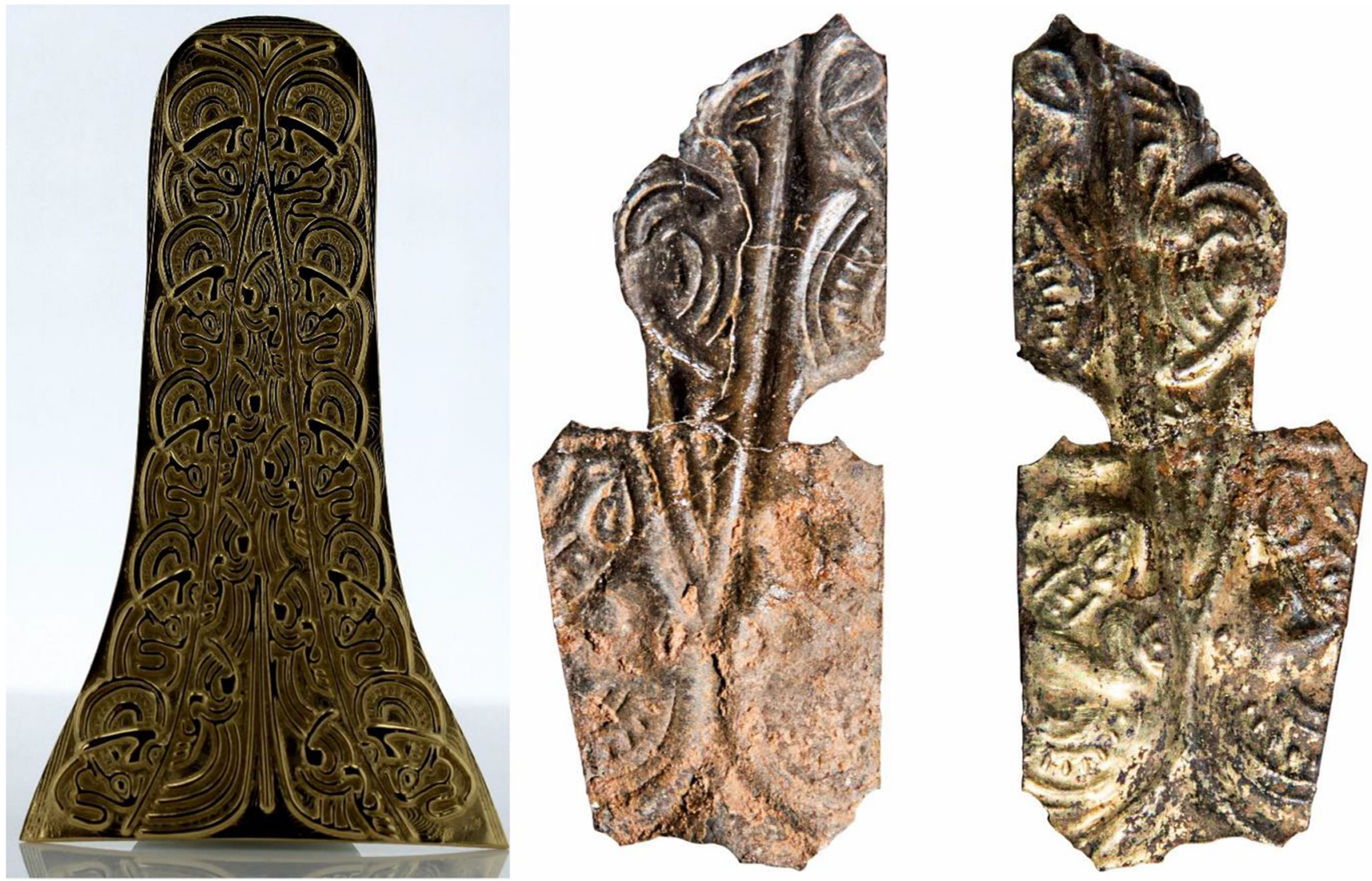

Image 41. The nasal reproduction and the fragment it was based on (front and rear of the same fragment) (Image (C) Birmingham Museums Trust) 


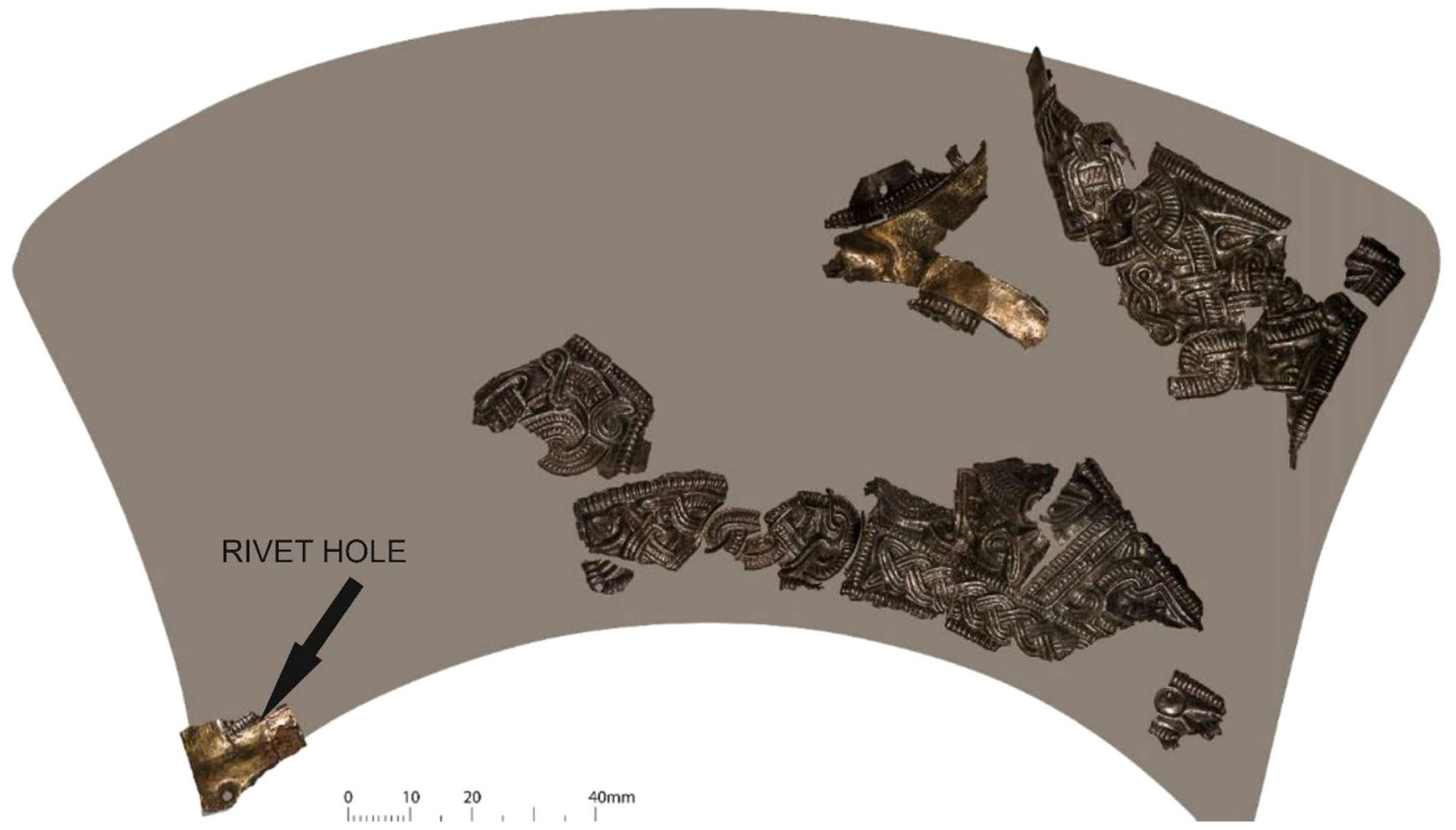

Image 42. The neck guard fragments (Image @ $\odot$ Birmingham Museums Trust)

Image 43. The components of the neck guard before assembly
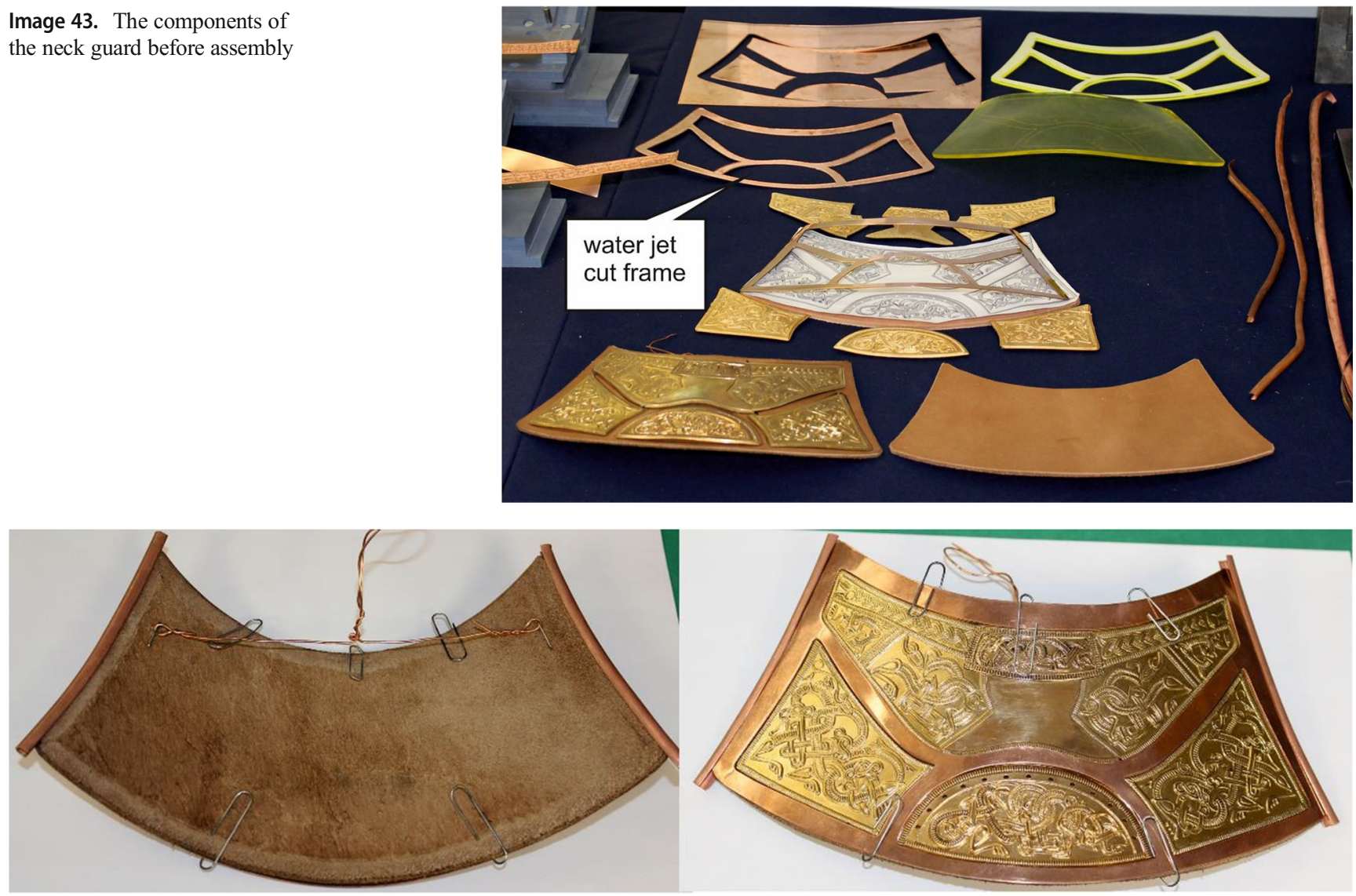

Image 44. Front and rear views of the neck guard reproduction during assembly test of proposed layout before final fixing onto the leather backing with rivets 
Image 45. The 3D printed and cast neck guard components after silver plating
Image 46. The finished neck guard attached to the helmet (Image (c) Birmingham Museums Trust)
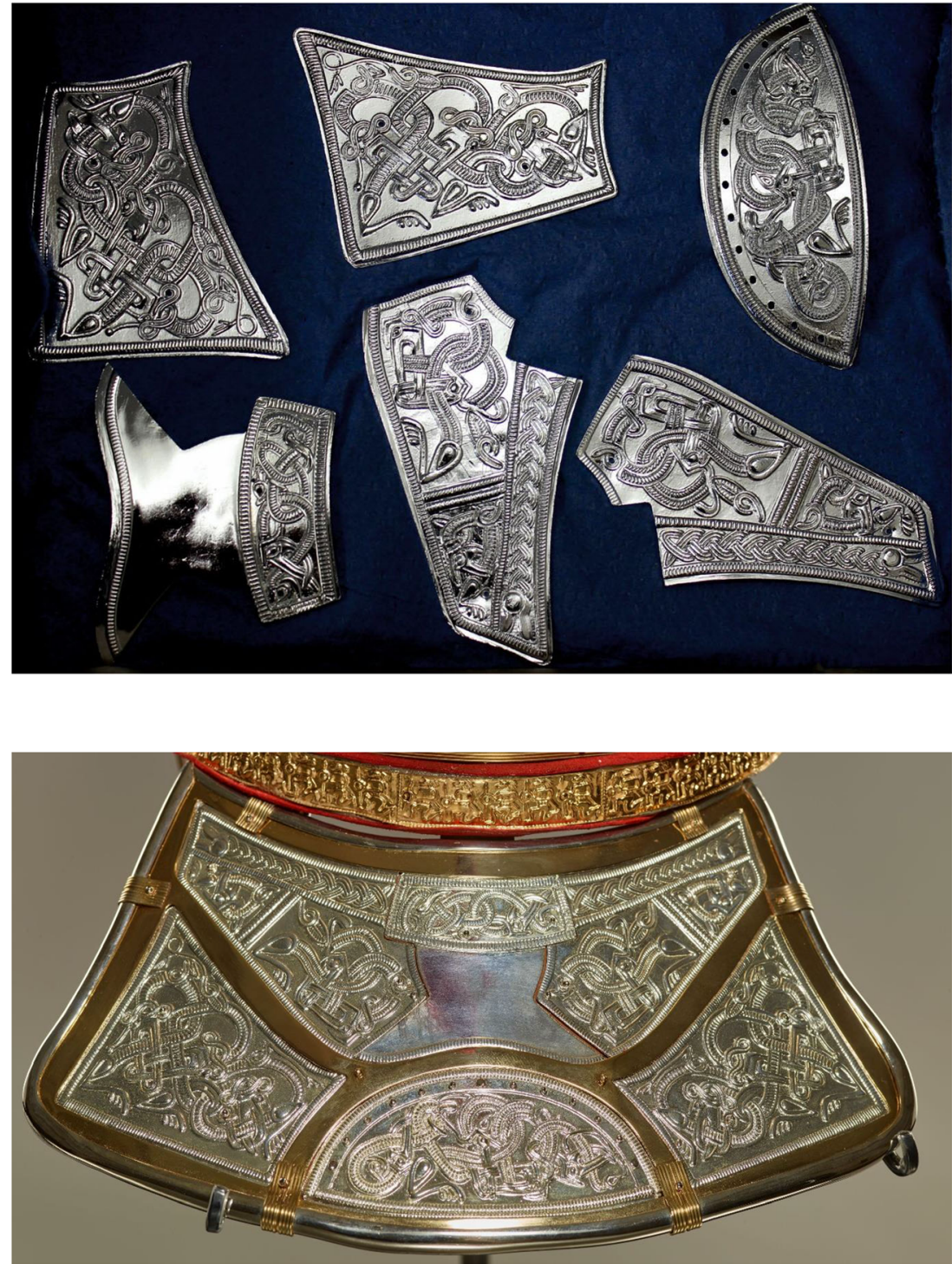

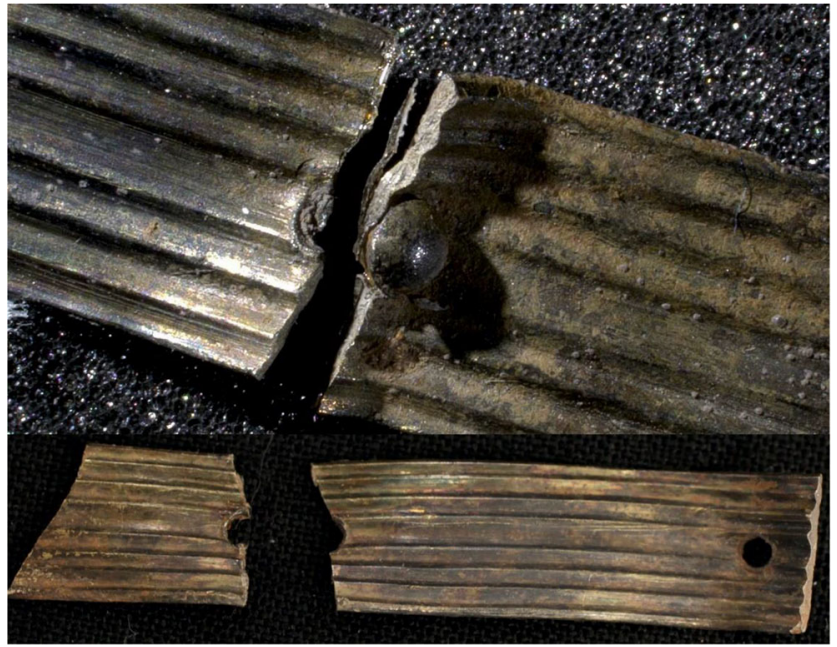

Image 47. Reeded strip, rivet, and rivet holes (Image (C) Birmingham Museums Trust) square-sectioned channel.(Image 52) A laser cut forming jig was also created for the semi-circular channel around the nasal using a mixture of the same laser scanning, file creation, and laser cutting techniques (Image 57).

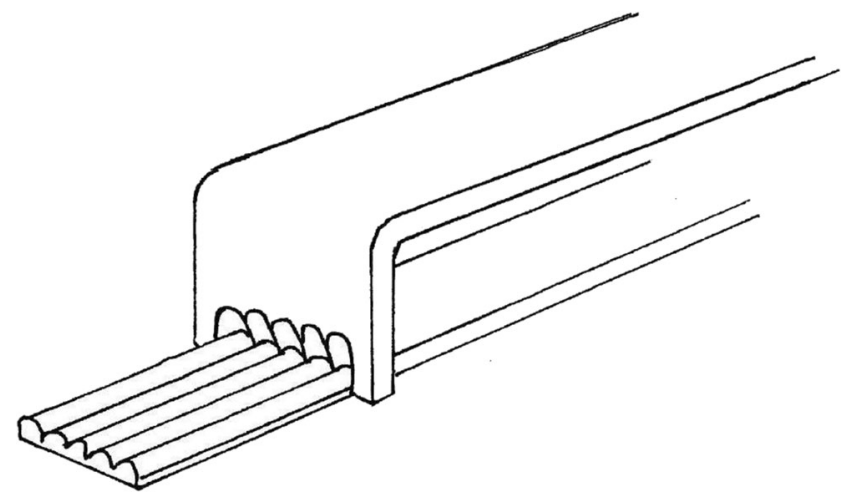

Image 48. The theoretical reeded strip scraping tool 
Image 49. Our draw-swage block and the two-sided wire eroded forming tool

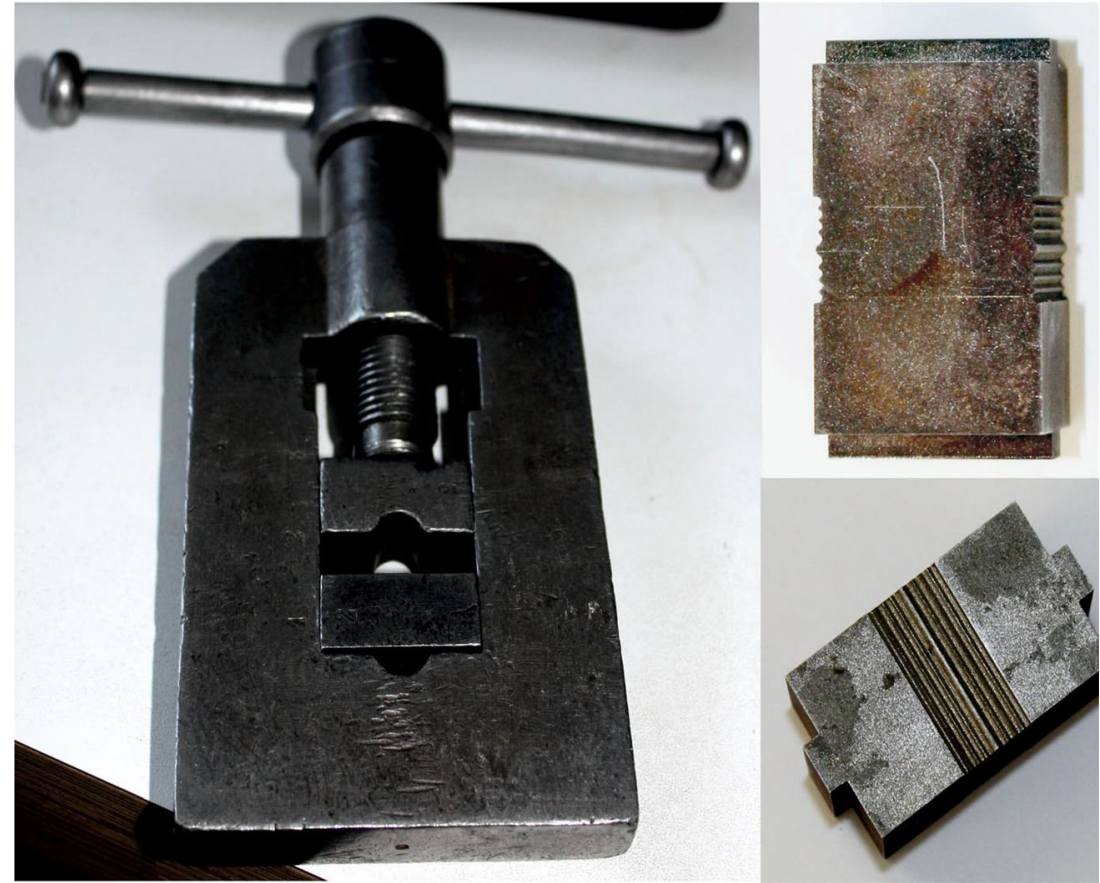

The museum had indicated that despite the original being silver this component was to be covered in a layer of thin leather which is to be dyed red and the kneeling warriors strip would be held in place using the same resin and beeswax simulation to be used in the crest pieces so there was no requirement to polish and plate this channel.

You can just make out in (Image 53) below a fragment of a kneeling warrior, circled, and slightly to the right of centre which strongly indicates that the other kneeling warrior fragments must also belong within this channel. You can also clearly see large and small rivet holes which would appear to indicate fixing to both the leather and steel of the helm and the two larger holes also line up with the lobes on the cheek pieces. It is also possible to make out in the enlarged image (Image 54) the remaining residues of the tree resin and beeswax-based 'glue' used to help fix the strip in place in the channel.

The evidence for the silver channels around the nasal and neck guard is equally fragmentary and has also been subject to some degree of 'academically respectable guesstimate.' These more semi-circular reproduction channels were formed from flat annealed copper strips using a large round draw plate and our ancient wooden draw benches were called into active service once more (Images 55, 56, 57, and 58).

Image 59 shows many of these reproduction reeded strip and channel components in situ on the finished helmet. You can see reeded strip and rivets holding in place the edges of the stamped panels and the zoomorphic strip, more reeded strip below that and a reeded strip clip and rivet helping to hold the silver brow and nasal channel in place and below that is the squared channel and kneeling warriors strip encased in red leather

\section{Polishing}

Polishing of all the reproduction components was carried out by SoJ colleague and silversmith Samantha Chilton, panels and strips were first polished on a spindle polishing motor using a medium hardness Calico polishing mop and Lustre Tripoli Rouge followed by a Swans-Down polishing mop and Red Jewellers Rouge and with the pieces held firmly in place on flat backing plates to prevent any distortion to the annealed 0.004-inch-thick material. Final detailed polishing

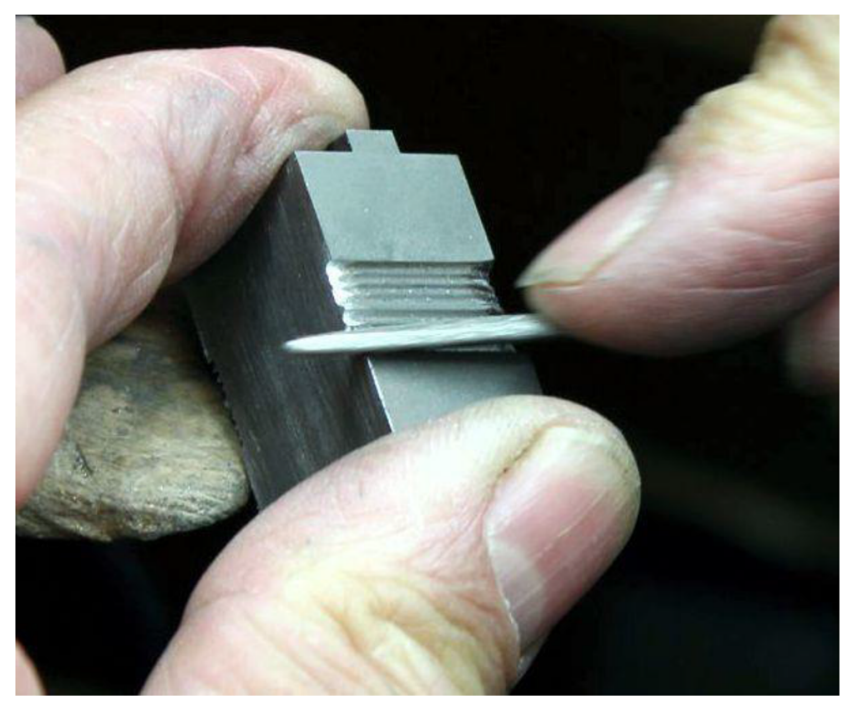

Image 50. Easing the draw-swage tool lead in and lead out edges 
Image 51. Draw-swaging the lubricated reeded strips on one of the SoJ draw benches

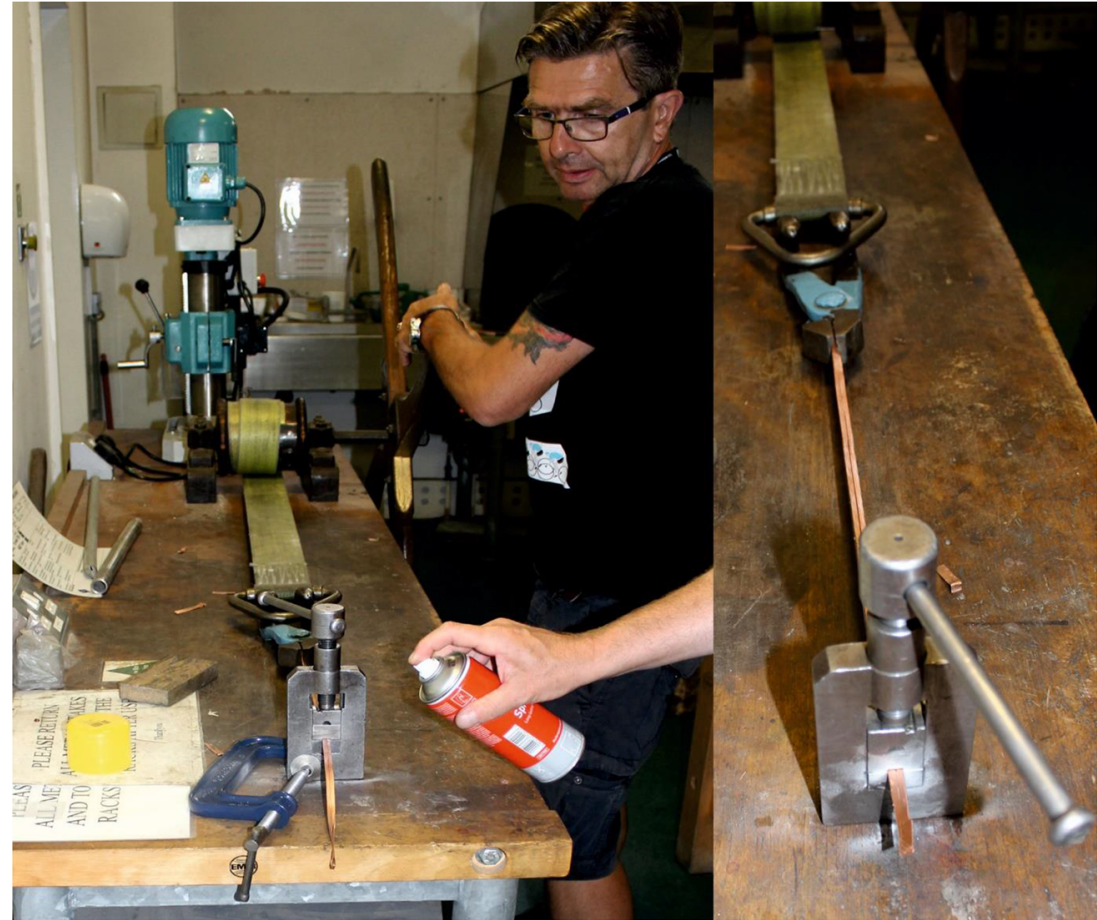

and extra working of plain flat areas of both panels and strips were done with a small Swans-Down polishing mop on a pendant drill and Dremmel motor (Image 60).

\section{Gold electro plating}

The gold plating was carried out using a small, portable rectifier which gave us the required precise control of the amperage outputs. The anode was a strip of stainless steel held in place with a crocodile clip and the cathode was the various copper- and bronze-polished components which were suspended in the plating solution and held in place with carefully positioned thin copper wire. The gold plating solution used was Crownclad $2000\left[{ }^{18}\right]$ which was contained in a two litre chemical laboratory-grade beaker placed above a magnetic stirring unit; the stirring of the plating solution is required in order to give an even deposition of the gold plating. The plating process also required the precise calculation of surface areas to determine amps required and length time in the plating tank for each helmet component to achieve the desired thickness of gold plating. All the components had to be scrupulously cleaned and grease free after the polishing process and before the plating process which deposited a 23.7 carat yellow gold layer of a hard gold alloy (hard gold was selected for its hard-wearing and scratch-resistant properties in readiness for the helmets eventual display in the museum environments), final rinsing was done in a hot water and soap solution

\footnotetext{
18 https://www.gold-plating-kits.co.uk/media/msds/Crownclad $\% 202000 \%$ $2024 \mathrm{k} \% 20$ Cobalt $\% 20$ Gold\%20Solution\%20MSDS.pdf
}

before being dried with hot air and from this point on all components were only allowed to be handled with cotton or neoprene gloves.

As the plating solution is also a potassium cyanide-based liquid the health and safety of the operators was at all times of paramount importance and suitably approved masks, goggles gloves and aprons were worn, and the process carried out under a fume hood.

\section{Rivets}

There are a number of different sizes and shapes of rivets to be found amongst the Hoard fragments, but it was agreed that it

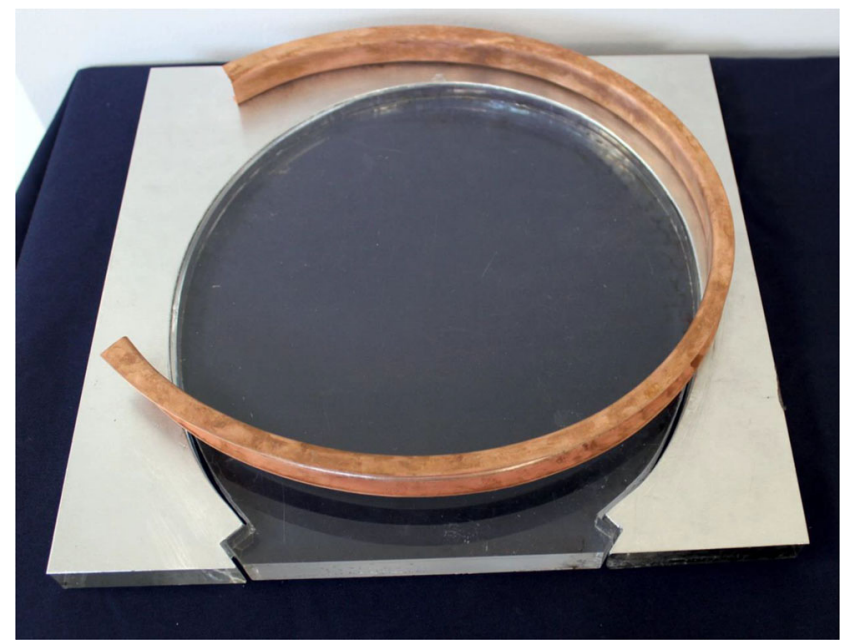

Image 52. The squared U-shaped channel and its laser cut forming jig 


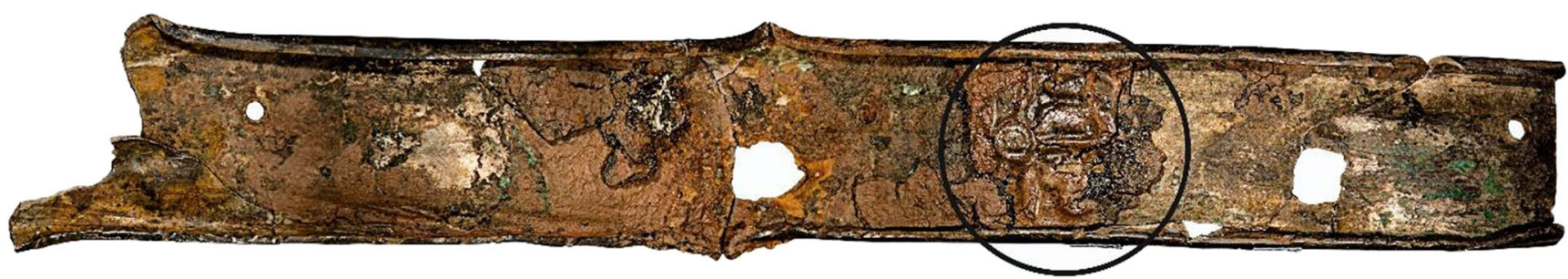

Image 53. A conserved fragment of the surviving original squared channel (Image @ $\mathrm{Birmingham} \mathrm{Museums} \mathrm{Trust)}$

would be expedient to keep the rivets in the reproduction to a single uniform diameter and just to vary their length. They were manufactured using $1.70 \mathrm{~mm}$ diameter copper wire and 'headed' by using an aquaflame torch to begin melting the tip and rolling it down into a suitably sized rivet head. Each rivet was also required to be polished and gold plated ready for use in the assembly process (Image 61).

\section{Assembly}

Final assembly of the Helmets could only begin once all the necessary components had been fabricated, polished, and plated as required; however, we did have enough data, information and advice from the conservators and test pieces to begin the process of figuring out quite just how they would all fit together onto a surface that curved in two directions at the same time. The surface of the leather to which all the components were to be fixed was not a single, uniform domed surface, it came to a distinctly pointed crown, and it was made from a living material that flexed, stretched, had raised and stitched seams, and occasionally chose to be very uncooperative about allowing the lining up of the holes for the riveting process. The double curvature issue we had always worried about now came to the fore where in essence we had to shape

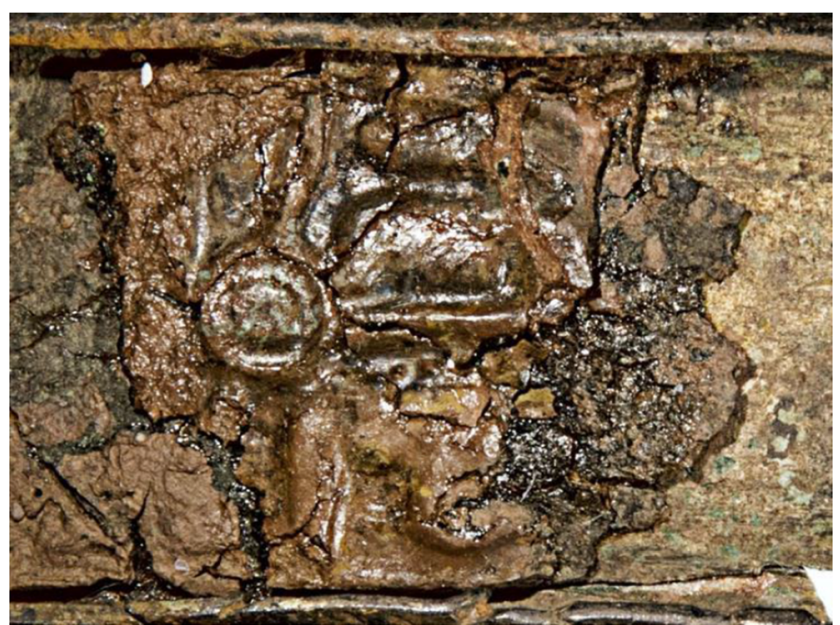

Image 54. Enlargement of the kneeling warrior fragment in the channel (Image (C) Birmingham Museums Trust) and form what were essentially flat sections of sheet and strip onto curved surfaces. This applied primarily to the stamped panels, we were allowed to form and shape the plain panels according to the shape of the helmet. Surfaces that curved in both plan and elevation and also changed their curvature irregularly as they went up towards the crown of the Helmet. These panels were formed and shaped using our silversmithing skills and the supply of variously shaped metal stakes available to us in the SoJ's specialised silversmithing workshops. Many were shaped by simply using pressure applied through hands and fingers and one or two also required some intervention from a rawhide mallet. We were also going to be relying heavily on the riveting process to hold these panels and strips in place and against a natural tendency to want to spring back towards their original shape.

A substructure for the helmets, comprising a leather layer over an iron foundation (known as a 'steel' and manufactured by Canadian armourer Jeffrey Hildebrandt) was chosen, based on analogy with other known helmets and decorative fittings. Hence, in manufacture, the majority of the decorative coverings were attached to the leather and not directly to the steel, with the leather and other major fittings then fixed, by rivets or roves, to the steel at key points, which were indicated by a more limited number of larger holes on the surviving crest, and encircling band. No 'functional' fixings suitable for attachment to the steel have survived, but this is not surprising given the overall lack of base metal and organics in the Hoard finds. The steel determines the shape of a helmet, but only the crest hinted at its original profile. However, as the crest was made in two parts, which would have allowed some flexibility

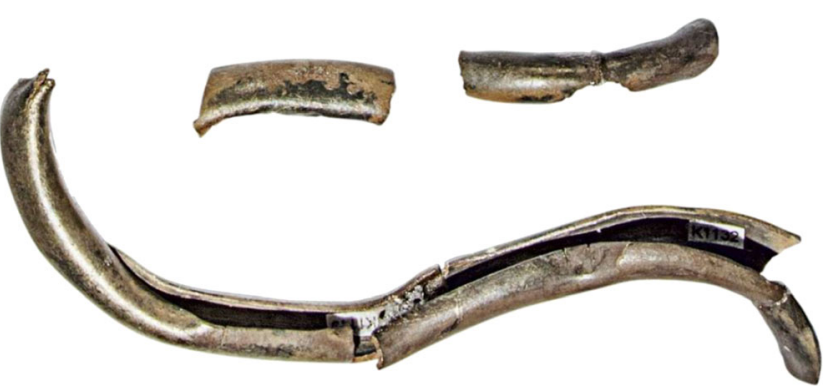

Image 55. Semi-Circular silver channel fragments (Image () Birmingham Museums Trust) 


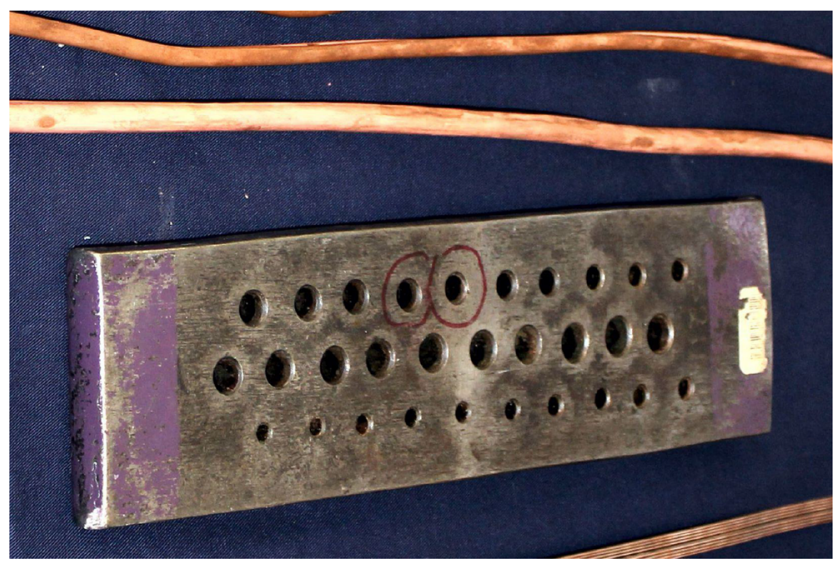

Image 56. Round draw plate used for preforming the semi-circular $U$ channels

in positioning, so it does not absolutely dictate a shape for the leather. There is little to inform the shape of the brow and nasal area, but the unusually small cheek pieces meant that the steel needed to have a certain depth (which would have covered the ears of the wearer). Nevertheless, the experience of master armourer, Jeffery Hildebrandt of Royal Oak Armoury $\left[{ }^{19}\right]$, who forged the steel, was invaluable in reconciling the limited parallels and evidence with the practicalities of creating a wearable helmet (Image 62).

Mark Routledge of Gallybagger Leather $\left[{ }^{20}\right]$ created the leather layer over the helm to which the sheet and strip decoration was to be attached. The leather was wet formed over the steel cap and then hand stitched together with linen thread.

First steps were to draw out onto the leather how and where the panels and strips might fit, the next stage was to print out, to actual size and on paper, each of the renders and attach them to the leather to test for a physical fit in position. At this point, the early $3 \mathrm{D}$ printing tests in nylon of the crest channels came into their own for testing for fit along the curve of the leather. Sticky tape and bluetack were our preferred methods of joining and fixing at this point. Once we had a reasonable idea of what would fit and where it sat, we moved on to physically testing out our theories about how the whole thing could be held together using nothing but rivets and roves. You can see in the upper left of Image 63 how the panels, both embossed and plain, began to want to become more trapezoid in shape as we went up the Helmet; however, we had to maintain the square section for the embossed panels and absorb the curvature distortions by careful profile shaping of the plain panels.

The two lower images show riveting trials and fixing options being explored using spare unfinished embossed panels and reeded strips.

At this stage, it was agreed where longer rivets would be used that passed through the leather and steel, to fix the leather

\footnotetext{
${ }^{19}$ https://royaloakarmoury.com/

${ }^{20} \mathrm{https}: / /$ www.indevizes.org.uk/782-2/
}

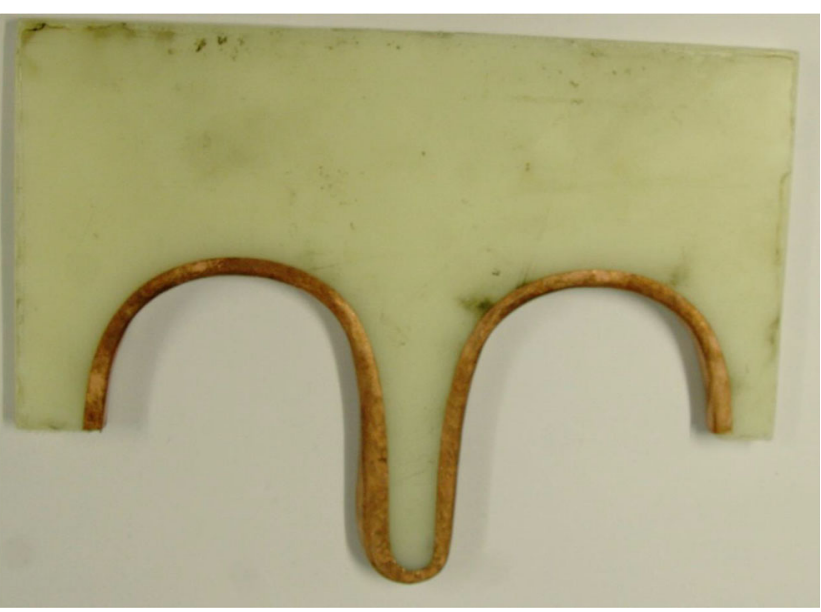

Image 57. Forming jig for the nasal channel

to the steel. These fixing points were through both ends and the centre of the two crest pieces as well as through the neck of the horsehead finial, additionally longer rivets were used to attach the square ' $U$ ' channel at five equidistant points around the circumference of the helmets. All other components were attached by rivets through the leather, the rivet holes in the leather were created using a traditional leatherworker's awl and a hand drill was used to create suitable holes in the steel.

Finally, we felt confident enough to begin complete assembly of the two helmets using the final, polished, and plated components. Most of this final phase of the work took place at the BMAG conservation lab under the careful guidance of the Hoard's conservation team and where it was also possible to cross reference a proposed assembly action or process with the original Hoard artefacts and fragments. The final components to be placed were the running/kneeling warrior strips within the square ' $U$ '-shaped channels which were held in place using a resin and beeswax concoction in a homage to the process used by the Anglo-Saxon Goldsmiths' all those years ago to secure the same strip of material (Image 64).

The Helmet reproductions were finally unveiled at simultaneous events in the Birmingham and Stoke museums on the 22nd of November 2018 where there was wide local and national media coverage (Images 65 and 66) $\left[{ }^{21}\right]$.

In Image 67, the magnificent looking gentleman is Mark Routledge who is not only a master leatherworker but also an Anglo-Saxon re-enactor!

In November 2019, the major research work and report into the Staffordshire Hoard was published, titled 'The Staffordshire Hoard An Anglo-Saxon Treasure' and published by the Society of Antiquaries of London; this is a 586-page tome that details the discovery, conservation, interpretation, and broader context of the Hoard. It also details all the research that went into informing the decisions about the

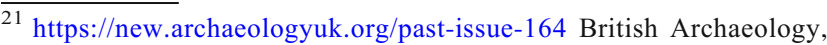
January February 2019
} 


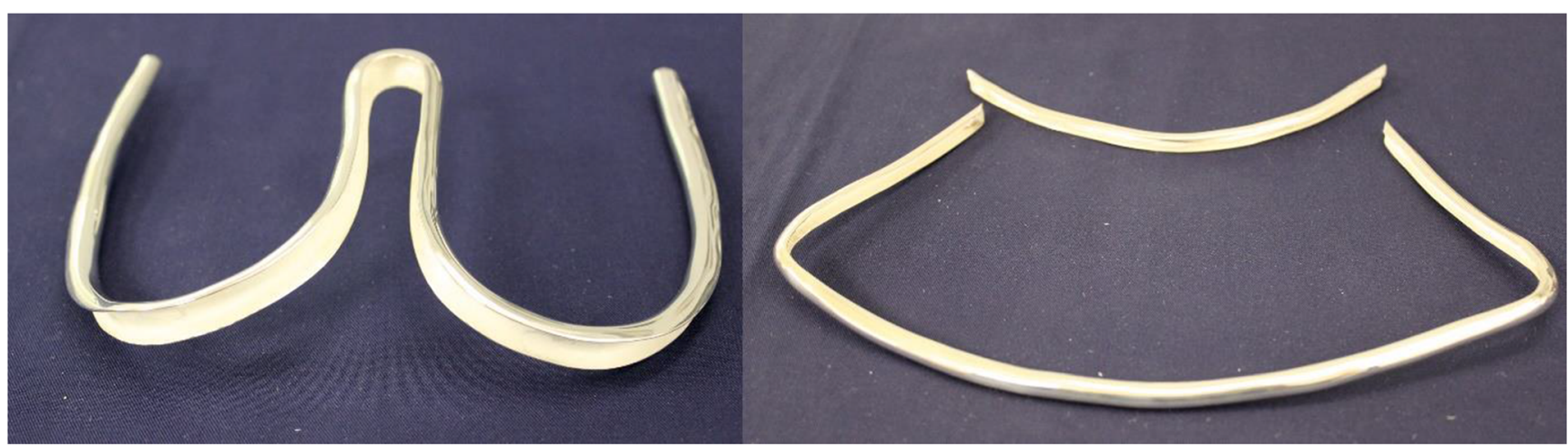

Image 58. The finished semi-circular nasal and neck piece channels after polishing and silver plating

Image 59. Finished and assembled Helmet reproduction components in detail (Image ( $)$ Birmingham Museums Trust)

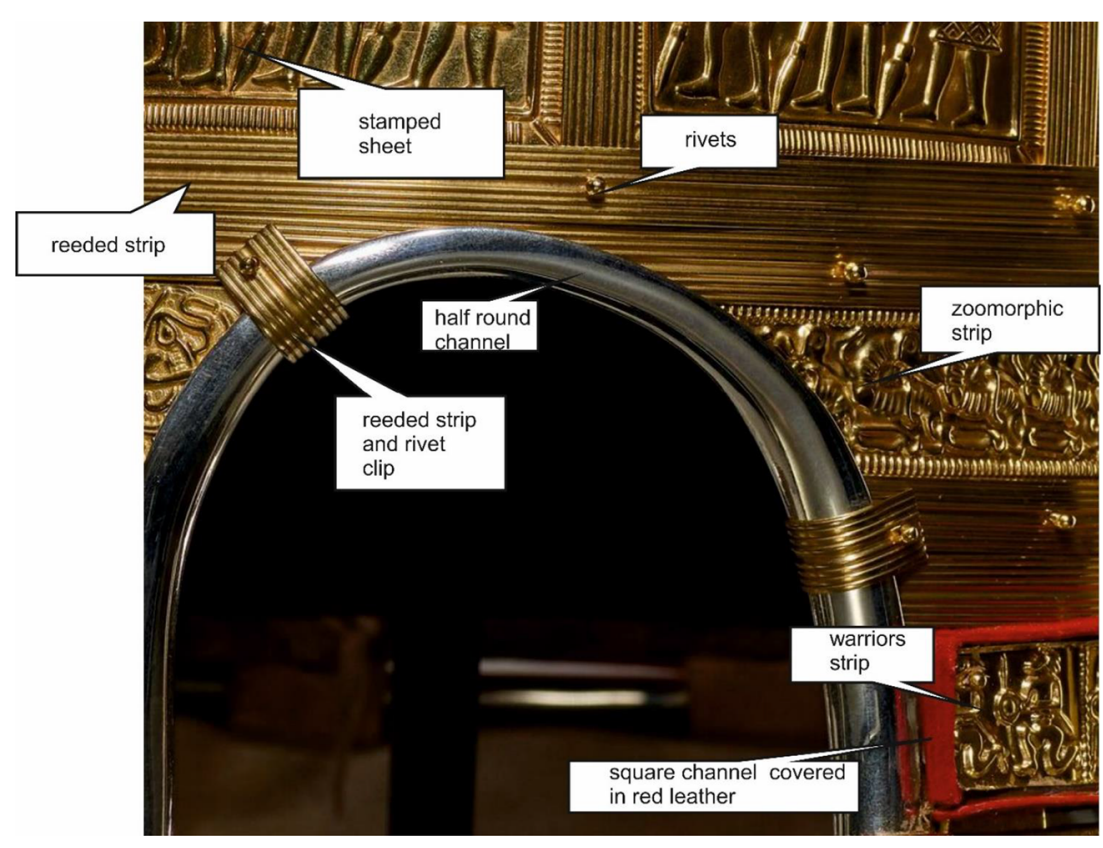

probable form, shape, and look of the reproduction Helmets and beautifully presents an abbreviated catalogue of each and every major item, in seven hundred fully referenced colour images (Image 68).

For those who may wish to seek this book out for themselves, the ISBN number is:

\section{ISBN-978-0-415-46768-1}

There is also digital access to much of this information on the Archaeology Data service website $\left[{ }^{22}\right]$ and the catalogue of the helmet fittings can be found on this page (Delete this ) $\left[{ }^{23}\right]$.

\footnotetext{
$\overline{22}$ https://archaeologydataservice.ac.uk/archives/view/staffshoard_he_2017/ downloads.cfm

${ }^{23}$ https://archaeologydataservice.ac.uk/archives/view/staffshoard_he_2017/ downloads.cfm
}

\section{Background of the Staffordshire Hoard and the origins of the Helmet}

'It was, and remains, the biggest collection of Anglo-Saxon gold $(4 \mathrm{~kg})$ and silver $(1.7 \mathrm{~kg})$ ever discovered and comprising of more than 4,000 fragments that equated to over 600 discrete objects and larger pieces. The Staffordshire Hoard is coowned by Birmingham and Stoke-on-Trent City Councils and is cared for on behalf of the nation by Birmingham Museums Trust and The Potteries Museum \& Art Gallery in the United Kingdom. Over the intervening years most of the larger and recognizably important pieces have now been identified and catalogued. We now also know an exceptional amount about their probable methods of manufacture, artistic styles, date and function, thanks to a large-scale research and conservation programme, the full results of which were published in late-2019, at the ten year anniversary of the Hoards 


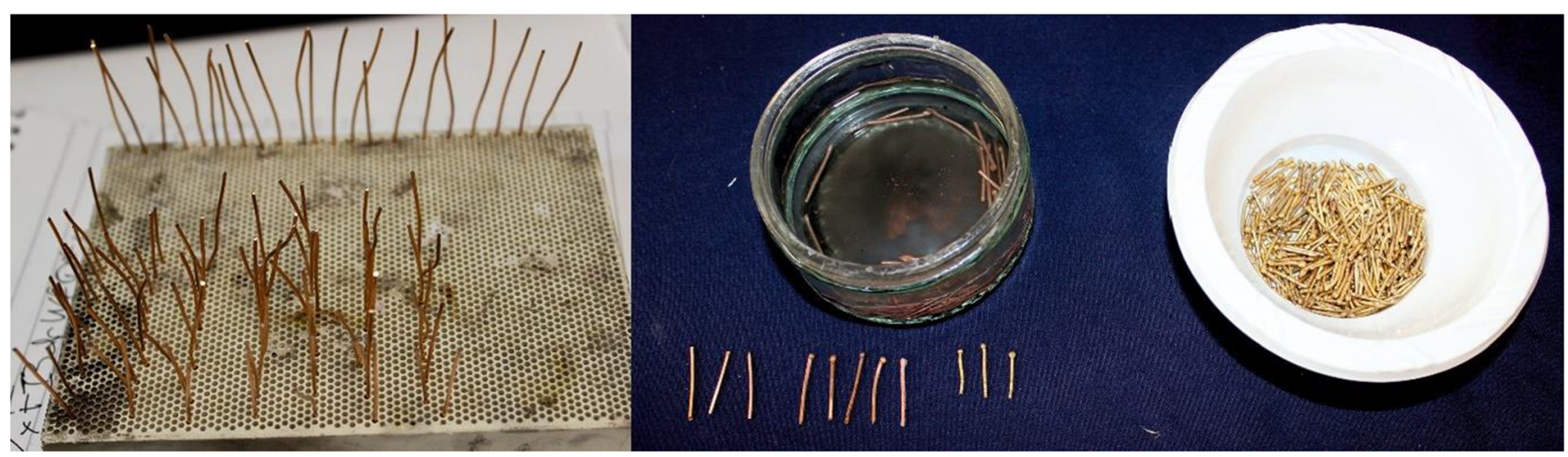

Image 61. Rivet manufacture process

discovery. This paper focuses on what is now known to be one of the most fragmented yet magnificent of its objects, a

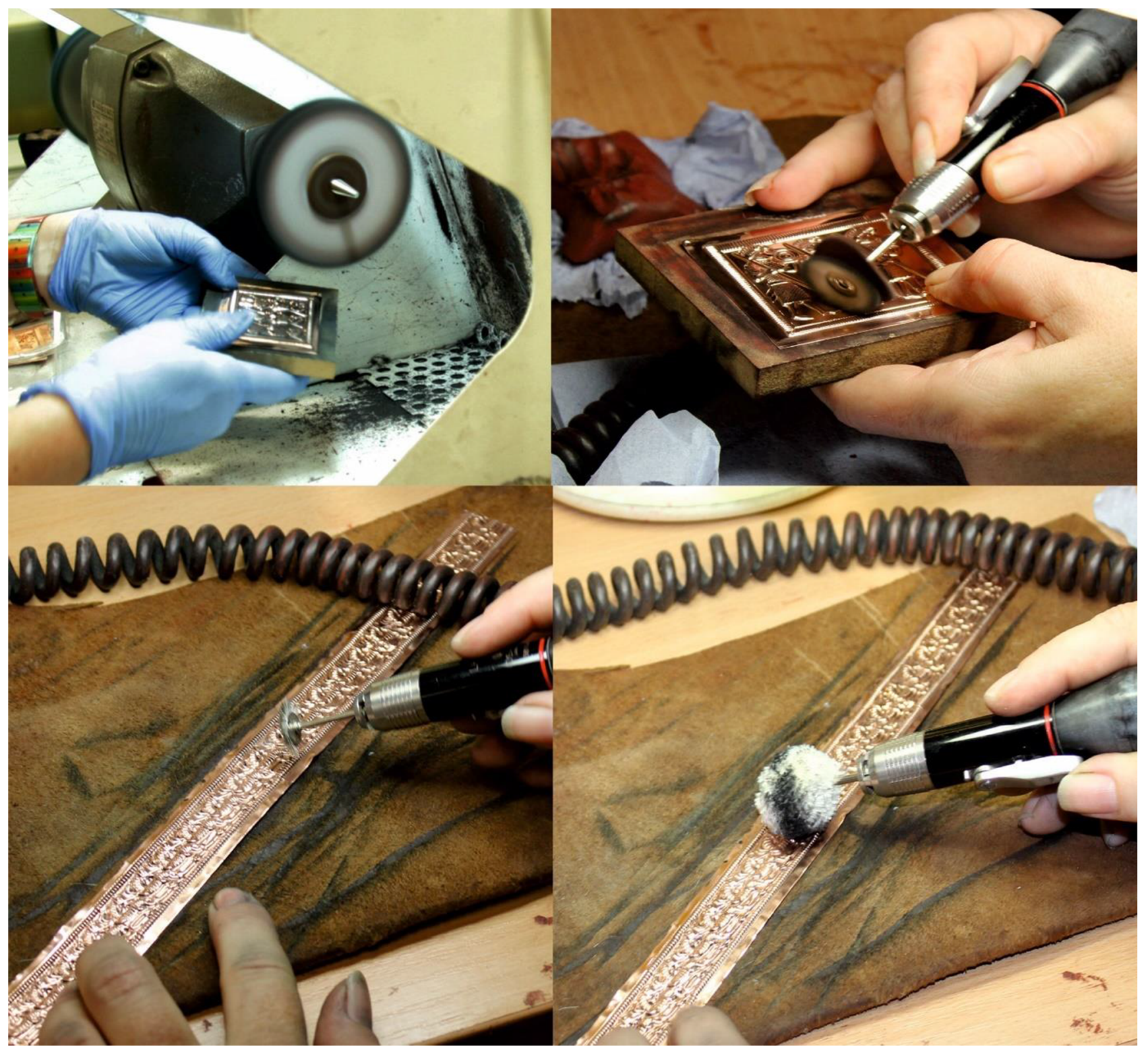

Image 60. Polishing of the panels and strips 


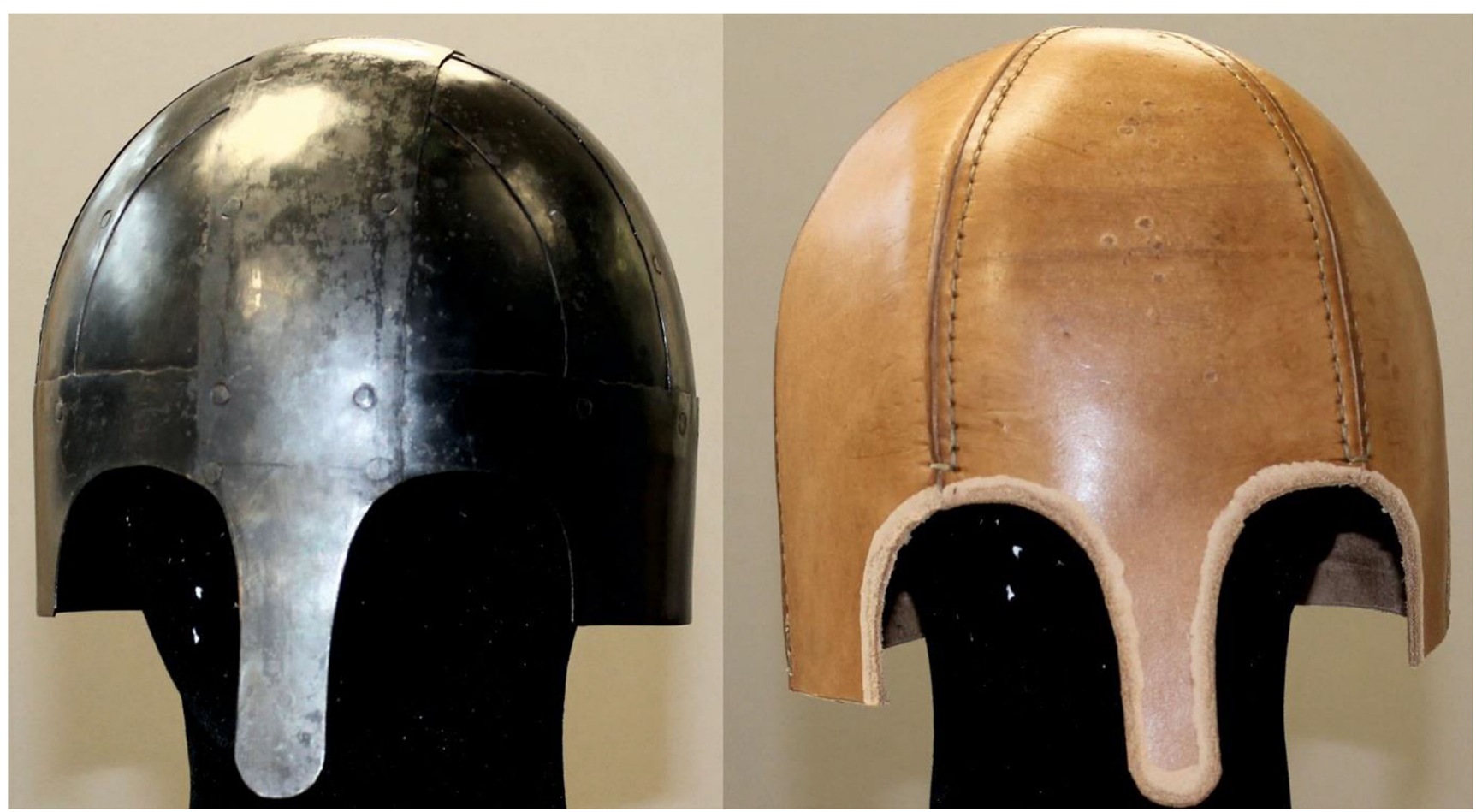

Image 62. The steel 'inner' and leather 'outer'

Helmet that has been declared as being 'fit for a king', but which was found scattered into well over 1000 disparate fragments. Fragments which are now considered to make up around one third of the Hoard's total of finds and compose this single high-status Helmet with many of these remaining sheet-metal fragments weighing less than one gram.

This paper describes in some considerable detail the various traditional artisanal crafts and modern digital technologies and techniques currently used in the jewellery and silversmithing industries to create two reproduction helmets. These reproductions were commissioned because the surviving helmet parts are too damaged and incomplete to be re-joined or displayed in a form that delivers to the casual observer a true sense of the majesty of the original. Thus, the museums responsible for the collection commissioned an experimental reconstruction project to create two of the helmets for display in their shared Hoard collections. This reconstruction project was to be based on the findings of the main Helmet research project, but it also provided a valuable opportunity to explore the questions of form and manufacture which could not be resolved by studying the original fragments alone.

The two largest elements of the Helmet fragments are a pair of silver-gilt cheekpieces (with additional collars of gold beaded wire) and a gold curved crest formed of two channels, set end-to-end, each with an animal-headed terminal. These were all decorated as a suite with animal art, comprising serpents, strange quadrupeds, and other zoomorphic creatures. A great quantity of stamp-decorated silver and gold sheet fragments, 'reeded' strips and rivets also survive. These are very similar to the ornaments and fittings used to cover comparable helmets from the period, such as that from the ship-burial at Sutton Hoo. The reconstruction of this ancient 'jigsaw' (missing many pieces and without a picture on the lid to follow) into a coherent scheme of decorative panels and bands, showing either animal art or warrior imagery, and fixed in place by the reeded strips and rivets, was achieved by the hard work of a select group of conservators, archaeologists, Hoard researchers, Anglo Saxon iconography experts, art historians and of course the various digital and traditional skill sets available at the Birmingham School of Jewellery $\left[{ }^{24}\right]$. One key breakthrough was the re-assembly of the fragments of a silver channel that is considered to have encircled the base of the helmet and which held one long continuous strip showing kneeling or running warrior spearmen. There are, at the moment, only five other similar and attributable Anglo-Saxon helmets from Scandinavia and continental Europe known to exist, along with a small collection of detached parts, and all of which exhibit remarkable parallels to the Hoard Helmet. Establishing the probable form of the Hoard Helmet and considering how to reconstruct it, in relation to these known examples, was complicated from the outset by the fact that, unlike many of the other examples quoted, none of the iron and leather under-pining's of the Hoard Helmet has survived. Nevertheless, the crest, cheekpieces and decorative sheet coverings all point to the strong likelihood that the Staffordshire Hoard find is a type known as a 'crested helmet'. This helmet

\footnotetext{
${ }^{24}$ https://www.bcu.ac.uk/jewellery
} 


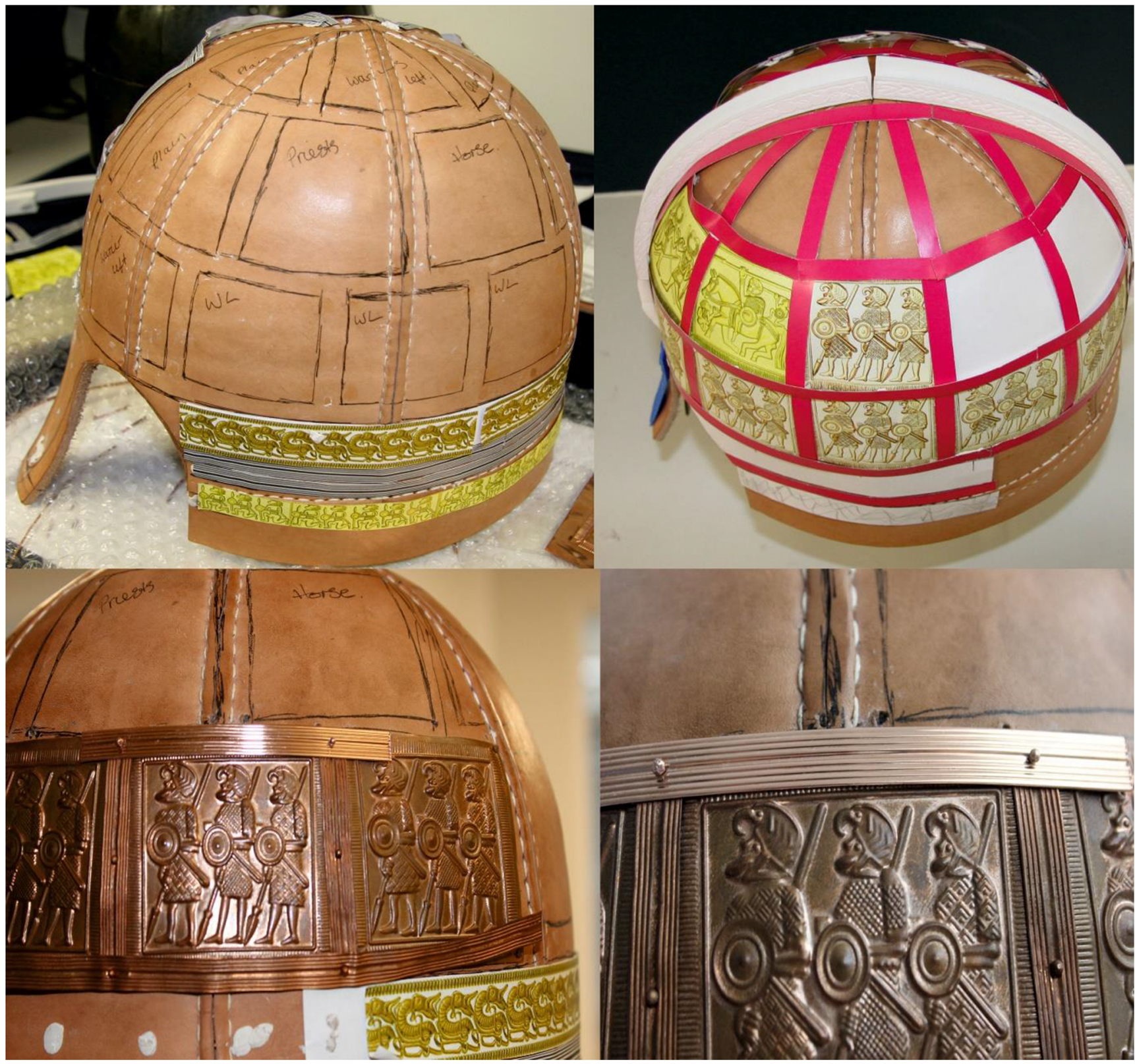

Image 63. Test assembly stages

form was especially widespread in use in Scandinavia at the time of the Hoard, with multiple contemporary helmets coming from ship-burials in Sweden.

The Hoard helmet, despite its incomplete state, can now be regarded as the grandest of the crested-type helmets to survive from the $6^{\text {th }} / 7^{\text {th }}$ centuries, and it is considered to have been made in around AD 600-650. Its golden ornamentation can be contrasted with the iconic and contemporary helmet of silver appearance from Sutton Hoo with tinned-bronze decorative coverings $\left[{ }^{25}\right]$. The Staffordshire hoard Helmet is also unique

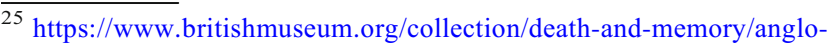
saxon-ship-burial-sutton-hoo
}

in having had an actual raised horsehair or feather crest, which is clearly indicated by the channel formed by its recovered metal crests. The inspiration for a hair crest can clearly be traced back to Roman helmets, and it can easily be imagined how prominent it would have made its royal wearer on the battlefield. Indeed, its magnificent form with the great rarity of helmets generally at the time in England points to the fact that first and foremost it was a ceremonial object of state, and we should regard it therefore as no less than a crown.

The initial challenge for the reconstruction project with the museums was to recreate the missing substructure to support the surviving fittings and decoration. The crest and encircling channel gave clues, but the cheekpieces are small by 


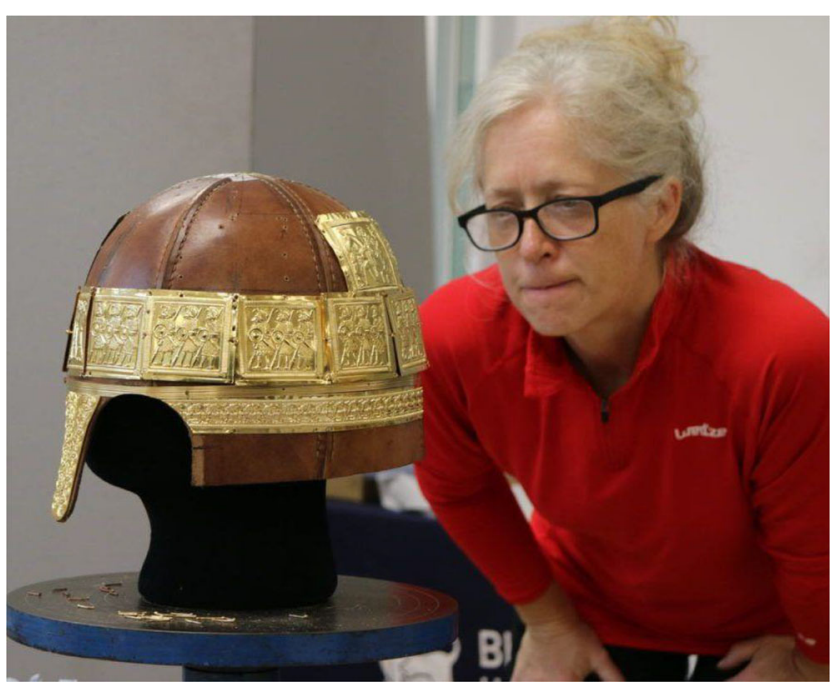

Image 64. School of Jewellery Silversmithing tutor Samantha Chilton studying where the next rivet and rivet hole needs to be placed with finished, polished, and gold-plated components

comparison to those on other helmets and, rather than being hinged, were fixed with lobes. Ultimately, the reconstructions had to be able to demonstrate a final output that was wearable and functionable as armour, within the parameters established by the surviving parts and by other Anglo-Saxon helmets. Where there was a distinct lack of evidence, for example, for the brow (which was often decorated on other helmets), embellishment was deliberately kept to a minimum. Testing the decorative scheme suggested by the museums research teams' project was also a key aim of these reconstructions.

A substructure comprising a leather layer over an iron foundation (known as a 'steel' was chosen, based on analogy with other known helmets and decorative fittings. Hence, in manufacture the decorative coverings were attached to the leather and not directly to the steel, with the leather and other major fittings then fixed, by rivets or roves, to the steel at key points, which were indicated by a more limited number of larger holes on the surviving crest, encircling band and cheekpieces. No 'functional' fixings suitable for attachment to the steel have survived, but this is not surprising given the overall lack of base metal and organics in the Hoard finds. The steel determines the shape of a helmet, but only the crest hinted at its original profile. However, as the crest was made in two parts, which would have allowed some flexibility in positioning, so it does not absolutely dictate a shape for the leather. There is little to inform the shape of the brow and nasal area, but the unusually small cheekpieces meant that the steel needed to have a certain depth (which would have covered the ears of the wearer.) No attempt was made to replicate exactly Anglo-Saxon craft methods or materials so this should not be considered as an exercise in experimental archaeology. This was for practical and financial reasons (the original fragmentary parts are all silver, gilt and gold) instead the most up-to-date digital and analogue techniques were used to capture as closely as possible the form and ornamentation of the original fragments.

The School of Jewellery team typically laser-scanned whatever fragments have survived, and appropriate CAD software was then used to create suitable files for both 3D Printed master patterns or sacrificial wax and resin models and for creating toolpaths for Computer Numerically Controlled (CNC) milled stamping dies. Creation of these files also included the considerable challenge of correcting for damage and missing elements a task requiring close collaboration with the museum's conservation team. The larger fittings were then reproduced, first in nylon for the traditional rapid prototyping concept of exploring form, feel and fit. Then 3D Printed in a castable resin or wax, and finally they were cast in bronze using the traditional jewellery lost wax casting method, before being polished and gold plated.

The original decorative panels and strips of the helmet were found to be gilt on silver sheet-metal. These were re-created by using low cost, low usage dies to stamp copper sheet, which was then polished, and gold plated. The nasal and neckguard were also proposed by the research project to originally have had sheet-metal decoration however for technical, cost, and practical reasons they too were chosen to be $3 \mathrm{D}$ Printed and cast in Bronze. The surviving fragments used to suggest the neckguard were largely of ungilded silver, however, in contrast with most of the ornament of the Helmet. Both required considerable creative design input by the $\mathrm{CAD}$ specialists, and consequently the patterns proposed on these parts are to be considered as more tentative.

The leather layer over the helm to which the sheet and strip decoration was to be attached was wet formed over the steel cap and then stitched together with linen. The actual assembly of the exterior of the Helmets was primarily undertaken by the School of Jewellery team.

A key question to be addressed was what the crest had most probably contained. Detailed scientific analysis has revealed the presence of a beeswax-based paste inside the channel, suggesting a fixing medium was used to hold another material in place, but the actual material of the crest and its assembly still remains largely a mystery to the researchers. In the end, beeswax and linen was used as the foundation, but this still leaves unsolved the purpose of the wood fragments found in the original. The crest may have been of horsehair or feathers, but the former was opted for. Pale horsetail hair was dyed with madder $\left[{ }^{26}\right]$, using alum $\left[{ }^{27}\right]$ as a mordant $\left[{ }^{28}\right]$, to create the magnificent red crest, which was cut to an $8-10 \mathrm{~cm}$ length. The colour was selected to echo the palette of the rest of the Hoard, which is dominated by gold and red garnet cloisonné objects.

\footnotetext{
${ }^{26} \mathrm{https} / / /$ en.wikipedia.org/wiki/Rubia_tinctorum

27 https://en.wikipedia.org/wiki/Alum

28 https://en.wikipedia.org/wiki/Mordant
} 
Image 65. The fully assembled Helmet finally goes public (Image (C) Birmingham Museums Trust)

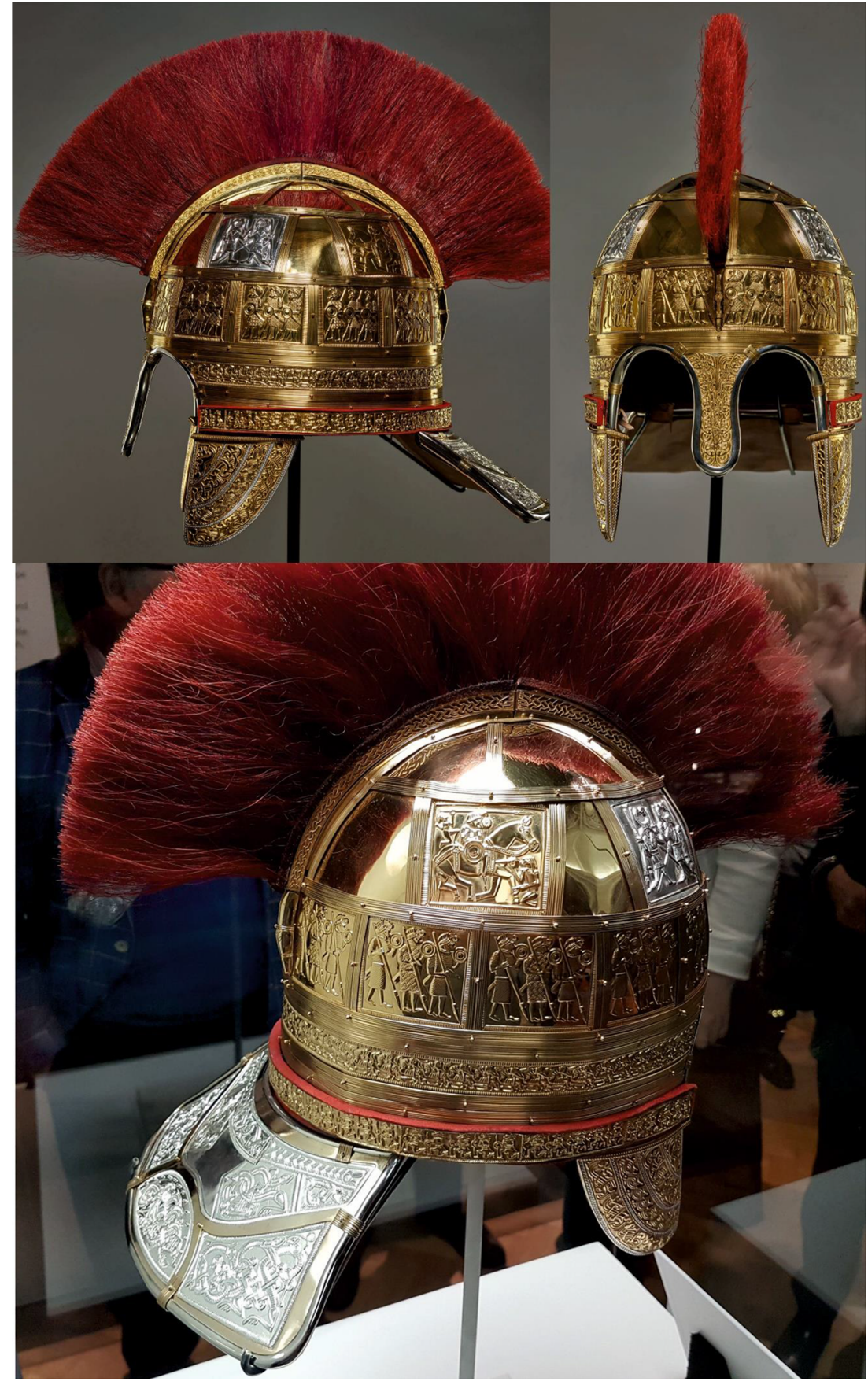

The final reconstruction is wearable and the weight is well balanced: it is stable without slipping, back-to-front and sideto-side, the head can be turned and there is no impediment to vision; the neckguard is self-supporting; and the flexible cheekpieces enable its easier equipping and removal. Overall, the reconstruction weighs around 3 kilos: this is heavy, but not overly so. The finished reconstruction gives us an indisputable glimpse of the magnificence and drama of the original. The contrast with the twisted and incomplete remains is striking. Two identical reconstructions have been produced and assembled by The School of Jewellery for the project, which are now displayed at Birmingham Museum \& Art Gallery (BMAG) $\left[{ }^{29}\right]$, and the Potteries Museum \& Art

\footnotetext{
${ }^{29} \mathrm{http}: / /$ www.birminghammuseums.org.uk/bmag

${ }^{0} \mathrm{http}: / /$ www.stokemuseums.org.uk/pmag/
} 


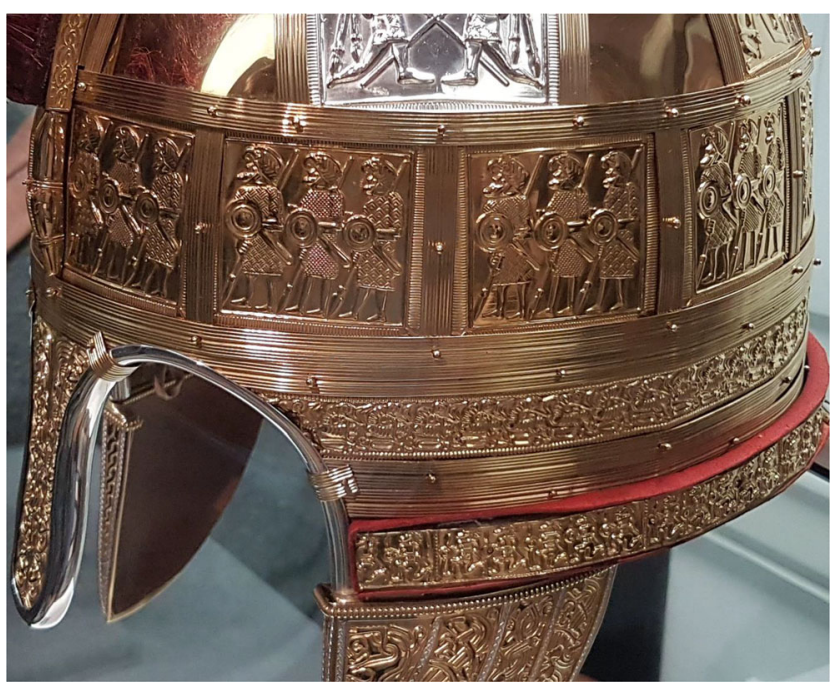

Image 66. Helmet detail (Image ( $)$ Birmingham Museums Trust)

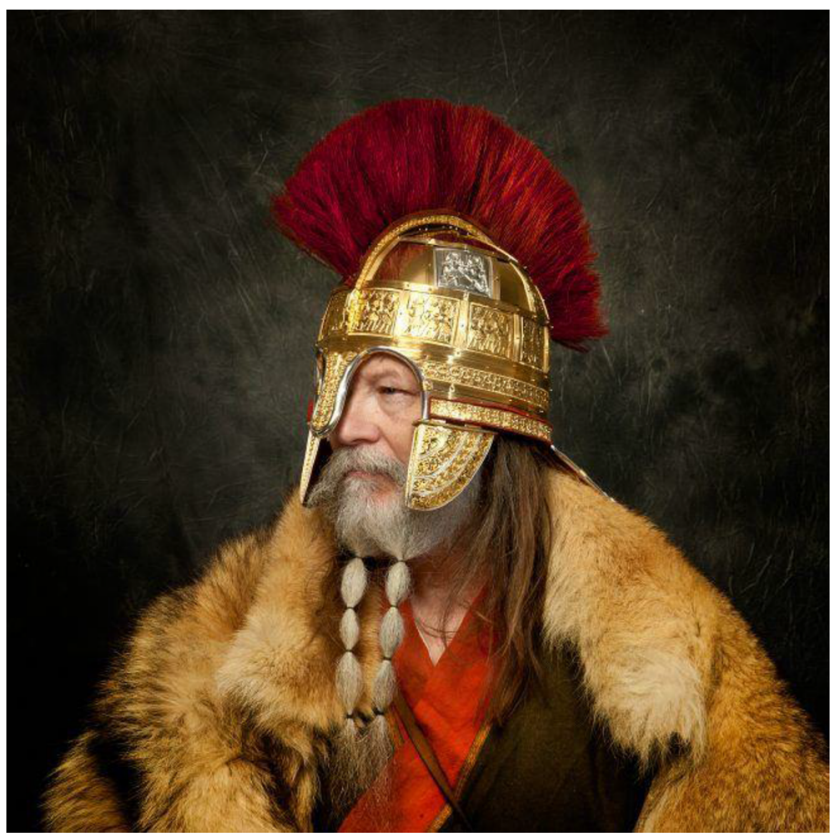

Image 67. Warrior bling fit for a king! (Image @ C Howard Maryon-Davis)

Gallery, Stoke-on-Trent $\left[{ }^{30}\right]$, alongside elements from the original Helmet and the rest of the Hoard. For both museums and Historic England $\left[{ }^{31}\right]$, this project has provided the opportunity to bring the collection and the years of research to life for the public. Although composed of undeniably beautiful and awe-inspiring art objects, it can be challenging for audiences to bridge the gap between the Hoard as a collection of

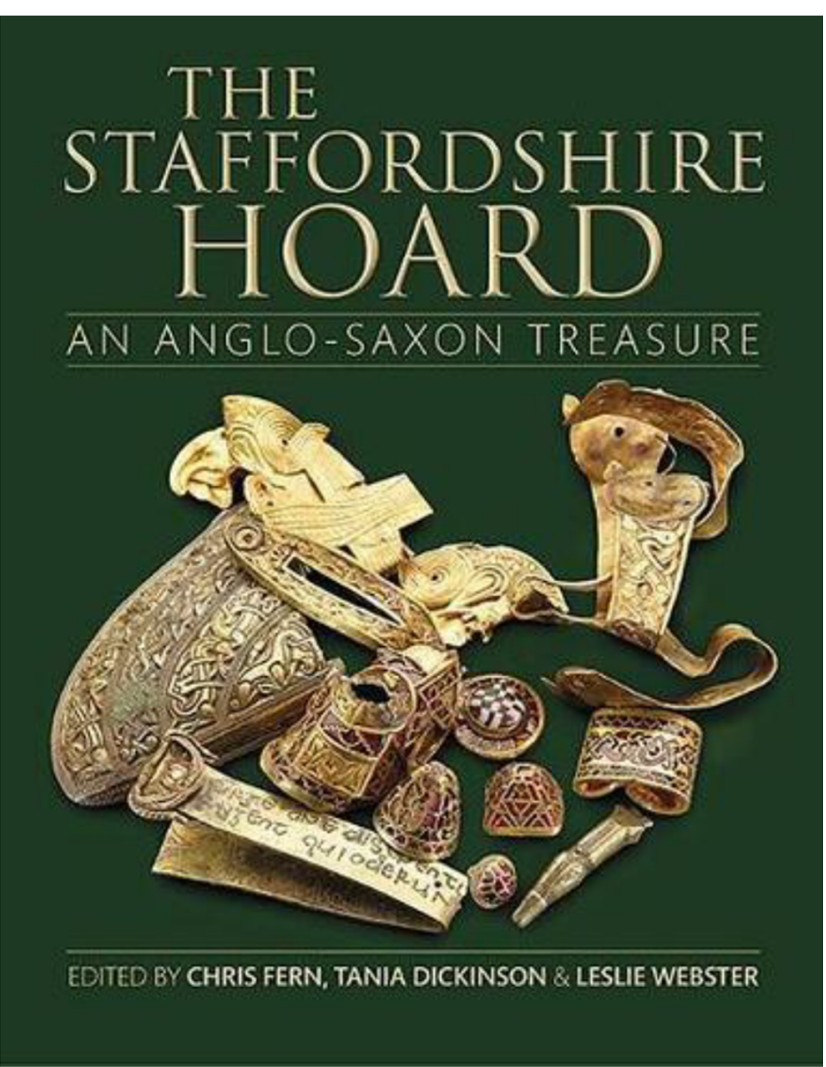

Image 68. The Staffordshire Hoard Research Report

diverse fragments and the function and purpose of the original objects they derive from.

These Helmet reconstructions do that in a very direct way.' $\left[{ }^{32}\right]$

Open Access This article is licensed under a Creative Commons Attribution 4.0 International License, which permits use, sharing, adaptation, distribution and reproduction in any medium or format, as long as you give appropriate credit to the original author(s) and the source, provide a link to the Creative Commons licence, and indicate if changes were made. The images or other third party material in this article are included in the article's Creative Commons licence, unless indicated otherwise in a credit line to the material. If material is not included in the article's Creative Commons licence and your intended use is not permitted by statutory regulation or exceeds the permitted use, you will need to obtain permission directly from the copyright holder. To view a copy of this licence, visit http://creativecommons.org/licenses/by/4.0/.

Publisher's Note Springer Nature remains neutral with regard to jurisdictional claims in published maps and institutional affiliations. 